\title{
Multiple Shaker Placement for Ground Vibration Test of X-59 Aircraft using Topology Optimization
}

\author{
Chan-gi Pak ${ }^{1}$ \\ NASA Armstrong Flight Research Center, Edwards, California, 93523-0273, USA
}

\begin{abstract}
A multiple shaker placement methodology is developed and tested using a topology optimization technique. Current multiple shaker placement methodology requires optimum accelerometer placement and optimum single-shaker placement techniques. The proposed methodology is tested using a finite element model of the X-59 Low Boom Flight Demonstrator aircraft. The effective independence and the driving point acceleration transfer function (DPATF) methods are used for the accelerometer placement study. In this study, four shakers are used to excite each mode more effectively during the ground vibration test; all the modes of interest thus are separated into four groups. Each shaker takes care of a separate group of modes. Grouping the modes of interest is performed utilizing topology optimization. The number of modes for each group therefore will be automatically decided during grouping. For each group of modes, perform the following two steps to determine optimal location of four shakers: 1) At each accelerometer location, compare the magnitude of DPATF values at natural frequencies, select the minimum value, and make a vector with these minimum values of the DPATF magnitudes for each group; and 2) Select the degrees of freedom corresponding to the maximum value of this vector. The objective function value is the maximum value of the vector with minimum value of the magnitude of the superposed acceleration transfer function. This objective function value is maximized by changing the modes for each group. Forty accelerometers are enough to have good correlation between mode shapes obtained from the reduced order model and the simulated ground vibration test.
\end{abstract}

\section{Nomenclature}

$\begin{array}{ll}\text { ASET } & =\text { analysis set } \\ \text { ATF } & =\text { acceleration transfer function } \\ a_{i} & =\text { degrees of freedom number corresponding to the location of the } i \text {-th accelerometer } \\ \mathbf{C} & =\text { damping matrix } \\ \text { CDW } & =\text { cruise design weight } \\ \text { DOF } & =\text { degrees of freedom } \\ \text { DPATF } & =\text { driving point acceleration transfer function } \\ \text { DV } & =\text { design variable } \\ \text { EI } & =\text { effective independence } \\ \boldsymbol{E I} & =\text { effective independence matrix } \\ e_{i} & =\text { degrees of freedom number corresponds to the location of the } i \text {-th shaker } \\ \boldsymbol{f}(t) & =\text { general force vector at time } t \\ \text { FE } & =\text { finite element } \\ \text { FOM } & =\text { full order model } \\ \text { GVT } & =\text { ground vibration test } \\ {[\mathbf{I}]} & =\text { identity matrix } \\ \mathbf{K} & =\text { stiffness matrix } \\ \text { LM } & =\text { The Lockheed Martin Corporation, Bethesda, Maryland } \\ \text { LBFD } & =\text { Low Boom Flight Demonstrator } \\ \text { MAC } & =\text { Modal Assurance Criterion }\end{array}$

\footnotetext{
${ }^{1}$ Subject Matter Expert in Structural Dynamics Group, Aerostructures Branch, Senior Member AIAA.
} 


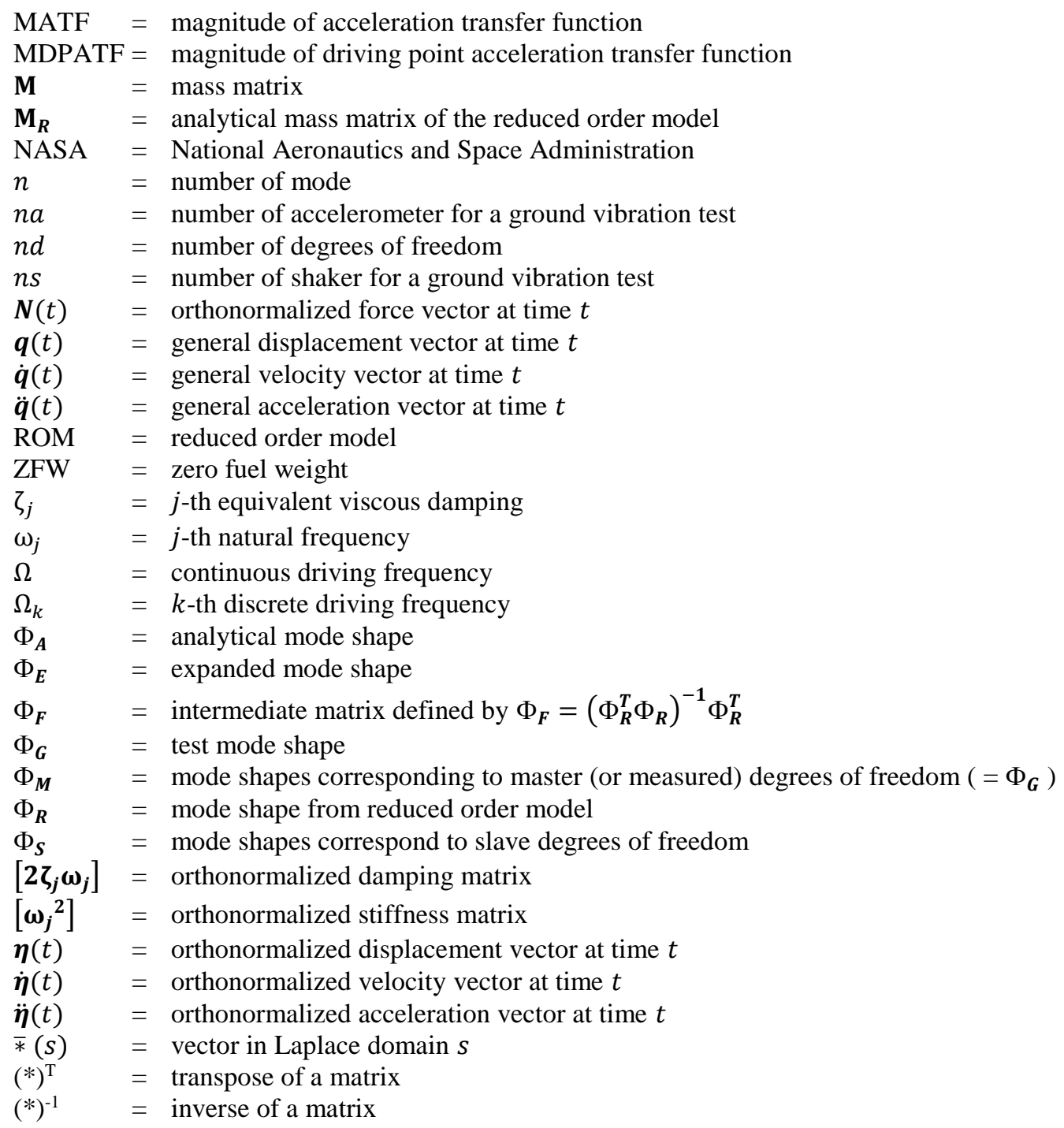

\section{Introduction}

The Lockheed Martin Corporation (Bethesda, Maryland) (LM) was awarded a contract to manufacture the X-59 Low Boom Flight Demonstrator (LBFD) aircraft in early 2018. This aircraft, shown in Fig. 1, was designed to have a maximum sonic-boom perceived loudness level of $75 \mathrm{~dB}$ at an altitude of 55,000 ft and Mach number of 1.40. Flight demonstration of the X-59 LBFD aircraft by the National Aeronautics and Space Administration (NASA) is expected in April 2021.

To minimize uncertainty in a structural dynamic finite element (FE) model, the FE model should be validated using the measured ground vibration test (GVT) data. If needed, the FE model should be updated to have good correlation with the measured test data. Usually, a reduced order model (ROM) is needed for a structural dynamics FE model tuning.[1] Once the GVT data are collected, the test data from each accelerometer should be expanded to the intermediate ROM to compare the modal data obtained from the ROM and the GVT. Optimum selection of accelerometer and shaker locations improves the accuracy of the test and of analysis correlation.

In November 2018, LM announced that the X-59 LBFD aircraft had officially entered production. The X-59 LBFD aircraft GVT will be performed late in fiscal year 2020. Analysis tools for optimum accelerometer and shaker placement thus should be developed and tested before the pre-test analysis is performed with the latest FE model version, C612.

The primary objective of this study is to develop a multiple shaker placement methodology using a topology optimization technique. Current multiple shaker placement methodology requires an optimum accelerometer 
placement and an optimum single-shaker placement technique. The proposed methodology is tested using the C609 FE model configuration, shown in Fig 2, during the development phase.

\section{Mathematical Background of Optimum Accelerometer and Shaker Placement}

The military standard and the NASA standard for comparing analytical and experimental modal data are observed in Refs. 2 and 3 as follows:

Military standard:

1) Analytical model frequencies are to be within 3 percent of test frequencies.[2]

2) Using a cross-orthogonality matrix formed from the analytical mass matrix and the analytical and test modes, corresponding modes are to exhibit at least 95-percent correlation, and dissimilar modes are to be orthogonal to within 10 percent.[2]

NASA standard:

1) Agreement between test and analysis natural frequencies shall, as a goal, be within 5 percent for the significant modes.[3]

2) Accurate mass representation of the test article shall be demonstrated with orthogonality checks using the analytical mass matrix $\mathbf{M}$ and the test mode shapes $\boldsymbol{\Phi}_{G}$. The orthogonality matrix is computed as $\boldsymbol{\Phi}_{G}^{\mathrm{T}} \mathbf{M} \boldsymbol{\Phi}_{G}$. As a goal, the off-diagonal terms of the orthogonality matrix should be less than 0.1 for significant modes based on the diagonal terms normalized to 1.0.[3]

3) Mode shape comparisons shall be required via cross-orthogonality checks using the test modes $\Phi_{G}$, the analytical modes $\boldsymbol{\Phi}_{\boldsymbol{A}}$, and the analytical mass matrix $\mathbf{M}$. The cross-orthogonality matrix is computed as $\Phi_{G}^{\mathrm{T}} \mathbf{M} \Phi_{A}$. As a goal, the absolute value of the cross-orthogonality between corresponding test and analytical mode shapes should be greater than 0.9 , and all other terms of the matrix should be less than 0.1 for all significant modes. Additionally, qualitative comparisons between test modes and analytical modes using mode shape animation and/or deflection plots shall be performed.[3]

Off-diagonal terms of the orthonormalized mass matrix $\Phi_{G}^{\mathrm{T}} \mathbf{M} \Phi_{G}$ and the cross-orthogonality matrix $\Phi_{G}^{\mathrm{T}} \mathbf{M} \Phi_{A}$ depend strongly on the accelerometer locations. On the other hand, the magnitude of acceleration transfer function (MATF) at each natural frequency depends on the shaker location. Moreover, the accuracy of the flexible frequencies are influenced by the number of degrees of freedom (DOF) in the ROM.

\section{A. Number of Degrees of Freedom for Reduced Order Model}

A ROM can be created using the MSC/NASTRAN software (MSC Software, Newport Beach, California).[4] The DOF for a ROM is defined through the use of an analysis set (ASET) entries in MSC/NASTRAN. Basically, the MSC/NASTRAN modal analysis with ASET cards is based on the Guyan reduction technique.[5] Frequency correlation between the full order model (FOM) and the ROM is good for the low frequency modes because of the static nature of the Guyan reduction. Therefore, a large number of ASET DOF is required to increase the accuracy of the high frequency modes.

During pre-test analysis, all of the target frequencies and mode shapes are computed from a full order FE model. Frequencies and mode shapes from the GVT will become the target frequencies and mode shapes when a structural dynamic model tuning is performed.[1] The off-diagonal terms of the orthonormalized mass and cross-orthogonality matrices between the FOM and the ROM should be as small as possible because the military standard [2] and the NASA standard [3] for comparing the analytical and experimental modal data will be applied to the correlation study between the analytical (based on the ROM) and the GVT data.

\section{B. Accelerometer Placement}

The effective independence [6] and the driving point acceleration transfer function (DPATF) [7] methods are used for this accelerometer placement study. Basic concepts of these two methods are explained in this section.

\section{Effective Independence Method}

The objective of the effective independence (EI) method is to select accelerometer locations that make the target mode shapes $\Phi_{R}$ linearly independent, while retaining as much information as possible. This procedure starts from a large set of candidate accelerometer locations in which the EI matrix $\boldsymbol{E I}$ can be formed, as shown in Eq. (1). 


$$
E I=\Phi_{R}\left(\Phi_{R}^{T} \Phi_{R}\right)^{-1} \Phi_{R}^{T}
$$

The row vector of the $\Phi_{R}$ matrix corresponding to the smallest diagonal value of the $\boldsymbol{E I}$ matrix is removed from the $\boldsymbol{\Phi}_{R}$ matrix to eliminate least important DOF, and the $\boldsymbol{E} \boldsymbol{I}$ matrix in Eq. (1) is calculated again for the new candidate DOF. This iterative process continues until the number of rows (DOF) in matrix $\Phi_{R}$ becomes the number of columns (modes) in the matrix $\boldsymbol{\Phi}_{R}$. The diagonal element of the $\boldsymbol{E} \boldsymbol{I}$ matrix is not reliable when the rank of matrix $\boldsymbol{\Phi}_{R}^{T} \boldsymbol{\Phi}_{R}$ is smaller than the number of modes of interest. The graphical illustration shown in Fig. 3 depicts the selecting and bookkeeping process based on the minimum diagonal element of the $\boldsymbol{E} \boldsymbol{I}$ matrix for the mode shape matrix $\boldsymbol{\Phi}_{\boldsymbol{R}}$ and corresponding grid and DOF information.

\section{Driving Point Acceleration Transfer Function Method}

In this study, the DPATF method in Ref. 7 is also used to guarantee a large magnitude of a transfer function value at an accelerometer location for each "primary mode." The derivation of the DPATF starts, Eq. (2), from the following governing equations of motion with external forcing function $\boldsymbol{f}(t)$.

$$
\mathbf{M} \ddot{\boldsymbol{q}}(t)+\mathbf{C} \dot{\boldsymbol{q}}(t)+\mathbf{K} \boldsymbol{q}(t)=\boldsymbol{f}(t)
$$

Define the orthonormalized displacement vector in Eq. (3).

$$
\boldsymbol{q}(t) \equiv \boldsymbol{\Phi} \boldsymbol{\eta}(t)
$$

Substituting Eq. (3) into Eq. (2) gives Eq. (4):

$$
\mathbf{M} \boldsymbol{\Phi} \ddot{\boldsymbol{\eta}}(t)+\mathbf{C} \boldsymbol{\Phi} \dot{\boldsymbol{\eta}}(t)+\mathbf{K} \boldsymbol{\Phi} \boldsymbol{\eta}(t)=\boldsymbol{f}(t)
$$

Pre-multiplying $\boldsymbol{\Phi}^{T}$ to Eq. (4) gives the following orthonormalized governing equations of motion, Eqs. (5) and (6):

$$
[\mathbf{I}] \ddot{\boldsymbol{\eta}}(t)+\left[2 \zeta_{j} \boldsymbol{\omega}_{j}\right] \dot{\boldsymbol{\eta}}(t)+\left[\boldsymbol{\omega}_{j}{ }^{2}\right] \boldsymbol{\eta}(t)=\boldsymbol{N}(t)
$$

where

$$
\boldsymbol{N}(t)=\boldsymbol{\Phi}^{T} \boldsymbol{f}(t)
$$

and matrices $[\mathbf{I}]=\boldsymbol{\Phi}^{T} \mathbf{M} \boldsymbol{\Phi},\left[2 \zeta_{j} \boldsymbol{\omega}_{j}\right]=\boldsymbol{\Phi}^{T} \mathbf{C} \boldsymbol{\Phi}$, and $\left[\boldsymbol{\omega}_{j}{ }^{2}\right]=\boldsymbol{\Phi}^{T} \mathbf{K} \boldsymbol{\Phi}$ are diagonal matrices. In the Laplace domain, the orthonormalized governing equations of motion in Eq. (5) become Eqs. (7) and (8):

$$
\begin{gathered}
\left(s^{2}[\mathbf{I}]+s\left[2 \zeta_{j} \boldsymbol{\omega}_{j}\right]+\left[\boldsymbol{\omega}_{\boldsymbol{j}}{ }^{2}\right]\right) \overline{\boldsymbol{\eta}}(s)=\overline{\boldsymbol{N}}(s) \\
\overline{\boldsymbol{\eta}}(s)=\left(s^{2}[\mathbf{I}]+s\left[\mathbf{2} \boldsymbol{\zeta}_{\boldsymbol{j}} \boldsymbol{\omega}_{\boldsymbol{j}}\right]+\left[\boldsymbol{\omega}_{\mathbf{j}}{ }^{2}\right]\right)^{-1} \overline{\boldsymbol{N}}(s)
\end{gathered}
$$

From Eq. (3), generalized acceleration $\ddot{\boldsymbol{q}}(t)$ can be written as in Eq. (9):

$$
\ddot{\boldsymbol{q}}(t)=\boldsymbol{\Phi} \ddot{\boldsymbol{\eta}}(t)
$$

In the Laplace domain, Eq. (9) yields Eq. (10):

$$
s^{2} \overline{\boldsymbol{q}}(s)=s^{2} \boldsymbol{\Phi} \overline{\boldsymbol{\eta}}(s)
$$

Substituting Eqs. (6) and (8) into Eq. (10) gives Eq. (11):

$$
s^{2} \overline{\boldsymbol{q}}(s)=s^{2} \boldsymbol{\Phi}\left(s^{2}[\mathbf{I}]+s\left[\mathbf{2} \zeta_{\boldsymbol{j}} \boldsymbol{\omega}_{\boldsymbol{j}}\right]+\left[\boldsymbol{\omega}_{\boldsymbol{j}}{ }^{2}\right]\right)^{-1} \boldsymbol{\Phi}^{\boldsymbol{T}} \overline{\boldsymbol{f}}(s)
$$

Therefore, the acceleration transfer function (ATF) matrix in the Laplace domain becomes Eqs. (12) and (13):

$$
\text { ATF matrix }=\left|\frac{s^{2} \overline{\boldsymbol{q}}(s)}{\overline{\boldsymbol{f}}(s)}\right|=s^{2} \boldsymbol{\Phi}\left(s^{2}[\mathbf{I}]+s\left[\mathbf{2} \boldsymbol{\zeta}_{\boldsymbol{j}} \boldsymbol{\omega}_{\boldsymbol{j}}\right]+\left[\boldsymbol{\omega}_{\boldsymbol{j}}{ }^{2}\right]\right)^{-1} \boldsymbol{\Phi}^{\boldsymbol{T}}
$$




$$
\operatorname{ATF} \text { matrix }=\boldsymbol{\Phi}\left[\frac{s^{2}}{s^{2}+2 \zeta_{j} \omega_{j} s+\omega_{j}^{2}}\right] \boldsymbol{\Phi}^{\boldsymbol{T}}
$$

where the matrix $\left[\frac{s^{2}}{s^{2}+2 \zeta_{j} \omega_{j} s+\omega_{j}^{2}}\right]$ is a diagonal matrix. Let $s=i \Omega$ (imaginary part); then Eq. (13) becomes Eq. (14):

$$
A T F \text { matrix }=\boldsymbol{\Phi}\left[\frac{-\Omega^{2}}{\omega_{j}^{2}-\Omega^{2}+i 2 \zeta_{j} \omega_{j} \Omega}\right] \boldsymbol{\Phi}^{\boldsymbol{T}}
$$

To derive the DPATF matrix, the mode shape matrix $\boldsymbol{\Phi}$ will be denoted as in Eq. (15):

$$
\boldsymbol{\Phi}=\left[\begin{array}{rrrr}
\left\lfloor\phi_{11}\right. & \phi_{12} & \cdots & \left.\phi_{1 n}\right\rfloor \\
\left\lfloor\phi_{21}\right. & \phi_{22} & \cdots & \left.\phi_{2 n}\right\rfloor \\
& \vdots & & \\
\left\lfloor\phi_{n d 1}\right. & \phi_{n d 2} & \cdots & \left.\phi_{n d n}\right\rfloor
\end{array}\right]
$$

where $n$ and $n d$ are the number of modes and of DOF, respectively. Transposing the mode shape matrix $\boldsymbol{\Phi}$ yields Eq. (16).

$$
\left.\boldsymbol{\Phi}^{\boldsymbol{T}}=\left[\begin{array}{c}
\phi_{11} \\
\phi_{12} \\
\vdots \\
\phi_{1 n}
\end{array}\right\} \quad\left\{\begin{array}{c}
\phi_{21} \\
\phi_{22} \\
\vdots \\
\phi_{2 n}
\end{array}\right\} \quad \cdots \quad\left\{\begin{array}{c}
\phi_{n d 1} \\
\phi_{n d 2} \\
\vdots \\
\phi_{n d n}
\end{array}\right\}\right]
$$

Substituting Eqs. (15) and (16) into Eq. (14) yields the equation shown as Eq. (17) for the ATF matrix.

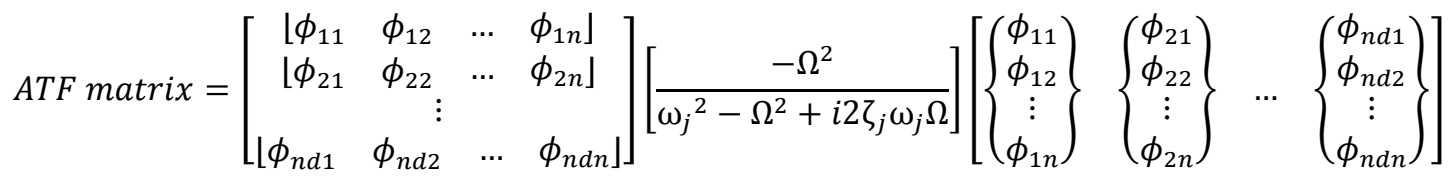

The DPATF matrix can be defined as shown in Eq. (18):

$$
\text { DPATF matrix } \equiv\left[\begin{array}{cccc}
\operatorname{DPATF}\left(1, \Omega_{1}\right) & \operatorname{DPATF}\left(1, \Omega_{2}\right) & \cdots & \operatorname{DPATF}\left(1, \Omega_{k}\right) \\
\operatorname{DPATF}\left(2, \Omega_{1}\right) & \operatorname{DPATF}\left(2, \Omega_{2}\right) & \cdots & \operatorname{DPATF}\left(2, \Omega_{k}\right) \\
\cdots & \cdots & \vdots & \cdots \\
\operatorname{DPATF}\left(n d, \Omega_{1}\right) & \operatorname{DPATF}\left(n d, \Omega_{2}\right) & \cdots & \operatorname{DPATF}\left(n d, \Omega_{k}\right)
\end{array}\right]
$$

where the ATF at the $r$-th DOF accelerometer due to $r$-th DOF loading under discrete frequency $\Omega_{k}$ for mode $j$ is as shown in Eq. (19):

$$
\operatorname{DPATF}\left(r, \Omega_{k}\right)=\left[\begin{array}{llll}
\phi_{r 1} & \phi_{r 2} & \ldots & \phi_{r n}
\end{array}\right]\left[\begin{array}{ccc}
\ddots & 0 & 0 \\
0 & \frac{-\Omega_{k}{ }^{2}}{\omega_{j}{ }^{2}-\Omega_{k}{ }^{2}+i 2 \zeta_{j} \omega_{j} \Omega_{k}} & 0 \\
0 & 0 & \ddots
\end{array}\right]\left\{\begin{array}{c}
\phi_{r 1} \\
\phi_{r 2} \\
\vdots \\
\phi_{r n}
\end{array}\right\}
$$

The $(r, k)$-th scalar element for mode $j$ in Eq. (19) therefore can be changed to a summation formulation as shown in Eq. (20).

$$
\operatorname{DPATF}\left(r, \Omega_{k}\right)=\sum_{j=1}^{n} \frac{-\Omega_{k}{ }^{2}}{\omega_{j}{ }^{2}-\Omega_{k}{ }^{2}+i 2 \zeta_{j} \omega_{j} \Omega_{k}} \phi_{r j}^{2}
$$

The accelerometer locations for the primary modes are selected as follows and mathematically represented as shown in Eq. (21):

1) Compute the magnitude of the driving point acceleration transfer function (MDPATF) matrix from real and imaginary parts of the DPATF matrix in Eq. (18). 
2) Select k-th column of the magnitude matrix based on the natural frequency of a primary mode $j$. Use a small damping factor $\zeta_{j}$ to avoid a numerically ill-conditioned ATF value at the $j$-th natural frequency. $\left(\Omega_{k}=\omega_{j}\right)$ :

$$
\text { MDPATF column vector at frequency } \omega_{j}=\left\{\begin{array}{c}
\operatorname{MDPATF}\left(1, \omega_{j}\right) \\
\operatorname{MDPATF}\left(2, \omega_{j}\right) \\
\cdots \\
\operatorname{MDPATF}\left(n d, \omega_{j}\right)
\end{array}\right\}
$$

3) Using the column vector at the primary frequency as shown in Eq. (21), select the $r$-th DOF for an accelerometer location where the magnitude is a maximum value.

A local maximum ATF is selected at the primary frequency in Eq. (21). Graphical explanation of the above three steps is given in Fig. 4.

\section{Multiple Shaker Placement}

The $n s$ number of shakers will be used to excite each mode more effectively during the pre-test analysis. As such, all the modes of interest are separated into ns number of groups. Each shaker will take care of each group of modes, as shown in Fig. 5. Grouping the modes of interest is performed by using the topology optimization technique. The number of modes for each group will be automatically decided during this grouping procedure. The process is:

1) The number of design variables is the number of modes of interest.

2) The lower and upper bounds of all design variables are 0 and 1 , respectively.

3) Design variables between 0 and 1 are generated using a uniform random number generator in a global optimizer, such as a genetic algorithm in the Object-Oriented Optimization tool.[8, 9]

4) Assign a group number to each mode using the integerization table shown in Table 1 and Fig. 5.

5) The DPATF matrix in Eq. (18) is separated into ns MDPATF matrices based on the group numbers from step 4. Number of columns for each MDPATF matrix are equal to the number of modes (or natural frequencies) belonging to each group. For example, let's assume 9 modes, and modes 1, 3, and 6; modes 4, 5,7 , and 9; and modes 2 and 8 belong to group 1,2, and 3, respectively. The following three MDPATF matrices, Eqs. (22), (23), and (24), thus will be obtained:

$$
\text { MDPATF matrix for Group } 1=\left[\begin{array}{ccc}
\operatorname{DPATF}\left(1, \omega_{1}\right) & \operatorname{DPATF}\left(1, \omega_{3}\right) & \operatorname{DPATF}\left(1, \omega_{6}\right) \\
\operatorname{DPATF}\left(2, \omega_{1}\right) & \operatorname{DPATF}\left(2, \omega_{3}\right) & \operatorname{DPATF}\left(2, \omega_{6}\right) \\
\cdots & \cdots & \cdots \\
\operatorname{DPATF}\left(n d, \omega_{1}\right) & \operatorname{DPATF}\left(n d, \omega_{3}\right) & \operatorname{DPATF}\left(n d, \omega_{6}\right)
\end{array}\right]
$$

MDPATF matrix for Group 2

$$
\begin{array}{r}
=\left[\begin{array}{cccc}
\operatorname{DPATF}\left(1, \omega_{4}\right) & \operatorname{DPATF}\left(1, \omega_{5}\right) & \operatorname{DPATF}\left(1, \omega_{7}\right) & \operatorname{DPATF}\left(1, \omega_{9}\right) \\
\operatorname{DPATF}\left(2, \omega_{4}\right) & \operatorname{DPATF}\left(2, \omega_{5}\right) & \operatorname{DPATF}\left(2, \omega_{7}\right) & \operatorname{DPATF}\left(2, \omega_{9}\right) \\
\cdots & \cdots & \cdots \\
\operatorname{DPATF}\left(n d, \omega_{4}\right) & \operatorname{DPATF}\left(n d, \omega_{5}\right) & \operatorname{DPATF}\left(n d, \omega_{7}\right) & \operatorname{DPATF}\left(n d, \omega_{9}\right)
\end{array}\right] \\
\text { MDPATF matrix for Group } 3=\left[\begin{array}{cc}
\operatorname{DPATF}\left(1, \omega_{2}\right) & \operatorname{DPATF}\left(1, \omega_{8}\right) \\
\operatorname{DPATF}\left(2, \omega_{2}\right) & \operatorname{DPATF}\left(2, \omega_{8}\right) \\
\cdots & \cdots \\
\operatorname{DPATF}\left(n d, \omega_{2}\right) & \operatorname{DPATF}\left(n d, \omega_{8}\right)
\end{array}\right]
\end{array}
$$

6) At each accelerometer location (that is, row vectors in Eqs. (22), (23), and (24)), compare the MDPATF values at natural frequencies, select the minimum value, and make the following $n s$ number of vectors for each group, as in Eq. (25):

$$
\left\{\begin{array}{c}
\text { select minimum MDPATF at accelerometer } \# 1 \\
\text { select minimum MDPATF at accelerometer } \# 2 \\
\vdots \\
\text { select minimum MDPATF at accelerometer } \# \text { na }
\end{array}\right\}
$$

7) Select the DOF corresponding to the maximum value of the vector in Eq. (25) as an shaker location. A graphical explanation of steps 6) and 7) is given in Fig. 6. Selecting shaker locations in this way guarantees 
that the MDPATF values at all other natural frequencies are larger than the maximum value of the vector in Eq. (25). Therefore, the $n s$ number of shaker locations are selected. When a duplicated shaker location is selected, use the next maximum location as a shaker location until all the different shaker locations have been selected.

8) Measured ATF matrices at discrete driving frequency $\Omega_{k}$ for mode $j$ obtained from each shaker are given in Eqs. (26), (27), and (28).

ATF matrix obtained from shaker \#1

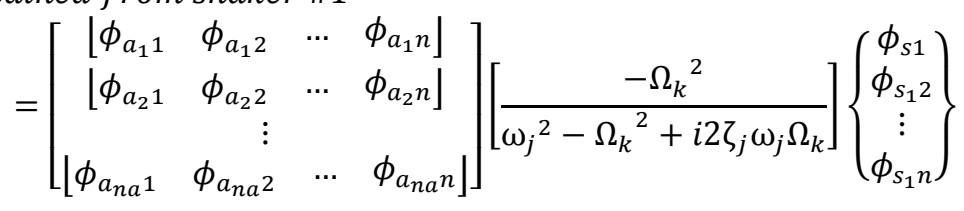

ATF matrix obtained from shaker \#2

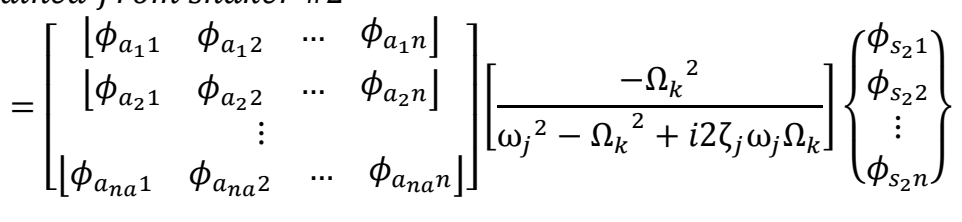

ATF matrix obtained from shaker \#ns

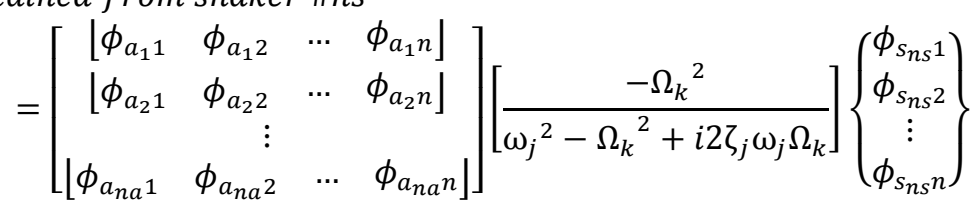

9) Assume all the shakers are controlled based on the same random generator and make the superposed MATF matrix shown as Eq. (29):

$$
\text { Superposed MATF Matrix }=\sum_{j=1}^{n s} \text { MATF matrix obtained from shaker \#j }
$$

10) At each accelerometer location, select the minimum magnitude of the superposed ATF matrix, as shown in Eq. (30):

$$
\left\{\begin{array}{c}
\text { select minimum magnitude of superposed ATF at accelerometer } \# 1 \\
\text { select minimum magnitude of superposed ATF at accelerometer \#2 } \\
\vdots \\
\text { select minimum magnitude of superposed ATF at accelerometer \#na }
\end{array}\right\}
$$

11) Select the maximum value of the vector in Eq. (30). This value becomes the objective function for the topology optimization procedure in this study. This objective function value will be maximized by changing the modes for each group.

\section{Results and Discussions}

The primary modes are selected using flutter analyses and the basis functions for a jig shape optimization study of the X-59 LBFD aircraft [10]. The jig shape optimization in Ref. 10 and the flutter analysis are based on the cruise design weight (CDW) condition at altitude of $55,000 \mathrm{ft}$ and Mach number of 1.40. There are no big differences between the mode shapes and numbers from the zero fuel weight (ZFW) and the CDW configurations. Modal frequencies for the selected primary modes for the ZFW and the CDW configurations using the FOM are given in Table 2. Mode shapes of the primary modes are commented upon in Table 3. Flutter analyses are performed using the ZAERO code (ZONA Technology, Scottsdale, Arizona).[11] The aerodynamic model of the C609 configuration is shown in Fig. 7. 


\section{A. Create a Reduced Order Model}

The ASET grid points with translational DOF of 1 (fore and aft), 2 (lateral), and 3 (vertical) created by LM is shown in Fig. 8(a). Only the right-hand side of the FE model is shown in this figure. All six DOF of the few grid points related to hinge points of control surfaces are also included in this ROM. The total number of DOF in the C609 FOM and the LM ROM are 544,162 and 1,879, respectively. First, modal analysis is performed using the MSC/NASTRAN code using the CDW configuration. Modal frequencies of the primary modes obtained from the LM ROM are compared with the C609 FOM results, shown in Table 4. The maximum frequency error is 0.85 percent, seen in Table 4.

A more detailed ROM than the LM ROM is created, as shown in Fig. 8(b), to have more candidate locations for optimum accelerometer and shaker placement study. The total number of DOF in the NASA ROM is 5,344, which is less than 1 percent of the DOF in the C609 FOM. The CDW configuration is also used for the modal analysis with the NASA ROM. Modal frequencies of the primary modes obtained from the NASA ROM are also compared with the C609 FOM results, shown in Table 4. The maximum frequency error of the primary modes becomes 0.32 percent, which is smaller than the previous results with the LM ROM.

The orthonormalized mass matrix, cross-orthogonality matrix, and Modal Assurance Criterion (MAC) matrix between mode shapes obtained from the FOM and the NASA ROM are shown in Tables 5, 6, and 7. The maximum off-diagonal term in the orthonormalized mass matrix and cross-orthogonality matrix are 9.8 percent and 14.6 percent, respectively. Four diagonal terms of the cross-orthogonality matrix, $0.853,0.812,0.815$, and 0.889 , are smaller than 0.9 , as shown in Table 6. Element cells containing off-diagonal terms greater than 1 percent and less than 10 percent are colored using the light cyan color in Tables 5 and 6 . The minimum diagonal term in the MAC matrix in Table 7 is 0.795 , which is an acceptable value. Four diagonal terms in Table 6 violate the military and the NASA standard; however, the violations are within acceptable ranges. The total number of DOF for the ROM should be increased to have better correlation between the FOM and the ROM; however, the number of DOF for the ROM cannot be increased due to computer memory limitations associated with the MSC/NASTRAN computation.

\section{B. Optimum Accelerometer Placement}

All of the 5,344 DOF in the ROM are ranked using the diagonal terms of the $\boldsymbol{E} \boldsymbol{I}$ matrix given in Eq. (1) and the sorting and bookkeeping procedure presented in Fig. 3. The first 40 highest ranked DOF are listed in Table 8. Grid numbers, DOF numbers, and accelerometer locations also are summarized in Table 8.

The MDPATF from Eq. (21) is also used to guarantee a strong transfer function signal for each primary modes. First, the column vector in Eq. (21) is selected for the primary mode $\omega_{j}$. Next, the DOF location corresponding to the maximum MDPATF is selected as an accelerometer location. In Table 9, the first 14 accelerometers (shown in yellow cells) are selected using the DPATF method. The EI method is used to select the next 26 accelerometers (shown in light cyan cells). The 39 accelerometer locations given in Table 9 are identical to those given in Table 8 .

The magnitudes of the DPATF at frequencies of primary modes are given in Table 10. The location for accelerometer 9 in Table 10 is the mirror image of the location for accelerometer 14 in the same table. The MDPATF values are not the same value, however, and therefore the FE model of the X-59 LBFD aircraft has an asymmetric motion (500 versus 315 for mode 22, and 247 versus 500 for mode 35).

Reorder the mode shape $\Phi_{R}$ as shown in Eq. (31):

$$
\Phi_{R}=\left[\begin{array}{l}
\Phi_{M} \\
\Phi_{S}
\end{array}\right]
$$

where the matrix $\Phi_{M}$ and $\Phi_{S}$ are mode shapes corresponding to the master (or measured) DOF and slave DOF, respectively. The expanded GVT mode shape $\Phi_{E}$ is computed using the system equivalent reduction and expansion process [12] in Eq. (32):

$$
\Phi_{E}=\left[\begin{array}{ll}
\Phi_{M}\left(\Phi_{M}^{T} \Phi_{M}\right)^{-1} & \Phi_{M}^{T} \\
\Phi_{S}\left(\Phi_{M}^{T} \Phi_{M}\right)^{-1} & \Phi_{M}^{T}
\end{array}\right] \Phi_{G}
$$

where the size of matrices $\Phi_{G}$ and $\Phi_{M}$ are $(n a \times 1)$ and $\Phi_{R}$ and $\Phi_{E}$ are $(n d \times 1)$.

The analytical mass matrix of the ROM is computed using Eqs. (33) and (34).

$$
\Phi_{F}=\left(\Phi_{R}^{T} \Phi_{R}\right)^{-1} \Phi_{R}^{T}
$$




$$
\mathbf{M}_{R}=\Phi_{F}^{T} \Phi_{F}
$$

Therefore, the orthonormalized mass matrix and cross-orthogonality matrix are computed using Eqs. (35) and (36).

$$
\begin{gathered}
\Phi_{E}^{T} \mathbf{M}_{R} \Phi_{E} \\
\Phi_{E}^{T} M_{R} \Phi_{R}
\end{gathered}
$$

The MAC matrix , $\mathbf{M A C}_{i j}$, is defined as Eq. (37).

$$
\operatorname{MAC}_{i j}=\frac{\left(\sum_{k=1}^{n_{d}} \Phi_{E}^{T}(k, i) \Phi_{R}(k, j)\right)}{\left(\sum_{k=1}^{n_{d}} \Phi_{E}^{T}(k, i) \Phi_{E}(k, i)\right)\left(\sum_{k=1}^{n_{d}} \Phi_{R}^{T}(k, j) \Phi_{\boldsymbol{R}}(k, j)\right)}
$$

The orthonormalized mass matrix, cross-orthogonality matrix, and MAC matrix with 40 accelerometers in Fig. 9 and Table 9 are shown in Tables 11, 12, and 13. It should be noted in Tables 5 and 11 that the maximum off-diagonal term of 0.098 in Table 11 converges to the target value 0.098 in Table 5 with 40 accelerometers. In Tables 6 and 12, the maximum off-diagonal term for the cross-orthogonality matrix, 0.145 , also meets its target value, 0.146 . Similarly, four diagonal terms $0.853,0.808,0.815$, and 0.893 approach the corresponding target values $0.853,0.812,0.815$, and 0.889 , respectively, and the minimum diagonal MAC value 0.792 in Table 13 also converges to the target value 0.795 in Table 7. A total of 40 accelerometers thus is enough to measure all of the modes correctly; however, to visualize mode shapes during the GVT, an additional 39 accelerometers, located as shown in Fig. 10 and Table 14, are recommended to be used.

The orthonormalized mass matrix, cross-orthogonality matrix, and MAC matrix with a total number of 79 accelerometers in Fig. 10 and Tables 9 and 14 are shown in Tables 15, 16, and 17. More zero off-diagonal terms are observed in Tables 15 and 16 than in Tables 11 and 12. Four diagonal terms $0.853,0.811,0.815$, and 0.890 in Table 16 become closer to their target values, $0.853,0.812,0.815$, and 0.889 in Table 6 . The modal correlation thus is improved with an additional 39 accelerometers.

\section{Multiple Shaker Placement using Topology Optimization}

A total number of 40 modes are used for the shaker placement study, therefore 40 design variables between 0.0 and 1.0 are randomly selected during the topology optimization procedure using a uniform random number generator. First, modes of interest (40 modes) are randomly separated into the total number of shaker groups based on the integerization procedure in Table 1, and an optimum grouping of modes with four shakers case is provided in Table 18. Each shaker will take care of the modes in each group. The number of modes for each group is also randomly decided during the topology optimization procedure. The genetic algorithm in the object-oriented optimization tool $[8,9]$ is selected for the topology optimization. The numbers of population and generation for the genetic algorithm are 10,000 and 10 , respectively.

In Tables 18 through 22, properties of group 1,2,3, and 4 modes are distinguished through the use of different four colors for columns and rows. First, at each accelerometer location, the minimum MDPATF value is selected among the modes belonged to each group, as shown in Fig. 6 and Table 19. The accelerometer location corresponds to the maximum of the minimum MDPATF values are chosen as shaker locations during the second step. Accelerometer locations 19, 5, 15, and 1 are selected as the shaker locations for each group as shown in Tables 19 and 20. Optimum shaker locations based on the one through four shakers are shown in Fig. 11. It is interesting in Fig. 11 that the shaker selections are all on the same side of the airplane in the case of two (left side), three (right side), and four (left side) shakers.

The transfer function values actually measured during the GVT are the MATF. The MATF at each accelerometer location in Appendix A are summarized in Tables 21 through 24. The minimum MATF for each group at the first 28 accelerometer locations using four shakers is summarized in Table 21. In Table 22, the maximum values of the minimum MDPATF for each group in Table 19 are compared with the maximum value of the minimum MATF for corresponding group in Table 21. The minimum MATF value at the same accelerometer location for the same mode with the maximum values of the minimum MDPATF for each group is also shown in Table 22. True maximum of the minimum MATF values for all the modes of interest (objective function value) are summarized in Table 23. It should be noted in Table 23 that maximum values are efficiently improved when the number of shakers is increased.

The maximum MATF for each mode with different numbers of shakers is summarized in Table 24 and Fig. 12. The minimum of the maximum MATF with four shakers in Table 24 is 67.82 for mode 19. The minimum values of the maximum MATF in Table 24 based on the different number of shakers are summarized in Table 25. The percent 
increase of maximum of minimum MATF and minimum of the maximum MATF values caused by increasing the number of shakers is drastically reduced, as shown in Tables 23 and 25.

\section{Conclusion}

A multiple shaker placement method using a topology optimization technique is proposed. The current method requires an optimum accelerometer placement and an optimum single-shaker placement technique. The proposed methodology is tested using the C609 finite element model of the X-59 Low Boom Flight Demonstrator aircraft.

A reduced-order model with degrees of freedom of 5,344 is created. Frequencies and mode shapes obtained from this reduced-order model are correlated with respect to the full-order model with cruise design weight configuration. Four diagonal terms of the cross-orthogonality matrix violate the NASA standard, 0.9 , slightly (0.81 0.89). The degrees of freedom of the reduced order model, however, cannot be increased any more, mainly because of computer memory requirement limitations associated with the utilized code.

Forty accelerometers are selected using the effective independence and the driving point acceleration transfer function methods. An additional 39 accelerometers are also selected to visualize mode shapes during the ground vibration test. The orthonormalized mass matrix, cross-orthogonality matrix, and modal assurance criterion matrix with a total number of 79 accelerometers converge to their target values.

Four shaker locations are selected using the topology optimization technique; therefore, four groups of modes are considered. Each shaker takes care of each group of modes. The objective function value for the topology optimization is obtained from the superposed magnitude of the acceleration transfer function matrix. The column and row of this matrix represent the magnitude of the acceleration transfer function at natural frequency and accelerometer location, respectively. The minimum magnitude of acceleration transfer functions thus are selected first at a fixed accelerometer location (row position) and a single vector is developed. The maximum value of this vector is selected as an objective function value. A genetic algorithm is used to maximize the objective function value.

\section{Acknowledgments}

The work presented in this paper was funded by the Low-Boom Flight Demonstration Project under the NASA Aeronautics Research Mission Directorate. The author thanks peer review committee members Keerti Bhamidipati, Dr. Shun-fat Lung, and Rachel Saltzman of the NASA Armstrong Flight Research Center.

\section{References}

[1] Pak, C.-g., and Truong, S., "Creating a Test-Validated Structural Dynamic Finite-Element Model of the X-56A Aircraft," Journal of Aircraft, Vol.52, No.5, 2015, pp. 1644-1667. DOI: 10.2514/1.C03.3043

[2] “Test Requirements for Launch, Upper-Stage, and Space Vehicles,” MIL-STD-1540C, Sec. 6.2.10, Sep. 1994.

[3] NASATechnical Standard, "Load Analyses of Spacecraft and Payloads," NASA STD-5002, Sec. 4.2.6.d-f, Jun. 1996.

[4] MSC/NASTRAN Quick Reference Guide Version 69, The MacNeal-Schwendler Corporation, Newport Beach, California, 1996.

[5] Guyan, R. J., "Reduction of Stiffness and Mass Matrices," AIAA Journal, Vol.3, No. 2, 1965, pp. 380-380. DOI: $10.2514 / 3.2874$

[6] Kammer, D. C., "Sensor Placement for On-Orbit Modal Identification and Correlation of Large Space Structures," AIAA J. Guidance, Control and Dynamics, Vol. 14, No. 2, 1991, pp. 251-259.

[7] Kopec, D. N., and Girolamo, P., "Selection and Evaluation of Optimum Exciter Locations for Modal Testing via Automated Acceleration Transfer Function Analysis," AIAA-84-0996, 25th Structures, Structural Dynamics and Materials Conference, Palm Springs,CA, May 14-16, 1984.

DOI: $10.2514 / 6.1984-996$

[8] Pak, C.-g., "Preliminary Development of an Object-Oriented Optimization Tool," NASA TM-2011-216419, 2011.

[9] Pak, C.-g. and Truong S. S., "Extension of an Object-Oriented Optimization Tool: User's Reference Manual," NASA/TM-2015-218733, 2015.

[10] Pak, C.-g., "Jig-Shape Optimization of a Low-Boom Supersonic Aircraft," Journal of Aircraft, Vol. 55, No. 5, 2018, pp. 2154-2161.

DOI: $10.2514 / 1 . C 034851$

[11] “ZAERO User's Manual Version 8.2,” ZONA Technology, Inc., Scottsdale, AZ, 2008.

[12] O'Callahan, J., Avitabile, P., and Riemer, R., "System Equivalent Reduction Expansion Process (SERP)," Proceedings of the 7th International Modal Analysis Conference, Vol. 1, 1989, pp. 29-37. 
Table 1. Integerization table for design variables.

\begin{tabular}{|c|c|c|}
\hline Group number & Lower bound of design variable & Upper bound of design variable \\
\hline 1 & 0 & $1 / n s$ \\
\hline 2 & $1 / n s$ & $2 / n s$ \\
\hline$\ldots$ & $\ldots$ & $\ldots$ \\
\hline$n s$ & $(n s-1) / n s$ & 1 \\
\hline
\end{tabular}

Table 2. Selection of primary modes from flutter analyses and jig shape optimization.

\begin{tabular}{|c|c|c|c|c|c|c|c|}
\hline \multirow{2}{*}{$\begin{array}{c}\text { Mode } \\
\text { number }\end{array}$} & $\begin{array}{c}\text { Frequency } \\
\text { (Hz) }\end{array}$ & $\begin{array}{c}\text { Primary } \\
\text { mode } \\
\text { ranking }\end{array}$ & $\begin{array}{c}\text { Modal } \\
\text { participation } \\
\text { factor }\end{array}$ & $\begin{array}{c}\text { Frequency } \\
\text { (Hz) }\end{array}$ & $\begin{array}{c}\text { Primary } \\
\text { mode } \\
\text { ranking }\end{array}$ & $\begin{array}{c}\text { Modal } \\
\text { participation } \\
\text { factor }\end{array}$ & $\begin{array}{c}\text { Modal participation } \\
\text { factor for basis } \\
\text { functions used in jig } \\
\text { shape optimization }\end{array}$ \\
\hline $\mathbf{7}$ & 5.627 & & 0.0000 & 5.548 & & 0.0000 & 0.1398 \\
\hline 8 & 8.016 & & 0.1033 & 7.793 & & 0.0004 & -1.4535 \\
\hline 12 & 11.810 & & 0.0703 & 11.468 & & 0.1404 & 0.2762 \\
\hline 14 & 15.749 & 2 & 34.25 & 15.742 & 1 & 37.46 & \\
\hline 15 & 16.103 & & 0.0009 & 16.092 & & 0.0034 & 0.6809 \\
\hline 16 & 16.980 & 10 & 1.259 & 16.802 & 6 & 1.057 & \\
\hline 17 & 17.826 & 7 & 1.847 & 17.442 & & 0.0091 & \\
\hline 18 & 18.012 & & 0.1195 & 17.726 & 5 & 1.270 & \\
\hline 20 & 19.072 & 5 & 3.210 & 18.647 & & 0.7743 & -0.3346 \\
\hline 22 & 22.046 & 1 & 34.97 & 21.686 & 2 & 37.36 & \\
\hline 26 & 25.712 & 8 & 1.746 & 24.767 & & 0.0831 & 0.1245 \\
\hline 30 & 27.461 & 4 & 5.949 & 27.417 & & 0.3513 & -0.02954 \\
\hline 31 & 28.261 & 9 & 1.434 & 27.699 & 4 & 1.543 & \\
\hline 34 & 29.902 & 6 & 3.039 & 29.334 & & 0.1395 & \\
\hline 35 & 30.852 & & 0.2033 & 30.600 & & 0.1045 & 0.04405 \\
\hline 36 & 31.855 & & 0.6808 & 31.833 & & 0.2679 & -0.4546 \\
\hline 37 & 34.799 & 3 & 7.116 & 33.229 & 3 & 8.142 & \\
\hline
\end{tabular}


Table 3. Comments about primary mode shapes.

\begin{tabular}{|l|l|}
\hline Mode number & \multicolumn{1}{|c|}{ Comments } \\
\hline 7 & First fuselage vertical bending \\
\hline 8 & First fuselage lateral bending \\
\hline 12 & $\begin{array}{l}\text { Vertical tail bending + anti-sym. wing bending + fwd fuselage lateral bending (vertical tail fwd } \\
\text { fuselage out-phase) }\end{array}$ \\
\hline 14 & Anti-sym. stabilator chord-wise bending \\
\hline 15 & Sym. stabilator chord-wise bending \\
\hline 16 & Anti-sym. canard bending + wing tip bending (in-phase) \\
\hline 17 & Asym. right canard bending + empennage lateral \\
\hline 18 & Aft fuselage yaw and roll + anti-sym. canard bending \\
\hline 20 & Anti-sym. canard bending + wing tip bending (out-phase) \\
\hline 22 & $\begin{array}{l}\text { Anti-sym. vertical tail bending \& torsion + stabilator chord-wise bending }+ \text { aft fuselage roll + } \\
\text { wing tip bending }\end{array}$ \\
\hline 26 & Sym. stabilator yawing \\
\hline 30 & Anti-sym. T-tail bending \\
\hline 31 & Sym. flap and aileron bending (flap and aileron out-phase) \\
\hline 34 & $\begin{array}{l}\text { Sym. flap and aileron bending (flap and aileron in-phase) + anti-sym. empennage roll + forward } \\
\text { fuselage bending }\end{array}$ \\
\hline 35 & Anti-sym. Stabilator chord-wise and span-wise bending + anti-sym. flap and aileron motion \\
\hline 36 & Sym. stabilator bending \\
\hline 37 & Anti-sym. high frequency mode \\
\hline
\end{tabular}

Table 4. Frequency comparison between results from the FOM, the LM ROM, and the NASA ROM.

\begin{tabular}{|c|c|c|c|c|c|c|c|}
\hline \multicolumn{2}{|c|}{ FOM $(\mathrm{DOF}=544,162)$} & \multicolumn{2}{|c|}{ LM ROM $(\mathrm{DOF}=1,879)$} & \multicolumn{2}{c|}{ NASA ROM (DOF = 5,344) } \\
\hline $\begin{array}{c}\text { Mode } \\
\text { number }\end{array}$ & $\begin{array}{c}\text { Frequency } \\
(\mathrm{Hz})\end{array}$ & $\begin{array}{c}\text { Mode } \\
\text { number }\end{array}$ & $\begin{array}{c}\text { Frequency } \\
(\mathrm{Hz})\end{array}$ & $\begin{array}{c}\text { Error } \\
(\text { percent })\end{array}$ & $\begin{array}{c}\text { Mode } \\
\text { number }\end{array}$ & $\begin{array}{c}\text { Frequency } \\
(\mathrm{Hz})\end{array}$ & $\begin{array}{c}\text { Error } \\
(\text { percent })\end{array}$ \\
\hline $\mathbf{7}$ & 5.548 & $\mathbf{7}$ & 5.552 & 0.07 & 7 & 5.550 & 0.03 \\
\hline 8 & 7.793 & 8 & 7.797 & 0.05 & 8 & 7.795 & 0.02 \\
\hline 12 & 11.175 & 12 & 11.477 & 0.08 & 12 & 11.470 & 0.03 \\
\hline 14 & 15.742 & 14 & 15.753 & 0.07 & 14 & 15.750 & 0.05 \\
\hline 15 & 16.092 & 15 & 16.105 & 0.08 & 15 & 16.101 & 0.06 \\
\hline 16 & 16.802 & 16 & 16.824 & 0.13 & 16 & 16.814 & 0.07 \\
\hline 17 & 17.442 & 17 & 17.531 & 0.51 & 17 & 17.498 & $\mathbf{0 . 3 2}$ \\
\hline 18 & 17.726 & 18 & 17.744 & 0.10 & 18 & 17.737 & 0.06 \\
\hline 20 & 18.647 & 20 & 18.680 & 0.17 & 20 & 18.659 & 0.06 \\
\hline 22 & 21.686 & 22 & 21.801 & 0.53 & 22 & 21.741 & 0.26 \\
\hline 26 & 24.767 & 25 & 24.855 & 0.36 & 25 & 24.792 & 0.10 \\
\hline 30 & 27.417 & 29 & 27.438 & 0.08 & 29 & 27.429 & 0.04 \\
\hline 31 & 27.699 & 30 & 27.810 & 0.40 & 30 & 27.774 & 0.27 \\
\hline 34 & 29.334 & 32 & 29.584 & $\mathbf{0 . 8 5}$ & 32 & 29.349 & 0.05 \\
\hline 35 & 30.600 & 33 & 30.710 & 0.36 & 33 & 30.640 & 0.13 \\
\hline 36 & 31.833 & 34 & 31.888 & 0.17 & 34 & 31.866 & 0.11 \\
\hline 37 & 33.229 & 35 & 33.457 & 0.69 & 35 & 33.282 & 0.16 \\
\hline
\end{tabular}


Table 5. Orthonormalized mass matrix using mode shapes from the FOM and the NASA ROM.

\begin{tabular}{|c|c|c|c|c|c|c|c|c|c|c|c|c|c|c|c|c|c|}
\hline Mode & 7 & 8 & 12 & 14 & 15 & 16 & 17 & 18 & 20 & 22 & 26 & 30 & 31 & 34 & 35 & 36 & 37 \\
\hline 7 & & .000 & .000 & .000 & .000 & -.001 & -.002 & -.002 & -.001 & -.004 & .000 & .000 & .000 & -.003 & -.001 & -.001 & -.002 \\
\hline 8 & .000 & & .000 & .000 & .000 & .000 & .000 & .000 & .000 & .002 & .000 & .000 & .000 & .000 & .002 & .000 & .000 \\
\hline 12 & .000 & .000 & & .000 & .000 & .000 & .000 & .000 & .000 & -.001 & .000 & .000 & .000 & .000 & -.001 & .000 & .001 \\
\hline 14 & .000 & .000 & .000 & & .000 & .000 & .001 & .001 & .000 & .001 & .000 & .000 & .000 & .001 & .000 & .000 & -.001 \\
\hline 15 & .000 & .000 & .000 & .000 & & .001 & .004 & .003 & .001 & .006 & .000 & .000 & .000 & .003 & .001 & .000 & .001 \\
\hline 16 & $\begin{array}{l}-.001 \\
\end{array}$ & .000 & .000 & .000 & .001 & & -.005 & -.001 & $\begin{array}{l}-004 \\
\end{array}$ & -.006 & .000 & -.001 & .000 & $\begin{array}{l}-006 \\
\end{array}$ & .000 & \begin{tabular}{l|l}
-001 \\
\end{tabular} & .000 \\
\hline 17 & -.002 & .000 & .000 & .001 & .004 & -.005 & & .098 & -.004 & -.019 & .000 & -.001 & .001 & -.012 & -.003 & -.002 & -.004 \\
\hline 18 & -.002 & .000 & .000 & .001 & .003 & -.001 & .098 & & -.012 & -.036 & .000 & -.003 & .001 & -.025 & -.005 & -.003 & -.008 \\
\hline 20 & -.001 & .000 & .000 & .000 & .001 & -.004 & -.004 & -.012 & & -.006 & .000 & .000 & .000 & -.002 & -.001 & .000 & .000 \\
\hline 22 & $\begin{array}{l}-.004 \\
\end{array}$ & .002 & -.001 & .001 & .006 & -.006 & -.019 & -.036 & -.006 & & .000 & -.007 & .003 & .013 & .000 & $\begin{array}{l}-002 \\
\end{array}$ & .004 \\
\hline 26 & .000 & .000 & .000 & .000 & .000 & .000 & .000 & .000 & .000 & .000 & & .000 & .001 & .001 & .000 & .000 & .000 \\
\hline 30 & .000 & .000 & .000 & .000 & .000 & -.001 & -.001 & -.003 & .000 & -.007 & .000 & & .000 & .025 & .016 & .001 & -.006 \\
\hline 31 & .000 & .000 & .000 & .000 & .000 & .000 & .001 & .001 & .000 & .003 & .001 & .000 & & -.002 & -.001 & \begin{tabular}{l|l}
-001 \\
\end{tabular} & .002 \\
\hline 34 & -.003 & .000 & .000 & .001 & .003 & -.006 & -.012 & -.025 & -.002 & .013 & .001 & .025 & -.002 & & -.007 & -.012 & .008 \\
\hline 35 & -.001 & .002 & -.001 & .000 & .001 & .000 & -.003 & -.005 & -.001 & .000 & .000 & .016 & -.001 & -.007 & & -.002 & .012 \\
\hline 36 & -.001 & .000 & .000 & .000 & .000 & -.001 & -.002 & -.003 & .000 & -.002 & .000 & .001 & -.001 & -.012 & -.002 & & .005 \\
\hline 37 & -.002 & .000 & .001 & -.001 & .001 & .000 & -.004 & -.008 & .000 & .004 & .000 & -.006 & .002 & .008 & .012 & .005 & \\
\hline
\end{tabular}

Table 6. Cross-orthogonality matrix using mode shapes from the FOM and the NASA ROM.

\begin{tabular}{|c|c|c|c|c|c|c|c|c|c|c|c|c|c|c|c|c|c|}
\hline Mode & 7 & 8 & 12 & 14 & 15 & 16 & 17 & 18 & 20 & 22 & 26 & 30 & 31 & 34 & 35 & 36 & 37 \\
\hline 7 & 1.00 & .000 & .000 & .000 & .000 & .000 & .000 & .000 & .000 & .000 & .000 & .000 & .000 & .000 & .000 & .000 & .000 \\
\hline 8 & .000 & 1.00 & .000 & .000 & .000 & .000 & .000 & .000 & .000 & .000 & .000 & .000 & .000 & .000 & .000 & .000 & .000 \\
\hline 12 & .000 & .000 & .977 & .000 & .000 & .000 & .000 & .000 & .000 & .000 & .000 & .000 & .000 & .000 & .000 & .000 & .000 \\
\hline 14 & .000 & .000 & .000 & .943 & .001 & .000 & .000 & -.001 & .000 & .000 & .000 & .000 & .000 & .000 & .000 & .000 & .000 \\
\hline 15 & .000 & .000 & .000 & -.001 & .941 & .002 & -.001 & -.004 & .000 & .000 & .000 & .000 & .000 & .000 & .000 & .000 & .000 \\
\hline 16 & -.001 & .000 & .000 & .000 & .003 & -.948 & .002 & .011 & .001 & -.001 & .000 & -.001 & .000 & .000 & .000 & .000 & .000 \\
\hline 17 & -.002 & .000 & .000 & .001 & .005 & .008 & .853 & .146 & .003 & -.003 & .000 & -.001 & .001 & -.001 & .000 & -.001 & .000 \\
\hline 18 & -.002 & .000 & .000 & .001 & .006 & .011 & -.066 & .921 & .002 & -.003 & .000 & -.002 & .001 & -.001 & -.001 & -.001 & .000 \\
\hline 20 & -001 & .000 & .000 & .001 & .001 & .005 & -.005 & -.014 & .936 & -.002 & .000 & .000 & .000 & .000 & .000 & .000 & .000 \\
\hline 22 & -.005 & .002 & .000 & .001 & .006 & .005 & -.010 & -.033 & -.004 & -.812 & .000 & -.011 & .003 & -.007 & $\begin{array}{l}.004 \\
\end{array}$ & -.004 & -.002 \\
\hline 26 & .000 & .000 & .000 & .000 & .000 & .000 & .000 & .000 & .000 & .000 & .934 & -.001 & .001 & .000 & .000 & .000 & .000 \\
\hline 30 & .000 & .000 & .000 & .000 & .000 & .000 & .000 & -.001 & .000 & .000 & .000 & .815 & .000 & -.002 & .000 & .000 & .000 \\
\hline 31 & .000 & .000 & .000 & .000 & .000 & .000 & .000 & .000 & .000 & .000 & -.001 & -.001 & .904 & .000 & .000 & .001 & .000 \\
\hline 34 & -.003 & .000 & .000 & .001 & .003 & .005 & -.006 & -.022 & -.002 & .013 & .002 & .032 & -.004 & .949 & -.017 & -.015 & -.012 \\
\hline 35 & -.001 & .002 & -.001 & .000 & .000 & .000 & -.002 & -.004 & -.001 & .002 & .000 & .018 & -.001 & .007 & .935 & -.005 & -.003 \\
\hline 36 & -.001 & .000 & .000 & .000 & -.001 & .001 & .000 & -.002 & .000 & .001 & .000 & .002 & -.002 & .002 & .003 & .921 & -.002 \\
\hline 37 & -.002 & .000 & .001 & -.001 & .001 & .000 & -.002 & -.007 & .000 & .004 & .000 & $\begin{array}{l}.007 \\
\end{array}$ & .002 & .015 & .013 & .006 & .889 \\
\hline
\end{tabular}


Table 7. Modal assurance criterion matrix using mode shapes from the FOM and the NASA ROM.

\begin{tabular}{|c|c|c|c|c|c|c|c|c|c|c|c|c|c|c|c|c|c|}
\hline Mode & 7 & 8 & 12 & 14 & 15 & 16 & 17 & 18 & 20 & 22 & 26 & 30 & 31 & 34 & 35 & 36 & 37 \\
\hline 7 & 1.000 & 0.000 & 0.000 & 0.000 & 0.018 & 0.000 & 0.000 & 0.000 & 0.000 & 0.000 & 0.000 & 0.000 & 0.000 & 0.009 & 0.002 & 0.019 & 0.000 \\
\hline 8 & 0.000 & 1.000 & 0.042 & 0.000 & 0.000 & 0.000 & 0.002 & 0.000 & 0.003 & 0.026 & 0.000 & 0.000 & 0.000 & 0.000 & 0.005 & 0.000 & 0.002 \\
\hline 12 & 0.000 & 0.042 & 1.000 & 0.003 & 0.000 & 0.002 & 0.017 & 0.002 & 0.047 & 0.166 & 0.000 & 0.003 & 0.000 & 0.002 & 0.027 & 0.002 & 0.046 \\
\hline 14 & 0.000 & 0.000 & 0.003 & 1.000 & 0.000 & 0.000 & 0.001 & 0.000 & 0.003 & 0.000 & 0.000 & 0.000 & 0.000 & 0.002 & 0.008 & 0.000 & 0.000 \\
\hline 15 & 0.018 & 0.000 & 0.000 & 0.000 & 1.000 & 0.000 & 0.000 & 0.000 & 0.000 & 0.000 & 0.000 & 0.000 & 0.000 & 0.001 & 0.000 & 0.015 & 0.000 \\
\hline 16 & 0.000 & 0.000 & 0.002 & 0.000 & 0.000 & 1.000 & 0.085 & 0.012 & 0.164 & 0.001 & 0.000 & 0.003 & 0.000 & 0.000 & 0.001 & 0.000 & 0.008 \\
\hline 17 & 0.000 & 0.002 & 0.018 & 0.001 & 0.000 & 0.099 & 0.985 & 0.001 & 0.040 & 0.007 & 0.000 & 0.011 & 0.000 & 0.000 & 0.004 & 0.000 & 0.039 \\
\hline 18 & 0.000 & 0.000 & 0.001 & 0.000 & 0.000 & 0.003 & 0.040 & 0.988 & 0.002 & 0.000 & 0.000 & 0.000 & 0.000 & 0.010 & 0.000 & 0.000 & 0.001 \\
\hline 20 & 0.000 & 0.003 & 0.047 & 0.003 & 0.000 & 0.159 & 0.032 & 0.006 & 1.000 & 0.009 & 0.000 & 0.000 & 0.000 & 0.000 & 0.000 & 0.000 & 0.000 \\
\hline 22 & 0.000 & 0.019 & 0.142 & 0.000 & 0.001 & 0.001 & 0.011 & 0.001 & 0.008 & 0.795 & 0.000 & 0.012 & 0.001 & 0.000 & 0.018 & 0.001 & 0.036 \\
\hline 26 & 0.000 & 0.000 & 0.000 & 0.000 & 0.000 & 0.000 & 0.000 & 0.000 & 0.000 & 0.000 & 1.000 & 0.000 & 0.000 & 0.001 & 0.000 & 0.000 & 0.000 \\
\hline 30 & 0.000 & 0.000 & 0.004 & 0.000 & 0.000 & 0.006 & 0.009 & 0.001 & 0.000 & 0.013 & 0.000 & 0.969 & 0.000 & 0.007 & 0.017 & 0.000 & 0.002 \\
\hline 31 & 0.000 & 0.000 & 0.000 & 0.000 & 0.000 & 0.000 & 0.000 & 0.000 & 0.000 & 0.000 & 0.000 & 0.000 & 0.999 & 0.008 & 0.000 & 0.001 & 0.000 \\
\hline 34 & 0.011 & 0.000 & 0.002 & 0.001 & 0.001 & 0.000 & 0.000 & 0.012 & 0.000 & 0.017 & 0.001 & 0.007 & 0.009 & 0.993 & 0.058 & 0.006 & 0.004 \\
\hline 35 & 0.002 & 0.005 & 0.027 & 0.008 & 0.000 & 0.001 & 0.004 & 0.000 & 0.000 & 0.016 & 0.000 & 0.018 & 0.000 & 0.073 & 1.000 & 0.000 & 0.049 \\
\hline 36 & 0.019 & 0.000 & 0.002 & 0.000 & 0.015 & 0.000 & 0.000 & 0.000 & 0.000 & 0.000 & 0.000 & 0.000 & 0.001 & 0.006 & 0.000 & 1.000 & 0.000 \\
\hline 37 & 0.000 & 0.002 & 0.046 & 0.000 & 0.000 & 0.009 & 0.036 & 0.003 & 0.000 & 0.043 & 0.000 & 0.004 & 0.000 & 0.007 & 0.043 & 0.000 & 0.998 \\
\hline
\end{tabular}


Table 8. The first 40 DOF selected using the effective independence method.

\begin{tabular}{|c|c|c|c|c|c|c|}
\hline Ranking & Diagonal of $\boldsymbol{E I}$ matrix & Grid number & DOF & $\mathrm{X}$ (inch) & $\mathrm{Y}$ (inch) & Z (inch) \\
\hline 1 & 1 & 342501 & 3 & 505.35 & -48.09 & 115.5012 \\
\hline 2 & 1 & 400123 & 3 & 979.80 & -74.92 & 99.68769 \\
\hline 3 & 1 & 410127 & 3 & 1007.34 & -150.00 & 101.1801 \\
\hline 4 & 1 & 213094 & 2 & 540.27 & 0.00 & 132.724 \\
\hline 5 & 1 & 280571 & 3 & 966.87 & -167.61 & 100.6525 \\
\hline 6 & 1 & 2342501 & 3 & 505.35 & 48.09 & 115.501 \\
\hline 7 & 1 & 200424 & 2 & 209.67 & 0.00 & 99.4739 \\
\hline 8 & 1 & 281159 & 3 & 1018.51 & -177.00 & 100.811 \\
\hline 9 & 1 & 2400123 & 3 & 979.80 & 74.92 & 99.6877 \\
\hline 10 & 1 & 410066 & 3 & 985.70 & -90.00 & 101.7254 \\
\hline 11 & 1 & 200001 & 3 & 25.46 & 0.00 & 82.5134 \\
\hline 12 & 1 & 200001 & 2 & 25.46 & 0.00 & 82.5134 \\
\hline 13 & 1 & 2281159 & 3 & 1018.51 & 177.00 & 100.811 \\
\hline 14 & 1 & 2410127 & 3 & 1007.34 & 150.00 & 101.18 \\
\hline 15 & 1 & 254577 & 3 & 880.50 & -129.82 & 102.898 \\
\hline 16 & 1 & 420001 & 3 & 1061.20 & -2.25 & 200.2605 \\
\hline 17 & 1 & 420290 & 3 & 1111.38 & -24.00 & 199.7829 \\
\hline 18 & 1 & 200364 & 3 & 192.00 & 0.00 & 75.0459 \\
\hline 19 & 1 & 211559 & 2 & 412.00 & 0.00 & 69.562 \\
\hline 20 & 1 & 2280571 & 3 & 966.87 & 167.61 & 100.653 \\
\hline 21 & 1 & 200424 & 3 & 209.67 & 0.00 & 99.4739 \\
\hline 22 & 1 & 2420290 & 3 & 1111.38 & 24.00 & 199.783 \\
\hline 23 & 0.999999 & 2410066 & 3 & 985.70 & 90.00 & 101.725 \\
\hline 24 & 0.999999 & 2430128 & 2 & 1108.11 & 0.05 & 193.362 \\
\hline 25 & 0.999999 & 2430125 & 2 & 1105.33 & 0.05 & 176.392 \\
\hline 26 & 0.999998 & 2254577 & 3 & 880.50 & 129.82 & 102.898 \\
\hline 27 & 0.999997 & 2420001 & 3 & 1061.20 & 2.25 & 200.261 \\
\hline 28 & 0.999991 & 2350277 & 2 & 990.00 & 0.91 & 163.961 \\
\hline 29 & 0.999982 & 253655 & 3 & 742.75 & -79.34 & 107.1873 \\
\hline 30 & 0.999974 & 2253655 & 3 & 742.75 & 79.34 & 107.187 \\
\hline 31 & 0.999941 & 2440869 & 3 & 998.70 & 20.50 & 94.9772 \\
\hline 32 & 0.999878 & 440869 & 3 & 998.70 & -20.50 & 94.97723 \\
\hline 33 & 0.999676 & 2350730 & 3 & 1110.83 & 0.50 & 199.903 \\
\hline 34 & 0.995382 & 441530 & 3 & 1148.39 & -85.32 & 100.0041 \\
\hline 35 & 0.99522 & 2441530 & 3 & 1148.39 & 85.32 & 100.004 \\
\hline 36 & 0.994146 & 441379 & 3 & 1134.49 & -20.50 & 94.28355 \\
\hline 37 & 0.99303 & 2441379 & 3 & 1134.49 & 20.50 & 94.2836 \\
\hline 38 & 0.794856 & 2440869 & 2 & 998.70 & 20.50 & 94.9772 \\
\hline 39 & 0.794535 & 440869 & 2 & 998.70 & -20.50 & 94.97723 \\
\hline 40 & 0.716964 & 2441530 & 2 & 1148.39 & 85.32 & 100.004 \\
\hline
\end{tabular}

DOF $=1$ : translational DOF in fore and aft direction

$\mathrm{DOF}=2$ : translational DOF in lateral direction

$\mathrm{DOF}=3$ : translational DOF in vertical direction 
Table 9. The 40 accelerometers selected using the DPATF and the EI methods.

\begin{tabular}{|c|c|c|c|c|c|c|c|}
\hline Method & $\begin{array}{c}\text { Accelerometer } \\
\text { number }\end{array}$ & $\begin{array}{c}\text { Ranking in } \\
\text { Table } 8\end{array}$ & $\begin{array}{c}\text { Grid } \\
\text { number }\end{array}$ & DOF & X (inch) & $\mathrm{Y}$ (inch) & Z (inch) \\
\hline \multirow{14}{*}{ 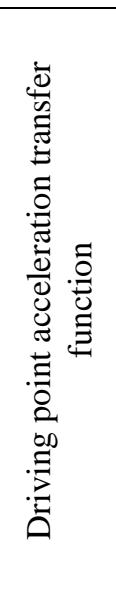 } & 1 & 11 & 200001 & 3 & 25.4649 & $1.78 \mathrm{E}-07$ & 82.5134 \\
\hline & 2 & 12 & 200001 & 2 & 25.4649 & $1.78 \mathrm{E}-07$ & 82.5134 \\
\hline & 3 & 47 & 2420290 & 2 & 1111.38 & 24 & 199.783 \\
\hline & 4 & 35 & 2441530 & 3 & 1148.39 & 85.3158 & 100.004 \\
\hline & 5 & 34 & 441530 & 3 & 1148.39 & -85.3158 & 100.004 \\
\hline & 6 & 1 & 342501 & 3 & 505.348 & -48.0879 & 115.501 \\
\hline & 7 & 6 & 2342501 & 3 & 505.348 & 48.0879 & 115.501 \\
\hline & 8 & 13 & 2281159 & 3 & 1018.51 & 177 & 100.811 \\
\hline & 9 & 32 & 440869 & 3 & 998.698 & -20.5 & 94.9772 \\
\hline & 10 & 39 & 440869 & 2 & 998.698 & -20.5 & 94.9772 \\
\hline & 11 & 17 & 420290 & 3 & 1111.38 & -24 & 199.783 \\
\hline & 12 & 2 & 400123 & 3 & 979.803 & -74.924 & 99.6877 \\
\hline & 13 & 14 & 2410127 & 3 & 1007.34 & 150.003 & 101.18 \\
\hline & 14 & 31 & 2440869 & 3 & 998.698 & 20.5 & 94.9772 \\
\hline \multirow{26}{*}{ 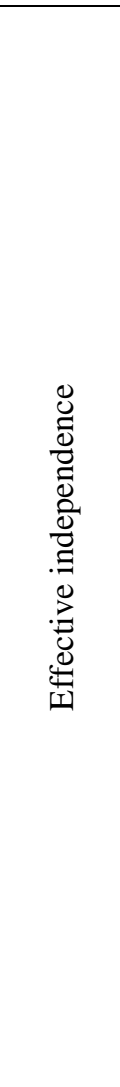 } & 15 & 3 & 410127 & 3 & 1007.34 & -150.003 & 101.18 \\
\hline & 16 & 4 & 213094 & 2 & 540.267 & 0 & 132.724 \\
\hline & 17 & 5 & 280571 & 3 & 966.865 & -167.611 & 100.653 \\
\hline & 18 & 7 & 200424 & 2 & 209.671 & $1.19 \mathrm{E}-15$ & 99.4739 \\
\hline & 19 & 8 & 281159 & 3 & 1018.51 & -177 & 100.811 \\
\hline & 20 & 9 & 2400123 & 3 & 979.803 & 74.924 & 99.6877 \\
\hline & 21 & 10 & 410066 & 3 & 985.701 & -90.0031 & 101.725 \\
\hline & 22 & 15 & 254577 & 3 & 880.498 & -129.816 & 102.898 \\
\hline & 23 & 16 & 420001 & 3 & 1061.2 & -2.25 & 200.261 \\
\hline & 24 & 18 & 200364 & 3 & 192 & $-1.68 \mathrm{E}-15$ & 75.0459 \\
\hline & 25 & 19 & 211559 & 2 & 411.999 & $-2.80 \mathrm{E}-15$ & 69.562 \\
\hline & 26 & 20 & 2280571 & 3 & 966.866 & 167.611 & 100.653 \\
\hline & 27 & 21 & 200424 & 3 & 209.671 & 1.19E-15 & 99.4739 \\
\hline & 28 & 22 & 2420290 & 3 & 1111.38 & 24 & 199.783 \\
\hline & 29 & 23 & 2410066 & 3 & 985.701 & 90.0031 & 101.725 \\
\hline & 30 & 24 & 2430128 & 2 & 1108.11 & $4.50 \mathrm{E}-02$ & 193.362 \\
\hline & 31 & 25 & 2430125 & 2 & 1105.33 & $4.50 \mathrm{E}-02$ & 176.392 \\
\hline & 32 & 26 & 2254577 & 3 & 880.498 & 129.816 & 102.898 \\
\hline & 33 & 27 & 2420001 & 3 & 1061.2 & 2.25 & 200.261 \\
\hline & 34 & 28 & 2350277 & 2 & 990.001 & 0.91178 & 163.961 \\
\hline & 35 & 29 & 253655 & 3 & 742.749 & -79.3372 & 107.187 \\
\hline & 36 & 30 & 2253655 & 3 & 742.749 & 79.3372 & 107.187 \\
\hline & 37 & 33 & 2350730 & 3 & 1110.83 & 0.499999 & 199.903 \\
\hline & 38 & 36 & 441379 & 3 & 1134.49 & -20.5 & 94.2836 \\
\hline & 39 & 37 & 2441379 & 3 & 1134.49 & 20.5 & 94.2836 \\
\hline & 40 & 38 & 2440869 & 2 & 998.698 & 20.5 & 94.9772 \\
\hline
\end{tabular}

DOF $=1$ : translational DOF in fore and aft direction

$\mathrm{DOF}=2$ : translational DOF in lateral direction

$\mathrm{DOF}=3$ : translational DOF in vertical direction 
Table 10. The MDPATF at the first 14 accelerometer locations $(M=$ Mode).

\begin{tabular}{|c|c|c|c|c|c|c|c|c|c|c|c|c|c|c|c|c|c|c|c|}
\hline \multirow{2}{*}{$\begin{array}{c}\text { Accel. } \\
\text { num. }\end{array}$} & \multirow{2}{*}{ Grid } & \multirow{2}{*}{ DOF } & \multicolumn{17}{|c|}{ MDPATF at frequencies of primary modes } \\
\hline & & & M7 & M8 & M12 & M14 & M15 & M16 & M17 & M18 & M20 & M22 & M26 & M30 & M31 & M34 & M35 & M36 & M37 \\
\hline 1 & 200001 & 3 & 500 & 1.8 & 9.1 & 0.0 & 4.2 & 0.2 & 2.6 & 6.6 & 1.0 & 285 & 1.3 & 2.6 & 6.2 & 475 & 27.7 & 11.1 & 5.9 \\
\hline 2 & 200001 & 2 & 1.0 & 500 & 112 & 1.8 & 1.7 & 1.6 & 8.1 & 2.1 & 8.5 & 2.1 & 1.5 & 1.4 & 1.4 & 1.4 & 2.5 & 1.4 & 1.9 \\
\hline 3 & 2420290 & 2 & 0.4 & 24.8 & 500 & 5.3 & 1.5 & 0.9 & 13.5 & 1.6 & 3.1 & 280 & 2.7 & 4.8 & 1.4 & 5.9 & 69.8 & 3.3 & 175 \\
\hline 4 & 2441530 & 3 & 26.3 & 1.4 & 4.6 & 501 & 495 & 16.1 & 16.4 & 9.3 & 5.8 & 24.8 & 0.7 & 2.3 & 4.5 & 39.9 & 423 & 310 & 39.3 \\
\hline 5 & 441530 & 3 & 26.4 & 2.3 & 14.0 & 497 & 502 & 16.5 & 10.9 & 9.1 & 5.9 & 14.0 & 0.8 & 1.8 & 3.7 & 39.5 & 215 & 500 & 16.1 \\
\hline 6 & 342501 & 3 & 1.2 & 1.1 & 34.5 & 12.3 & 15.7 & 500 & 99.4 & 501 & 323 & 87.5 & 6.1 & 5.6 & 5.0 & 5.9 & 4.4 & 4.0 & 66.1 \\
\hline 7 & 2342501 & 3 & 1.2 & 1.4 & 62.2 & 13.6 & 17.2 & 491 & 503 & 331 & 294 & 9.6 & 6.2 & 5.8 & 5.3 & 5.7 & 4.7 & 4.3 & 65.3 \\
\hline 8 & 2281159 & 3 & 0.4 & 1.0 & 335 & 2.7 & 3.6 & 49.3 & 17.1 & 60.7 & 500 & 379 & 5.1 & 3.4 & 7.9 & 4.3 & 4.7 & 0.7 & 500 \\
\hline 9 & 440869 & 3 & 0.9 & 0.7 & 2.4 & 301 & 383 & 10.3 & 13.2 & 6.0 & 4.3 & 500 & 3.2 & 0.3 & 2.7 & 63.0 & 247 & 469 & 13.8 \\
\hline 10 & 440869 & 2 & 0.1 & 0.1 & 0.3 & 2.0 & 1.7 & 1.5 & 10.3 & 0.3 & 1.2 & 12.8 & 500 & 8.5 & 4.8 & 32.2 & 38.9 & 8.7 & 3.0 \\
\hline 11 & 420290 & 3 & 16.0 & 1.4 & 75.2 & 0.9 & 0.8 & 0.8 & 15.0 & 0.6 & 1.3 & 15.6 & 7.6 & 500 & 14.3 & 108 & 24.9 & 7.5 & 86.2 \\
\hline 12 & 400123 & 3 & 0.1 & 0.2 & 0.5 & 1.2 & 1.3 & 4.3 & 2.4 & 3.8 & 38.2 & 12.6 & 9.3 & 84.7 & 500 & 344 & 21.4 & 10.7 & 216 \\
\hline 13 & 2410127 & 3 & 0.2 & 0.2 & 77.7 & 0.2 & 0.3 & 0.5 & 0.7 & 0.8 & 16.5 & 30.4 & 3.0 & 8.1 & 62.2 & 500 & 17.0 & 9.4 & 4.5 \\
\hline 14 & 2440869 & 3 & 0.9 & 0.7 & 2.2 & 305 & 378 & 10.4 & 22.7 & 6.1 & 4.3 & 315 & 1.7 & 2.0 & 4.6 & 43.0 & 500 & 284 & 23.2 \\
\hline
\end{tabular}

Table 11. Orthonormalized mass matrix using 40 accelerometer and mode shapes $\Phi_{R}$ and $\Phi_{E}$.

\begin{tabular}{|c|c|c|c|c|c|c|c|c|c|c|c|c|c|c|c|c|c|}
\hline Mode & 7 & 8 & 12 & 14 & 15 & 16 & 17 & 18 & 20 & 22 & 26 & 30 & 31 & 34 & 35 & 36 & 37 \\
\hline 7 & & .000 & .000 & .000 & .001 & -.001 & -.003 & -.004 & -.001 & -.008 & .000 & .000 & .000 & -.009 & -.002 & -.001 & -.005 \\
\hline 8 & .000 & & .000 & .000 & .000 & .000 & -.001 & .000 & -.001 & -.003 & .000 & .001 & .000 & -.002 & -.002 & -.001 & .001 \\
\hline 12 & .000 & .000 & & .000 & .000 & $\begin{array}{l}-001 \\
\end{array}$ & .000 & -.001 & .000 & -.001 & .000 & .000 & .000 & -.001 & .001 & .000 & -.001 \\
\hline 14 & .000 & .000 & .000 & & .000 & .000 & .000 & .000 & .000 & -.002 & .000 & .001 & .000 & .001 & -.003 & .000 & .001 \\
\hline 15 & .001 & .000 & .000 & .000 & & .002 & .006 & .004 & .002 & .009 & .000 & .001 & .000 & .008 & .002 & .000 & .004 \\
\hline 16 & -.001 & .000 & -.001 & .000 & .002 & & -.005 & -.003 & -.006 & -.017 & .000 & .002 & .000 & -.011 & -.015 & -.002 & .005 \\
\hline 17 & -.003 & -.001 & .000 & .000 & .006 & -.005 & & .098 & -.003 & -.009 & .000 & -.004 & .001 & -.010 & .015 & .000 & -.015 \\
\hline 18 & -.004 & .000 & -.001 & .000 & .004 & -.003 & .098 & & -.014 & -.042 & .000 & -.001 & .002 & -.032 & -.014 & -.003 & -.009 \\
\hline 20 & -.001 & -.001 & .000 & .000 & .002 & -.006 & -.003 & -.014 & & -.005 & .000 & -.001 & .000 & -.003 & .000 & .000 & -.003 \\
\hline 22 & -.008 & -.003 & -.001 & -.002 & .009 & -.017 & -.009 & -.042 & -.005 & & -.001 & -.005 & .003 & .022 & .003 & .001 & .008 \\
\hline 26 & .000 & .000 & .000 & .000 & .000 & .000 & .000 & .000 & .000 & -.001 & & .000 & .001 & .002 & .000 & .000 & .000 \\
\hline 30 & .000 & .001 & .000 & .001 & .001 & .002 & -.004 & -.001 & -.001 & -.005 & . 000. & & .000 & .028 & .018 & .002 & -.006 \\
\hline 31 & .000 & .000 & .000 & . & . 000. & .000 & .001 & .002 & .000 & .003 & . & . 000. & & -.005 & -.001 & -.002 & .000 \\
\hline 34 & -.009 & -.002 & -.001 & .001 & .008 & -.011 & -.010 & -.032 & -.003 & .022 & .002 & .028 & -.005 & & -.001 & -.004 & .010 \\
\hline 35 & -.002 & -.002 & .001 & -.003 & .002 & -.015 & .015 & -.014 & .000 & .003 & .000 & .018 & -.001 & -.001 & & .000 & .013 \\
\hline 36 & -.001 & -.001 & .000 & .000 & .000 & -.002 & .000 & -.003 & .000 & .001 & . & .002 & -.002 & -.004 & . 000 & & .008 \\
\hline 37 & -.005 & .001 & -.001 & .001 & .004 & .005 & -.015 & -.009 & -.003 & .008 & . 000. & -.006 & .000 & .010 & .013 & .008. & \\
\hline
\end{tabular}


Table 12. Cross-orthogonality matrix using 40 accelerometers and mode shapes $\Phi_{R}$ and $\Phi_{E}$.

\begin{tabular}{|c|c|c|c|c|c|c|c|c|c|c|c|c|c|c|c|c|c|}
\hline Mode & 7 & 8 & 12 & 14 & 15 & 16 & 17 & 18 & 20 & 22 & 26 & 30 & 31 & 34 & 35 & 36 & 37 \\
\hline 7 & 1.000 & .000 & .000 & .000 & .000 & .000 & .000 & .000 & .000 & .000 & .000 & .000 & .000 & .000 & .000 & .000 & .000 \\
\hline 8 & .000 & 1.001 & .000 & .000 & .000 & -.001 & -.001 & .000 & .000 & .000 & .000 & .000 & .000 & .000 & .000 & .000 & .000 \\
\hline 12 & .000 & .000 & .977 & .000 & .000 & .000 & .001 & .000 & .000 & .000 & .000 & .000 & .000 & .000 & .000 & .000 & .000 \\
\hline 14 & .000 & .000 & .000 & .943 & .001 & .000 & .000 & .000 & .000 & .000 & .000 & .000 & .000 & .000 & .000 & .000 & .000 \\
\hline 15 & .001 & .000 & .000 & -.001 & .941 & .002 & -.001 & -.003 & .000 & .000 & .000 & .000 & .000 & .000 & .000 & .000 & .000 \\
\hline 16 & -.001 & .000 & .000 & .000 & .004 & -.948 & .003 & .010 & .001 & .000 & .000 & .000 & .000 & .000 & .000 & .000 & .000 \\
\hline 17 & -.003 & .000 & -.001 & .001 & .006 & .008 & .853 & .145 & .003 & -.002 & .000 & -.001 & .001 & .000 & .000 & .000 & .000 \\
\hline 18 & -.003 & .000 & -.001 & .001 & .007 & .012 & -.065 & .919 & .002 & -.003 & .000 & -.001 & .001 & .001 & .000 & .000 & .000 \\
\hline 20 & -.001 & -.001 & .000 & .000 & .002 & .007 & -.003 & -.015 & .936 & -.001 & .000 & .000 & .000 & .000 & .000 & .000 & .000 \\
\hline 22 & -.009 & -.004 & -.001 & -.002 & .009 & .017 & .002 & -.041 & -.003 & -.808 & -.001 & -.010 & .003 & -.003 & -.001 & -.001 & -.001 \\
\hline 26 & .000 & .000 & .000 & .000 & .000 & .000 & .000 & .000 & .000 & .000 & .934 & -.001 & .001 & .000 & .000 & .000 & .000 \\
\hline 30 & .000 & .001 & .000 & .001 & .000 & -.002 & -.003 & .000 & -.001 & .000 & .000 & .815 & .000 & -.001 & .000 & .000 & .000 \\
\hline 31 & .000 & .000 & .000 & .000 & .000 & .000 & .000 & .000 & .000 & .000 & -.001 & -.001 & .904 & .000 & .000 & .001 & .000 \\
\hline 34 & -.009 & -.001 & -.001 & .001 & .008 & .010 & -.004 & -.030 & -.003 & .016 & .002 & .035 & -.007 & .952 & -.014 & -.008 & -.012 \\
\hline 35 & -.002 & -.001 & .000 & -.003 & .002 & .015 & .016 & -.012 & .000 & .005 & .000 & .020 & -.002 & .008 & .936 & -.004 & -.002 \\
\hline 36 & -.001 & -.001 & .000 & .000 & .000 & .002 & .000 & -.003 & .000 & .002 & .000 & .002 & -.002 & .003 & .003 & .922 & -.002 \\
\hline 37 & -.004 & .001 & -.001 & .001 & .003 & -.005 & -.011 & -.008 & -.003 & .006 & .000 & -.007 & .000 & .017 & .013 & .009 & .893 \\
\hline
\end{tabular}

Table 13. The modal assurance criterion matrix using 40 accelerometers and mode shapes $\Phi_{R}$ and $\Phi_{E} \cdot$

\begin{tabular}{|c|c|c|c|c|c|c|c|c|c|c|c|c|c|c|c|c|c|}
\hline Mode & 7 & 8 & 12 & 14 & 15 & 16 & 17 & 18 & 20 & 22 & 26 & 30 & 31 & 34 & 35 & 36 & 37 \\
\hline 7 & 1.000 & 0.000 & 0.000 & 0.000 & 0.018 & 0.000 & 0.000 & 0.000 & 0.000 & 0.000 & 0.000 & 0.000 & 0.000 & 0.008 & 0.002 & 0.019 & 0.000 \\
\hline 8 & 0.000 & 1.000 & 0.042 & 0.000 & 0.000 & 0.000 & 0.002 & 0.000 & 0.003 & 0.026 & 0.000 & 0.000 & 0.000 & 0.000 & 0.005 & 0.000 & 0.002 \\
\hline 12 & 0.000 & 0.042 & 1.000 & 0.003 & 0.000 & 0.002 & 0.017 & 0.002 & 0.047 & 0.165 & 0.000 & 0.003 & 0.000 & 0.002 & 0.027 & 0.002 & 0.046 \\
\hline 14 & 0.000 & 0.000 & 0.003 & 1.000 & 0.000 & 0.000 & 0.001 & 0.000 & 0.003 & 0.000 & 0.000 & 0.000 & 0.000 & 0.002 & 0.008 & 0.000 & 0.000 \\
\hline 15 & 0.018 & 0.000 & 0.000 & 0.000 & 1.000 & 0.000 & 0.000 & 0.000 & 0.000 & 0.000 & 0.000 & 0.000 & 0.000 & 0.001 & 0.000 & 0.015 & 0.000 \\
\hline 16 & 0.000 & 0.000 & 0.002 & 0.000 & 0.000 & 1.000 & 0.085 & 0.012 & 0.164 & 0.001 & 0.000 & 0.003 & 0.000 & 0.000 & 0.001 & 0.000 & 0.008 \\
\hline 17 & 0.000 & 0.002 & 0.018 & 0.001 & 0.000 & 0.099 & 0.985 & 0.001 & 0.040 & 0.007 & 0.000 & 0.012 & 0.000 & 0.000 & 0.005 & 0.000 & 0.038 \\
\hline 18 & 0.000 & 0.000 & 0.001 & 0.000 & 0.000 & 0.003 & 0.040 & 0.988 & 0.002 & 0.000 & 0.000 & 0.000 & 0.000 & 0.010 & 0.000 & 0.000 & 0.001 \\
\hline 20 & 0.000 & 0.003 & 0.047 & 0.003 & 0.000 & 0.159 & 0.032 & 0.006 & 1.000 & 0.009 & 0.000 & 0.000 & 0.000 & 0.000 & 0.000 & 0.000 & 0.000 \\
\hline 22 & 0.000 & 0.019 & 0.142 & 0.000 & 0.001 & 0.001 & 0.011 & 0.001 & 0.008 & 0.792 & 0.000 & 0.012 & 0.001 & 0.000 & 0.018 & 0.001 & 0.036 \\
\hline 26 & 0.000 & 0.000 & 0.000 & 0.000 & 0.000 & 0.000 & 0.000 & 0.000 & 0.000 & 0.000 & 1.000 & 0.000 & 0.000 & 0.001 & 0.000 & 0.000 & 0.000 \\
\hline 30 & 0.000 & 0.000 & 0.004 & 0.000 & 0.000 & 0.006 & 0.009 & 0.001 & 0.000 & 0.013 & 0.000 & 0.969 & 0.000 & 0.007 & 0.017 & 0.000 & 0.002 \\
\hline 31 & 0.000 & 0.000 & 0.000 & 0.000 & 0.000 & 0.000 & 0.000 & 0.000 & 0.000 & 0.000 & 0.000 & 0.000 & 0.999 & 0.008 & 0.000 & 0.001 & 0.000 \\
\hline 34 & 0.011 & 0.000 & 0.002 & 0.001 & 0.001 & 0.000 & 0.000 & 0.013 & 0.000 & 0.017 & 0.001 & 0.007 & 0.009 & 0.992 & 0.058 & 0.006 & 0.004 \\
\hline 35 & 0.002 & 0.005 & 0.027 & 0.008 & 0.000 & 0.001 & 0.004 & 0.000 & 0.000 & 0.016 & 0.000 & 0.018 & 0.000 & 0.072 & 1.000 & 0.000 & 0.049 \\
\hline 36 & 0.019 & 0.000 & 0.002 & 0.000 & 0.015 & 0.000 & 0.000 & 0.000 & 0.000 & 0.000 & 0.000 & 0.000 & 0.001 & 0.006 & 0.000 & 1.000 & 0.000 \\
\hline 37 & 0.000 & 0.002 & 0.046 & 0.000 & 0.000 & 0.009 & 0.036 & 0.003 & 0.000 & 0.043 & 0.000 & 0.004 & 0.000 & 0.007 & 0.043 & 0.000 & 0.998 \\
\hline
\end{tabular}


Table 14. The additional 39 accelerometers selected for mode visualization during the GVT.

\begin{tabular}{|c|c|c|c|c|c|}
\hline Accelerometer number & Grid number & DOF & $X$ (inch) & Y (inch) & Z (inch) \\
\hline 41 & 2350003 & 2 & 1070.76 & 1.8208 & 142.838 \\
\hline 42 & 2350061 & 2 & 1086.01 & 0.993923 & 196 \\
\hline 43 & 2350155 & 2 & 1043.33 & 0.722021 & 196.002 \\
\hline 44 & 2350238 & 2 & 960.455 & 0.957993 & 146.208 \\
\hline 45 & 2430076 & 2 & 1090.74 & 0.864463 & 195.5 \\
\hline 46 & 2430114 & 2 & 1099.76 & $4.50 \mathrm{E}-02$ & 142.452 \\
\hline 47 & 2255378 & 3 & 742.749 & 34.6499 & 103.934 \\
\hline 48 & 2300016 & 3 & 554.999 & 25.2244 & 109.364 \\
\hline 49 & 2342037 & 3 & 489.38 & 48.4112 & 116.246 \\
\hline 50 & 2342063 & 3 & 426.387 & 16.2727 & 113.456 \\
\hline 51 & 2342609 & 3 & 492.294 & 20.3561 & 106.404 \\
\hline 52 & 2400001 & 3 & 935.567 & 19.7273 & 87.0531 \\
\hline 53 & 2400046 & 3 & 955.36 & 74.6253 & 101.369 \\
\hline 54 & 2400069 & 3 & 960.783 & 21.4446 & 84.5237 \\
\hline 55 & 2410001 & 3 & 960.591 & 90.0195 & 103.353 \\
\hline 56 & 2410052 & 3 & 982.223 & 150.017 & 102.578 \\
\hline 57 & 2420252 & 3 & 1103.07 & 24 & 199.929 \\
\hline 58 & 2420264 & 3 & 1104.95 & 2.25 & 199.783 \\
\hline 59 & 2430003 & 3 & 1075.76 & 1.57729 & 143.186 \\
\hline 60 & 2441295 & 3 & 1125.66 & 85.3158 & 100.459 \\
\hline 61 & 4330029 & 3 & 931.297 & 28.9999 & 89.1548 \\
\hline 62 & 255378 & 3 & 742.7485 & -34.6499 & 103.9337 \\
\hline 63 & 300016 & 3 & 554.9989 & -25.2244 & 109.3644 \\
\hline 64 & 342037 & 3 & 489.3803 & -48.4112 & 116.2455 \\
\hline 65 & 342063 & 3 & 426.3869 & -16.2727 & 113.4559 \\
\hline 66 & 342609 & 3 & 492.294 & -20.3561 & 106.4036 \\
\hline 67 & 400001 & 3 & 935.5669 & -19.7273 & 87.05307 \\
\hline 68 & 400046 & 3 & 955.36 & -74.6253 & 101.3687 \\
\hline 69 & 400069 & 3 & 960.7825 & -21.4445 & 84.52368 \\
\hline 70 & 410001 & 3 & 960.5913 & -90.0195 & 103.3525 \\
\hline 71 & 410052 & 3 & 982.2228 & -150.017 & 102.5775 \\
\hline 72 & 420252 & 3 & 1103.066 & -24 & 199.9287 \\
\hline 73 & 420264 & 3 & 1104.946 & -2.25 & 199.7829 \\
\hline 74 & 441295 & 3 & 1125.656 & -85.3158 & 100.459 \\
\hline 75 & 261816 & 3 & 931.2971 & -28.9999 & 89.15475 \\
\hline 76 & 2259179 & 3 & 950.406 & 81.9998 & 103.292 \\
\hline 77 & 259179 & 3 & 950.4058 & -81.9998 & 103.292 \\
\hline 78 & 2280491 & 3 & 972.435 & 150.47 & 102.842 \\
\hline 79 & 280491 & 3 & 972.4346 & -150.47 & 102.8418 \\
\hline
\end{tabular}

DOF $=1$ : translational DOF in fore and aft direction

$\mathrm{DOF}=2$ : translational DOF in lateral direction

$\mathrm{DOF}=3$ : translational DOF in vertical direction 
Table 15. Orthonormalized mass matrix using 79 accelerometer and mode shapes $\Phi_{R}$ and $\Phi_{E}$.

\begin{tabular}{|c|c|c|c|c|c|c|c|c|c|c|c|c|c|c|c|c|c|}
\hline Mode & 7 & 8 & 12 & 14 & 15 & 16 & 17 & 18 & 20 & 22 & 26 & 30 & 31 & 34 & 35 & 36 & 37 \\
\hline 7 & & .000 & .000 & .000 & .000 & .000 & -.001 & -.001 & .000 & -.002 & .000 & .000 & .000 & .001 & .000 & .000 & .000 \\
\hline 8 & .000 & & .000 & .000 & .000 & .000 & -.001 & .000 & .000 & -.002 & .000 & .000 & .000 & -.001 & .000 & .000 & .000 \\
\hline 12 & .000 & .000 & & .000 & .000 & .000 & .000 & .000 & .000 & .000 & .000 & .000 & .000 & -.001 & .000 & .000 & .001 \\
\hline 14 & .000 & .000 & .000 & & .000 & .000 & .001 & .000 & .000 & -.001 & .000 & .001 & .000 & .001 & -.002 & .000 & .000 \\
\hline 15 & .000 & .000 & .000 & .000 & & .001 & .004 & .002 & .001 & .005 & .000 & .000 & .000 & .001 & .000 & .000 & .000 \\
\hline 16 & .000 & .000 & .000 & .000 & .001 & & -.005 & -.002 & -.005 & -.014 & .000 & .001 & .000 & -.007 & -.010 & -.001 & .000 \\
\hline 17 & -.001 & -.001 & .000 & .001 & .004 & -.005 & & .100 & -.004 & -.011 & .000 & -.004 & .001 & -.015 & .007 & -.002 & -.007 \\
\hline 18 & -.001 & .000 & .000 & .000 & .002 & -.002 & .100 & & -.013 & -.038 & .000 & -.001 & .001 & -.026 & -.011 & -.003 & -.008 \\
\hline 20 & .000 & .000 & .000 & .000 & .001 & -.005 & -.004 & -.013 & & -.006 & .000 & -.001 & .000 & -.004 & -.001 & -.001 & -.001 \\
\hline 22 & -.002 & -.002 & .000 & -.001 & .005 & -.014 & -.011 & -.038 & -.006 & & .000 & -.006 & .002 & .011 & -.001 & -.002 & .004 \\
\hline 26 & .000 & .000 & .000 & .000 & .000 & .000 & .000 & .000 & .000 & .000 & & .000 & .001 & .002 & .000 & .000 & .000 \\
\hline 30 & .000 & .000 & .000 & .001 & .000 & .001 & -.004 & -.001 & -.001 & -.006 & .000 & & .000 & .025 & .017 & .001 & -.006 \\
\hline 31 & .000 & .000 & .000 & .000 & .000 & .000 & .001 & .001 & .000 & .002 & .001 & .000 & & -.005 & -.001 & -.002 & .000 \\
\hline 34 & .001 & -.001 & -.001 & .001 & .001 & -.007 & -.015 & -.026 & -.004 & .011 & .002 & .025 & -.005 & & -.009 & -.011 & .004 \\
\hline 35 & .000 & .000 & .000 & -.002 & .000 & -.010 & .007 & -.011 & -.001 & -.001 & .000 & .017 & -.001 & -.009 & & -.002 & .013 \\
\hline 36 & .000 & .000 & .000 & .000 & .000 & -.001 & -.002 & -.003 & -.001 & -.002 & .000 & .001 & -.002 & -.011 & -.002 & & .006 \\
\hline 37 & .000 & .000 & .001 & .000 & .000 & .000 & -.007 & -.008 & -.001 & .004 & .000 & -.006 & .000 & .004 & .013 & .006 & \\
\hline
\end{tabular}

Table 16. Cross-orthogonality matrix using 79 accelerometer and mode shapes $\Phi_{R}$ and $\Phi_{E}$.

\begin{tabular}{|c|c|c|c|c|c|c|c|c|c|c|c|c|c|c|c|c|c|}
\hline Mode & 7 & 8 & 12 & 14 & 15 & 16 & 17 & 18 & 20 & 22 & 26 & 30 & 31 & 34 & 35 & 36 & 37 \\
\hline 7 & 1.000 & .000 & .000 & .000 & .000 & .000 & .000 & .000 & .000 & .000 & .000 & .000 & .000 & .000 & .000 & .000 & .000 \\
\hline 8 & .000 & 1.001 & .000 & .000 & .000 & .000 & .000 & .000 & .000 & .000 & .000 & .000 & .000 & .000 & .000 & .000 & .000 \\
\hline 12 & .000 & .000 & .977 & .000 & .000 & .000 & .001 & .000 & .000 & .000 & .000 & .000 & .000 & .000 & .000 & .000 & .000 \\
\hline 14 & .000 & .000 & .000 & .943 & .001 & .000 & .000 & -.001 & .000 & .000 & .000 & .000 & .000 & .000 & .000 & .000 & .000 \\
\hline 15 & .000 & .000 & .000 & -.001 & .941 & .002 & -.001 & -.004 & .000 & .000 & .000 & .000 & .000 & .000 & .000 & .000 & .000 \\
\hline 16 & .000 & .000 & .000 & .000 & .003 & -.948 & .003 & .011 & .001 & -.001 & .000 & .000 & .000 & .000 & .000 & .000 & .000 \\
\hline 17 & -.001 & .000 & .000 & .001 & .005 & .008 & .853 & .146 & .003 & -.003 & .000 & -.001 & .001 & -.002 & -001 & -.001 & .000 \\
\hline 18 & -.001 & .000 & .000 & .001 & .006 & .012 & -.065 & .921 & .002 & -.003 & .000 & -.002 & .001 & -.002 & -.001 & -.001 & -.001 \\
\hline 20 & .000 & .000 & .000 & .000 & .001 & .006 & -.004 & -.015 & .936 & -.002 & .000 & .000 & .000 & -.001 & .000 & .000 & .000 \\
\hline 22 & -.002 & -.002 & .000 & -.001 & .005 & .013 & -.001 & -.035 & -.004 & -.811 & .000 & -.010 & .003 & -.009 & -.004 & -.004 & -.002 \\
\hline 26 & .000 & .000 & .000 & .000 & .000 & .000 & .000 & .000 & .000 & .000 & .934 & $\begin{array}{l}-001 \\
\end{array}$ & .001 & .000 & .000 & .000 & .000 \\
\hline 30 & .000 & .000 & .000 & .000 & .000 & -.001 & -.002 & .000 & .000 & .000 & .000 & .815 & .000 & -.002 & -.001 & .000 & .000 \\
\hline 31 & .000 & .000 & .000 & .000 & .000 & .000 & .000 & .000 & .000 & .000 & -.001 & -.001 & .903 & .000 & .000 & .001 & .000 \\
\hline 34 & .001 & -.001 & -.001 & .001 & .001 & .005 & -.008 & -.022 & -.003 & .014 & .002 & .033 & -.007 & .944 & -.018 & -.013 & -.012 \\
\hline 35 & .000 & .000 & .000 & -.002 & .000 & .009 & .009 & $\begin{array}{l}-008 \\
\end{array}$ & -.001 & .004 & .001 & .019 & -.002 & .007 & .935 & -.005 & -.002 \\
\hline 36 & .000 & .000 & .000 & .000 & -.001 & .001 & -.001 & -.002 & .000 & .001 & .000 & .002 & -.002 & .002 & .003 & .921 & -.002 \\
\hline 37 & .000 & .000 & .001 & .000 & .000 & -.001 & -.005 & -.007 & -.001 & .005 & .000 & -.006 & .000 & .012 & .012 & .007 & .890 \\
\hline
\end{tabular}


Table 17. Modal assurance criterion matrix using 79 accelerometer and mode shapes $\Phi_{R}$ and $\Phi_{E}$.

\begin{tabular}{|c|c|c|c|c|c|c|c|c|c|c|c|c|c|c|c|c|c|}
\hline Mode & 7 & 8 & 12 & 14 & 15 & 16 & 17 & 18 & 20 & 22 & 26 & 30 & 31 & 34 & 35 & 36 & 37 \\
\hline 7 & 1.000 & 0.000 & 0.000 & 0.000 & 0.018 & 0.000 & 0.000 & 0.000 & 0.000 & 0.000 & 0.000 & 0.000 & 0.000 & 0.010 & 0.002 & 0.019 & 0.000 \\
\hline 8 & 0.000 & 1.000 & 0.042 & 0.000 & 0.000 & 0.000 & 0.002 & 0.000 & 0.003 & 0.026 & 0.000 & 0.000 & 0.000 & 0.000 & 0.005 & 0.000 & 0.002 \\
\hline 12 & 0.000 & 0.042 & 1.000 & 0.003 & 0.000 & 0.002 & 0.017 & 0.002 & 0.047 & 0.166 & 0.000 & 0.003 & 0.000 & 0.002 & 0.027 & 0.002 & 0.046 \\
\hline 14 & 0.000 & 0.000 & 0.003 & 1.000 & 0.000 & 0.000 & 0.001 & 0.000 & 0.003 & 0.000 & 0.000 & 0.000 & 0.000 & 0.002 & 0.008 & 0.000 & 0.000 \\
\hline 15 & 0.018 & 0.000 & 0.000 & 0.000 & 1.000 & 0.000 & 0.000 & 0.000 & 0.000 & 0.000 & 0.000 & 0.000 & 0.000 & 0.001 & 0.000 & 0.015 & 0.000 \\
\hline 16 & 0.000 & 0.000 & 0.002 & 0.000 & 0.000 & 1.000 & 0.085 & 0.012 & 0.164 & 0.001 & 0.000 & 0.003 & 0.000 & 0.000 & 0.001 & 0.000 & 0.008 \\
\hline 17 & 0.000 & 0.002 & 0.018 & 0.001 & 0.000 & 0.099 & 0.985 & 0.001 & 0.040 & 0.007 & 0.000 & 0.012 & 0.000 & 0.000 & 0.005 & 0.000 & 0.038 \\
\hline 18 & 0.000 & 0.000 & 0.001 & 0.000 & 0.000 & 0.003 & 0.040 & 0.988 & 0.002 & 0.000 & 0.000 & 0.000 & 0.000 & 0.010 & 0.000 & 0.000 & 0.001 \\
\hline 20 & 0.000 & 0.003 & 0.047 & 0.003 & 0.000 & 0.159 & 0.032 & 0.006 & 1.000 & 0.009 & 0.000 & 0.000 & 0.000 & 0.000 & 0.000 & 0.000 & 0.000 \\
\hline 22 & 0.000 & 0.019 & 0.142 & 0.000 & 0.001 & 0.001 & 0.011 & 0.001 & 0.008 & 0.794 & 0.000 & 0.012 & 0.001 & 0.000 & 0.018 & 0.001 & 0.036 \\
\hline 26 & 0.000 & 0.000 & 0.000 & 0.000 & 0.000 & 0.000 & 0.000 & 0.000 & 0.000 & 0.000 & 1.000 & 0.000 & 0.000 & 0.001 & 0.000 & 0.000 & 0.000 \\
\hline 30 & 0.000 & 0.000 & 0.004 & 0.000 & 0.000 & 0.006 & 0.009 & 0.001 & 0.000 & 0.013 & 0.000 & 0.969 & 0.000 & 0.007 & 0.017 & 0.000 & 0.002 \\
\hline 31 & 0.000 & 0.000 & 0.000 & 0.000 & 0.000 & 0.000 & 0.000 & 0.000 & 0.000 & 0.000 & 0.000 & 0.000 & 0.999 & 0.008 & 0.000 & 0.001 & 0.000 \\
\hline 34 & 0.011 & 0.000 & 0.002 & 0.001 & 0.001 & 0.000 & 0.000 & 0.012 & 0.000 & 0.017 & 0.001 & 0.007 & 0.009 & 0.993 & 0.058 & 0.006 & 0.004 \\
\hline 35 & 0.002 & 0.005 & 0.027 & 0.008 & 0.000 & 0.001 & 0.004 & 0.000 & 0.000 & 0.016 & 0.000 & 0.018 & 0.000 & 0.073 & 1.000 & 0.000 & 0.049 \\
\hline 36 & 0.019 & 0.000 & 0.002 & 0.000 & 0.015 & 0.000 & 0.000 & 0.000 & 0.000 & 0.000 & 0.000 & 0.000 & 0.001 & 0.006 & 0.000 & 1.000 & 0.000 \\
\hline 37 & 0.000 & 0.002 & 0.046 & 0.000 & 0.000 & 0.009 & 0.036 & 0.003 & 0.000 & 0.043 & 0.000 & 0.004 & 0.000 & 0.007 & 0.043 & 0.000 & 0.998 \\
\hline
\end{tabular}


Table 18. Groups of modes for the optimum shaker placement using four shakers.

\begin{tabular}{|c|c|c|c|c|}
\hline Mode number & Group 1 modes & Group 2 modes & Group 3 modes & Group 4 modes \\
\hline 1 & 3 & 1 & 2 & 5 \\
\hline 2 & 4 & 6 & 15 & 12 \\
\hline 3 & 7 & 8 & 16 & 18 \\
\hline 4 & 10 & 9 & 17 & 20 \\
\hline 5 & 22 & 11 & 21 & 35 \\
\hline 6 & 23 & 13 & 25 & 37 \\
\hline 7 & 24 & 14 & 28 & \\
\hline 8 & 26 & 36 & 30 & \\
\hline 9 & 29 & 40 & & \\
\hline 10 & 31 & & & \\
\hline 11 & 32 & & & \\
\hline 12 & 33 & & & \\
\hline 13 & 34 & & & \\
\hline 15 & 39 & & & \\
\hline
\end{tabular}

Table 19. The minimum MDPATF for each group at the first 28 accelerometer locations using four shakers.

\begin{tabular}{|c|c|c|c|c|}
\hline $\begin{array}{c}\text { Accelerometer } \\
\text { number }\end{array}$ & Group 1 modes & Group 2 modes & Group 3 modes & Group 4 modes \\
\hline 1 & 0.34 & 0.78 & 1.70 & $6.88(12)^{*}$ \\
\hline 2 & 1.95 & 1.40 & 1.40 & 2.86 \\
\hline 3 & 0.26 & 0.70 & 0.27 & 1.70 \\
\hline 4 & 2.56 & 3.84 & 0.48 & 0.78 \\
\hline 5 & 1.68 & $5.86(14)^{*}$ & 0.36 & 0.43 \\
\hline 6 & 1.20 & 1.25 & 1.49 & 5.21 \\
\hline 7 & 1.15 & 1.24 & 1.68 & 5.86 \\
\hline 8 & 5.66 & 1.08 & 0.42 & 5.13 \\
\hline 9 & 0.84 & 0.87 & 0.83 & 5.61 \\
\hline 10 & 0.32 & 0.15 & 0.33 & 0.80 \\
\hline 11 & 3.24 & 2.31 & 1.99 & 3.00 \\
\hline 12 & 1.14 & 0.28 & 1.56 & 1.63 \\
\hline 13 & 1.70 & 0.84 & 2.21 & 2.56 \\
\hline 14 & 0.62 & 0.86 & 0.81 & 1.48 \\
\hline 15 & 1.36 & 0.66 & $4.41(28)^{*}$ & 2.14 \\
\hline 16 & 0.38 & 0.03 & 0.22 & 0.02 \\
\hline 17 & 0.86 & 0.43 & 0.35 & 0.49 \\
\hline 18 & 0.35 & 0.13 & 0.08 & 0.17 \\
\hline 19 & $6.69(23)^{*}$ & 0.91 & 0.47 & 2.45 \\
\hline 20 & 1.20 & 0.27 & 1.44 & 1.47 \\
\hline 21 & 0.35 & 0.19 & 0.33 & 0.66 \\
\hline 22 & 0.17 & 0.03 & 0.39 & 0.05 \\
\hline 23 & 0.12 & 0.34 & 0.33 & 0.62 \\
\hline 24 & 0.04 & 0.05 & 0.41 & 0.07 \\
\hline 25 & 0.28 & 0.03 & 0.10 & 0.06 \\
\hline 26 & 1.00 & 0.37 & 0.41 & 0.43 \\
\hline 27 & 0.13 & 0.15 & 0.09 & 0.19 \\
\hline 28 & 3.65 & 2.63 & 1.70 & 4.34 \\
\hline
\end{tabular}

$(\#) *$ mode number 
Table 20. Four shaker locations and exciting DOF.

\begin{tabular}{|c|c|c|c|c|c|c|}
\hline $\begin{array}{c}\text { Shaker } \\
\text { number }\end{array}$ & $\begin{array}{c}\text { Accelerometer } \\
\text { number }\end{array}$ & Grid number & DOF & X (inch) & Y (inch) & Z (inch) \\
\hline 1 & 19 & 281159 & 3 & 1018.51 & -177.00 & 100.81 \\
\hline 2 & 5 & 441530 & 3 & 1148.39 & -85.32 & 100.00 \\
\hline 3 & 15 & 410127 & 3 & 1007.34 & -150.00 & 101.18 \\
\hline 4 & 1 & 200001 & 3 & 25.46 & 0.00 & 82.51 \\
\hline
\end{tabular}

$\mathrm{DOF}=3$ : translational DOF in vertical direction

Table 21. The minimum MATF for each group at the first 28 accelerometer locations using four shakers.

\begin{tabular}{|c|c|c|c|c|c|}
\hline $\begin{array}{c}\text { Accelerometer } \\
\text { number }\end{array}$ & Group 1 modes & Group 2 modes & Group 3 modes & Group 4 modes & All modes \\
\hline 1 & 2.85 & 4.89 & 7.66 & 24.24 & 2.85 \\
\hline 2 & 3.44 & 1.45 & 6.39 & 3.09 & 1.45 \\
\hline 3 & 5.00 & 0.48 & 4.33 & 4.75 & 0.48 \\
\hline 4 & 4.47 & 9.84 & 2.64 & 5.14 & 2.64 \\
\hline 5 & 5.45 & $16.89(13)^{*}$ & 2.77 & 12.63 & 2.77 \\
\hline 6 & 8.76 & 3.33 & 4.12 & 6.85 & 3.33 \\
\hline 7 & 9.96 & 2.26 & 3.65 & 9.14 & 2.26 \\
\hline 8 & 6.49 & 5.06 & 5.92 & 18.29 & 5.06 \\
\hline 9 & 3.88 & 8.59 & 4.65 & 9.69 & 3.88 \\
\hline 10 & 2.76 & 0.71 & 1.92 & 4.55 & 0.71 \\
\hline 11 & 4.25 & 2.72 & 15.09 & 8.02 & 2.72 \\
\hline 12 & 9.20 & 7.85 & 7.06 & 9.28 & 7.06 \\
\hline 13 & 2.12 & 2.31 & 3.54 & 3.07 & 2.12 \\
\hline 14 & 3.89 & 1.33 & 4.30 & 14.08 & 1.33 \\
\hline 15 & 6.22 & 5.72 & 14.74 & 9.61 & 5.72 \\
\hline 16 & 3.45 & 0.28 & 0.39 & 0.53 & 0.28 \\
\hline 17 & 5.85 & 4.32 & 4.71 & 7.50 & 4.32 \\
\hline 18 & 4.17 & 0.45 & 2.04 & 0.32 & 0.32 \\
\hline 19 & $14.20(23)^{*}$ & 11.23 & 11.06 & $24.71(35)^{*}$ & 11.06(19)* \\
\hline 20 & 3.85 & 5.51 & 9.22 & 11.32 & 3.85 \\
\hline 21 & 2.35 & 6.82 & 7.49 & 9.29 & 2.35 \\
\hline 22 & 4.32 & 3.56 & 2.94 & 4.39 & 2.94 \\
\hline 23 & 0.77 & 1.09 & 8.06 & 0.93 & 0.77 \\
\hline 24 & 2.23 & 2.22 & 2.61 & 2.70 & 2.22 \\
\hline 25 & 1.95 & 0.18 & 1.88 & 1.08 & 0.18 \\
\hline 26 & 4.30 & 1.57 & 1.24 & 5.81 & 1.24 \\
\hline 27 & 1.66 & 1.53 & 1.69 & 2.37 & 1.53 \\
\hline 28 & 3.97 & 4.50 & $15.78(2)^{*}$ & 3.94 & 3.94 \\
\hline
\end{tabular}

(\#)*: mode number 
Table 22. The maximum of minimum MDPATF and minimum MATF for each group.

\begin{tabular}{|c|c|c|c|}
\hline $\begin{array}{c}\text { Shaker } \\
\text { number }\end{array}$ & $\begin{array}{c}\text { Maximum of minimum } \\
\text { MDPATF for shaker selection } \\
\text { (summary of Table 19) }\end{array}$ & $\begin{array}{c}\text { Maximum of minimum MATF } \\
\text { (summary of Table 21) }\end{array}$ & $\begin{array}{c}\text { MATF at same accelerometer } \\
\text { location with same mode in the } \\
\text { second column }\end{array}$ \\
\hline 1 & $6.69(23)^{*}$ & $14.20(23)^{*}$ & $14.20(23)^{*}$ \\
\hline 2 & $5.86(14)^{*}$ & $\mathbf{1 6 . 8 9}(\mathbf{1 3})^{*}$ & $\mathbf{1 7 . 3 1 ( 1 4 ) ^ { * + }}$ \\
\hline 3 & $4.41(28)^{*}$ & $\mathbf{1 5 . 7 8 ( 2 ) ^ { * }}$ & $\mathbf{3 3 . 2 6 ( 2 8})^{*+}$ \\
\hline 4 & $6.88(12)^{*}$ & $\mathbf{2 4 . 7 1 ( 3 5 ) ^ { * }}$ & $\mathbf{2 9 . 5 1 ( 1 2 ) ^ { * + + }}$ \\
\hline
\end{tabular}

(\#)*: mode number

+-: from Table A2; accelerometer number 5

+: from Table A3; accelerometer number 15

++ : from Table A2: accelerometer number 1

Table 23. The maximum of minimum MATF for all the modes of interest using different numbers of shakers.

\begin{tabular}{|c|c|c|}
\hline $\begin{array}{c}\text { Number } \\
\text { of shakers }\end{array}$ & $\begin{array}{c}\text { Maximum of minimum MATF value (= objective } \\
\text { function value at the global optimum point ) }\end{array}$ & $\begin{array}{c}\text { Increase of maximum of minimum MATF } \\
\text { value based on number of shaker increase } \\
\text { (percent) }\end{array}$ \\
\hline 1 & 1.987 & N/A \\
\hline 2 & 5.031 & 153.1 \\
\hline 3 & 7.5522 & 50.1 \\
\hline 4 & 11.06 & 46.5 \\
\hline
\end{tabular}


Table 24. The maximum MATF for each mode using different numbers of shakers.

\begin{tabular}{|c|c|c|c|c|c|c|c|c|c|c|}
\hline $\begin{array}{c}\text { Number of } \\
\text { Shakers }\end{array}$ & Mode 1 & Mode 2 & Mode 3 & Mode 4 & Mode 5 & Mode 6 & Mode 7 & Mode 8 & Mode 9 & Mode 10 \\
\hline 1 & 89.35 & 25.88 & 39.81 & 96.94 & 63.85 & 193.94 & 178.11 & 19.93 & 18.19 & 7.11 \\
\hline 2 & 28.69 & 100.38 & 512.69 & 470.25 & 226.96 & 462.51 & 213.94 & 395.47 & 442.25 & 198.76 \\
\hline 3 & 118.28 & 98.10 & 533.84 & 602.68 & 375.97 & 584.12 & 392.77 & 419.34 & 455.50 & 205.21 \\
\hline 4 & 630.96 & 192.42 & 986.17 & 862.07 & 897.10 & 811.72 & 324.16 & 510.13 & 554.06 & 192.92 \\
\hline $\begin{array}{c}\text { Number of } \\
\text { Shakers }\end{array}$ & Mode 11 & Mode 12 & Mode 13 & Mode 14 & Mode 15 & Mode 16 & Mode 17 & Mode 18 & Mode 19 & Mode 20 \\
\hline 1 & 86.46 & 12.63 & 4.95 & 23.26 & 297.99 & 88.15 & 500.00 & 95.68 & 29.46 & 97.44 \\
\hline 2 & 263.06 & 199.81 & 505.68 & 454.29 & 338.38 & 697.73 & 23.19 & 223.77 & 36.56 & 80.26 \\
\hline 3 & 255.58 & 229.43 & 441.02 & 571.36 & 405.24 & 1253.65 & 523.29 & 409.77 & 55.11 & 387.52 \\
\hline 4 & 277.73 & 251.83 & 681.69 & 512.38 & 897.43 & 709.98 & 70.81 & 250.04 & 67.82 & 450.57 \\
\hline $\begin{array}{c}\text { Number of } \\
\text { Shakers }\end{array}$ & Mode 21 & Mode 22 & Mode 23 & Mode 24 & Mode 25 & Mode 26 & Mode 27 & Mode 28 & Mode 29 & Mode 30 \\
\hline 1 & 424.33 & 563.25 & 566.83 & 60.22 & 139.71 & 231.83 & 108.44 & 47.98 & 207.45 & 145.10 \\
\hline 2 & 144.85 & 96.27 & 31.56 & 98.95 & 178.81 & 232.89 & 371.19 & 497.69 & 494.99 & 118.62 \\
\hline 3 & 348.14 & 662.88 & 599.56 & 137.51 & 339.34 & 249.98 & 695.72 & 433.00 & 818.45 & 314.78 \\
\hline 4 & 286.49 & 114.97 & 69.21 & 370.28 & 502.51 & 1097.39 & 590.53 & 567.43 & 610.75 & 706.03 \\
\hline $\begin{array}{c}\text { Number of } \\
\text { Shakers }\end{array}$ & Mode 31 & Mode 32 & Mode 33 & Mode 34 & Mode 35 & Mode 36 & Mode 37 & Mode 38 & Mode 39 & Mode 40 \\
\hline 1 & 148.78 & 103.91 & 341.77 & 201.69 & 38.18 & 14.82 & 11.14 & 8.34 & 12.93 & 280.10 \\
\hline 2 & 235.85 & 535.59 & 67.88 & 333.97 & 31.21 & 132.51 & 175.28 & 81.64 & 156.32 & 26.40 \\
\hline 3 & 307.94 & 526.50 & 852.19 & 367.26 & 74.17 & 172.16 & 172.64 & 81.96 & 154.02 & 290.05 \\
\hline 4 & 765.64 & 1189.52 & 276.98 & 1229.22 & 69.36 & 652.60 & 801.17 & 627.69 & 668.16 & 236.62 \\
\hline
\end{tabular}

Table 25. The minimum of maximum MATF for all the modes of interest using different numbers of shakers.

\begin{tabular}{|c|c|c|}
\hline Number of shakers & Minimum of maximum MATF value & $\begin{array}{c}\text { Increase of minimum of maximum MATF value } \\
\text { based on number of shaker increase (percent) }\end{array}$ \\
\hline 1 & 4.95 & N/A \\
\hline 2 & 23.19 & 368.5 \\
\hline 3 & 55.11 & 137.6 \\
\hline 4 & 67.82 & 23.1 \\
\hline
\end{tabular}




\section{Figures}

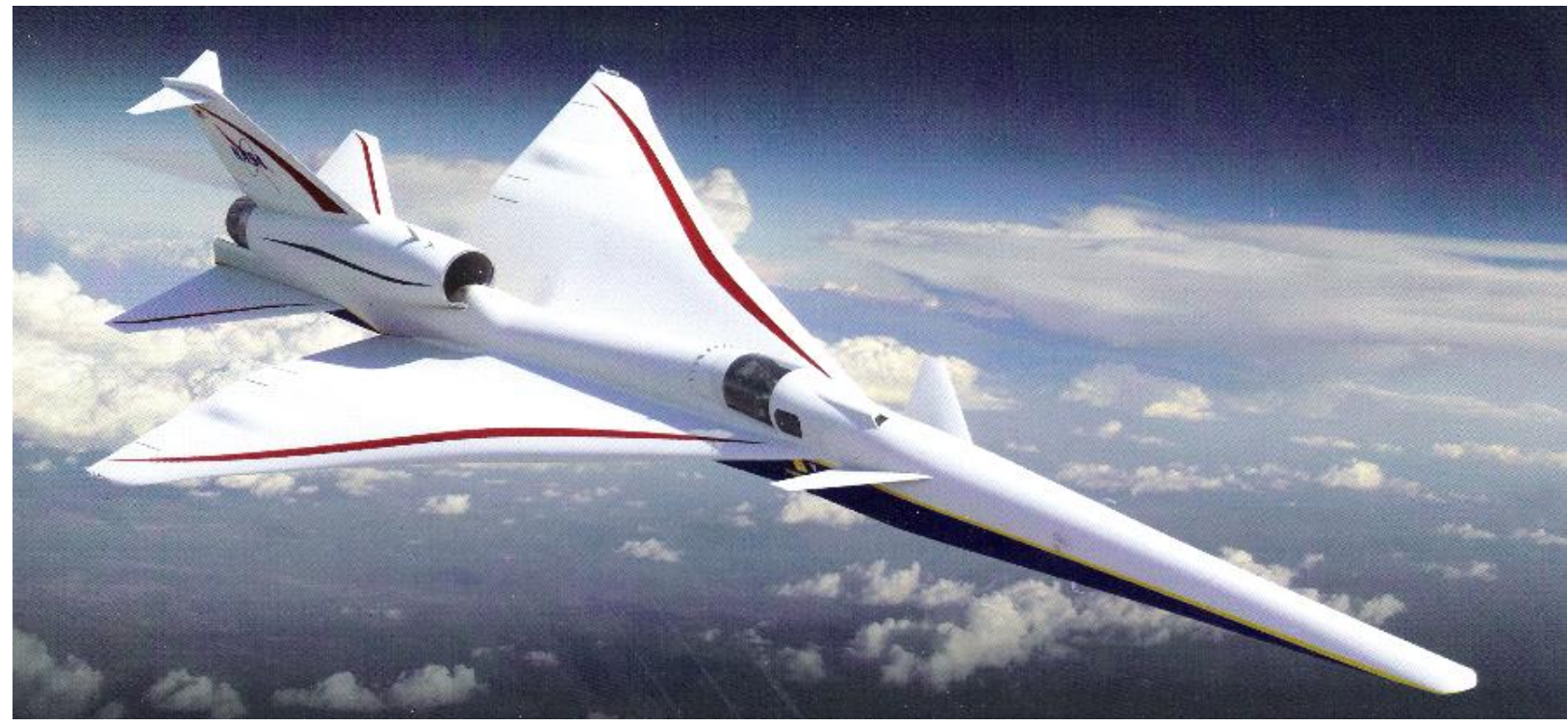

Fig. 1. The X-59 Low Boom Flight Demonstrator aircraft.

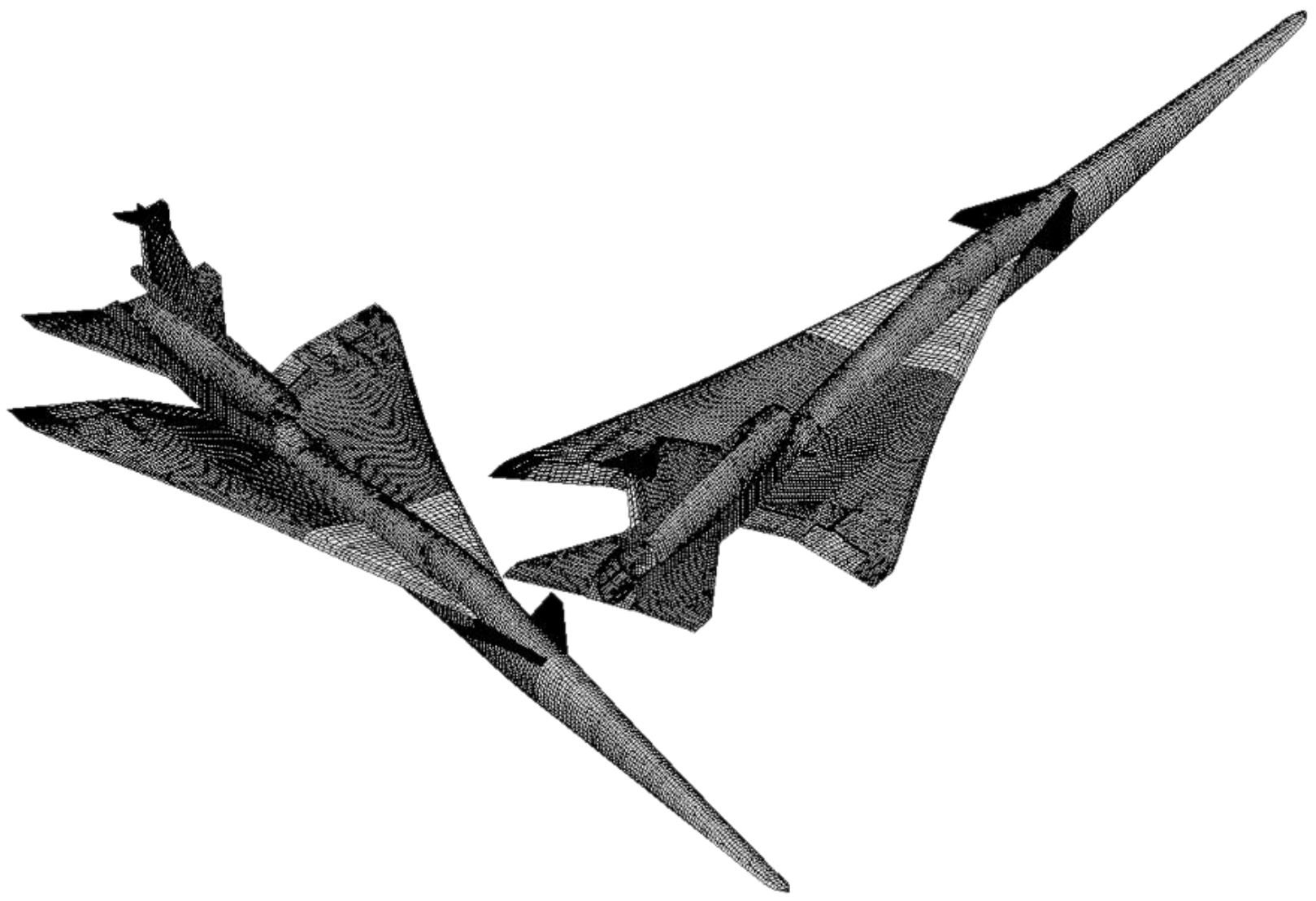

Fig. 2. The finite-element structural model of the $\mathrm{C609}$ configuration. 


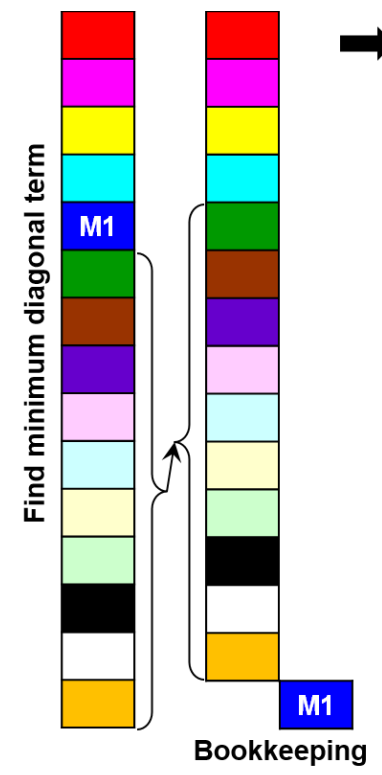

(a) First minimum

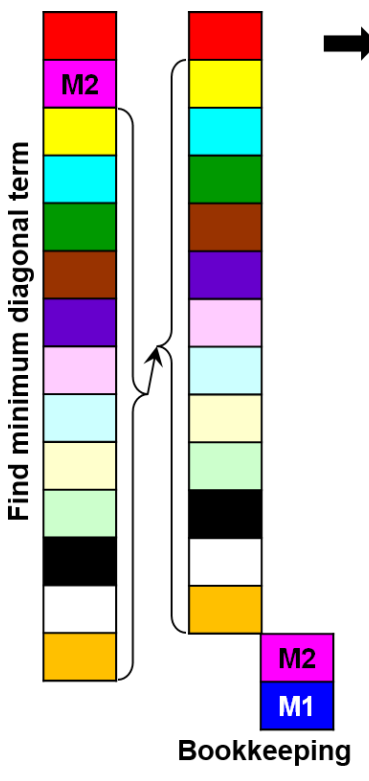

(b) Second minimum

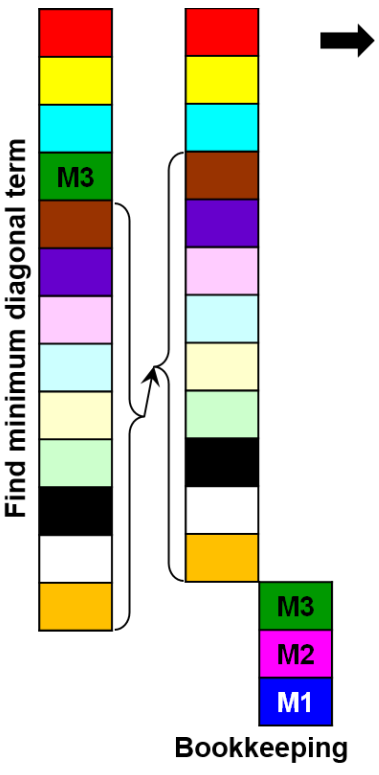

(c) Third minimum

Fig. 3. Sorting and bookkeeping based on minimum diagonal terms of the effective independence method. 


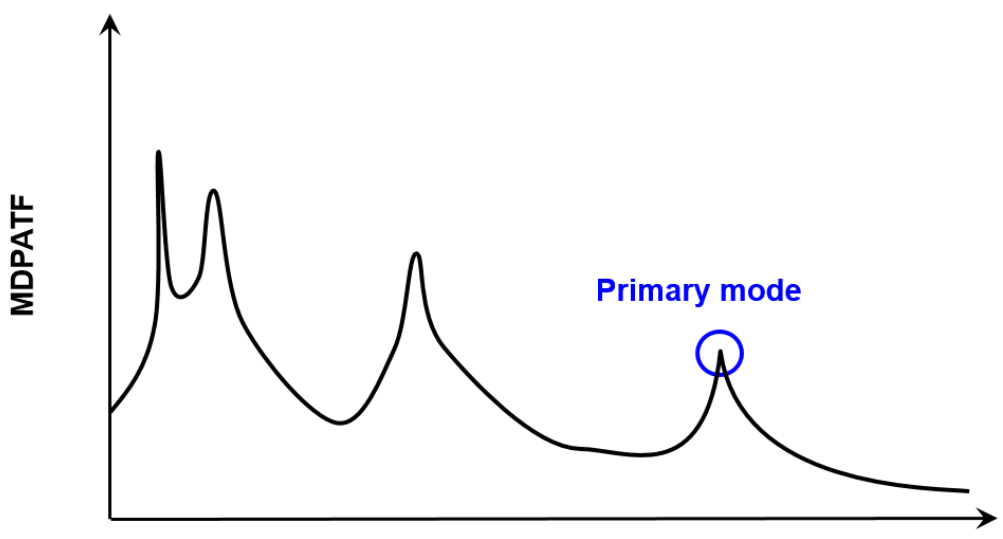

Frequency $(\mathrm{Hz})$

(a) Sensor location 1

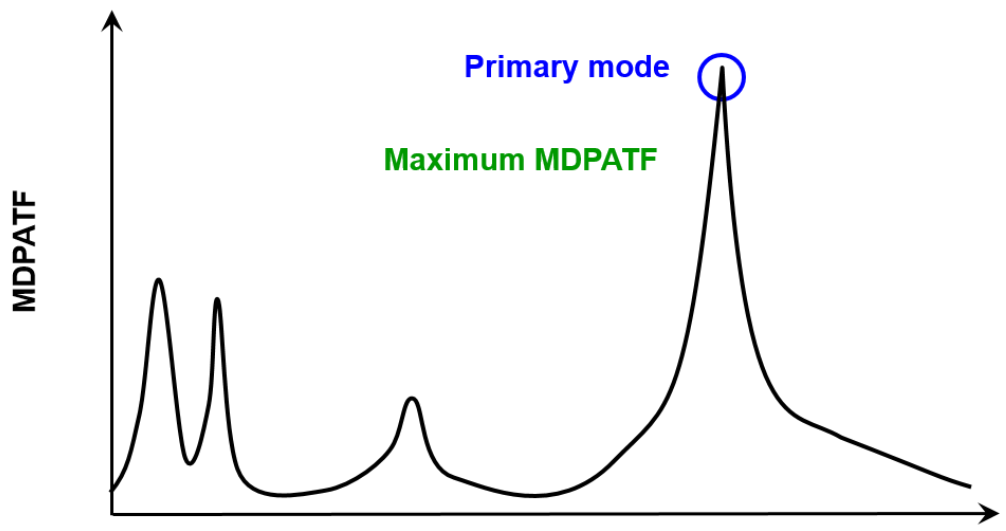

Frequency $(\mathrm{Hz})$

(b) Sensor location 2

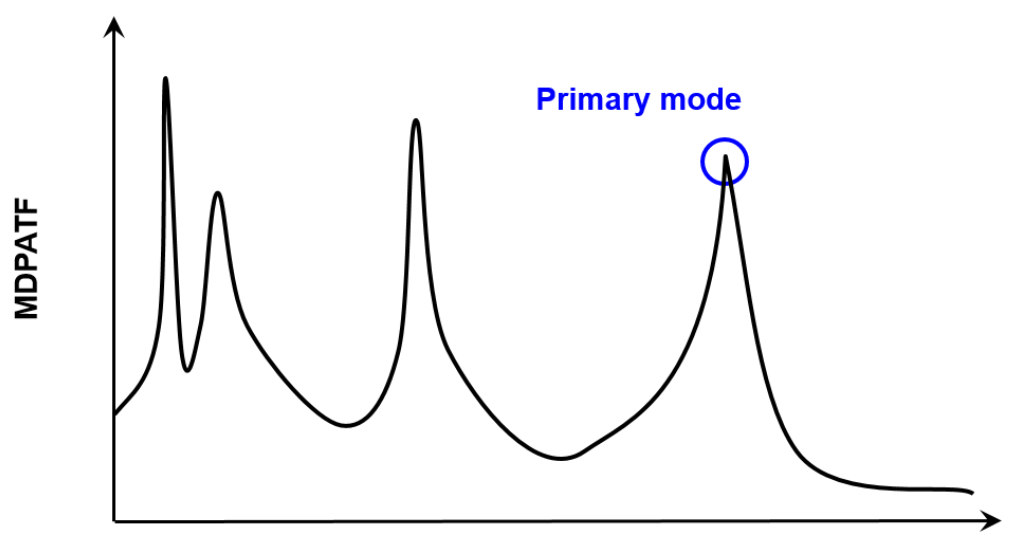

Frequency $(\mathrm{Hz})$

(c) Sensor location 3

Fig. 4. Magnitude of driving point acceleration transfer function at three candidate sensor locations. 


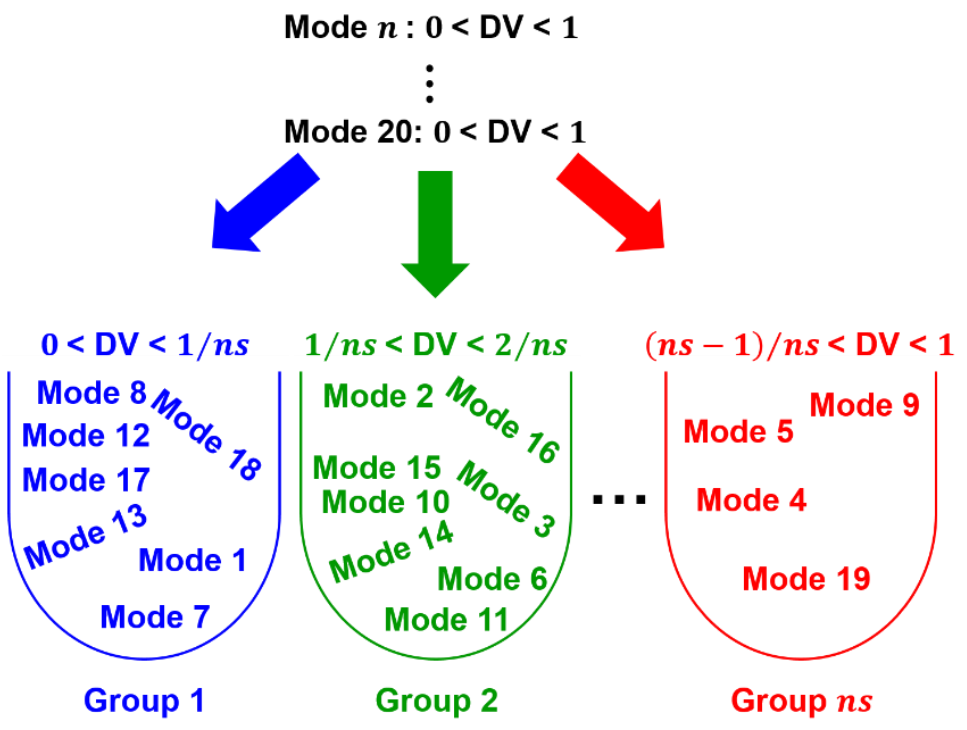

Fig. 5. Random grouping of modes based on random design variable (DV). 


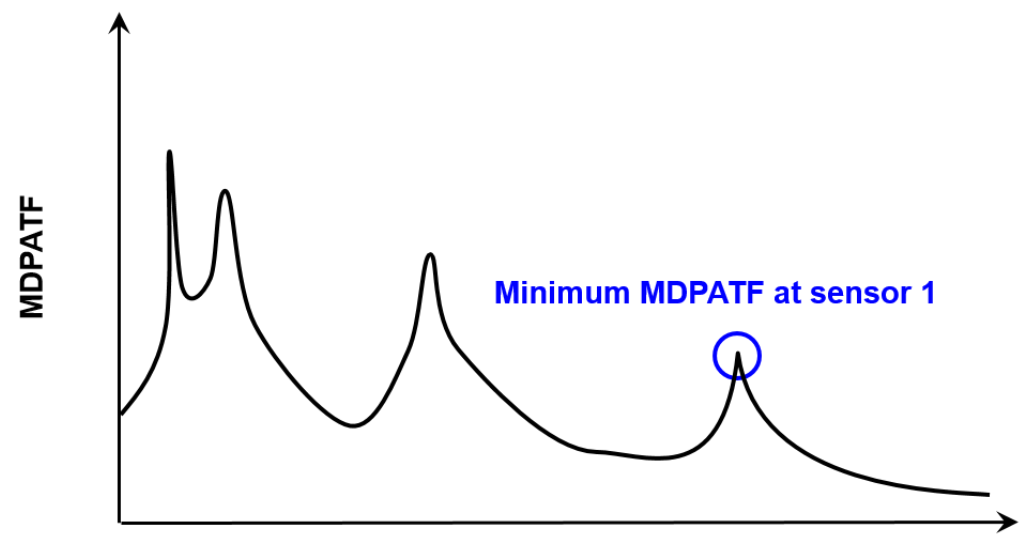

Frequency $(\mathrm{Hz})$

(a) Sensor location 1

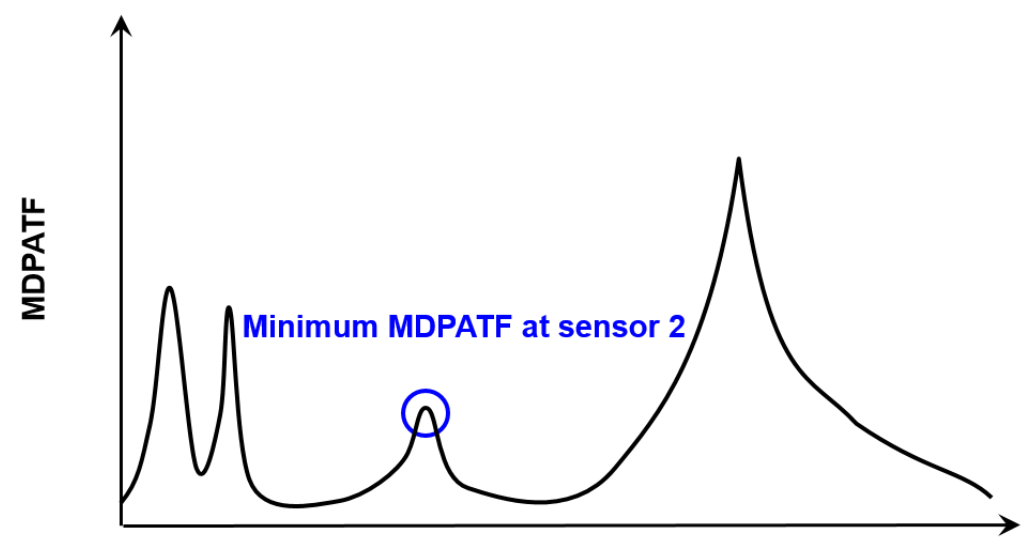

Frequency $(\mathrm{Hz})$

(b) Sensor location 2

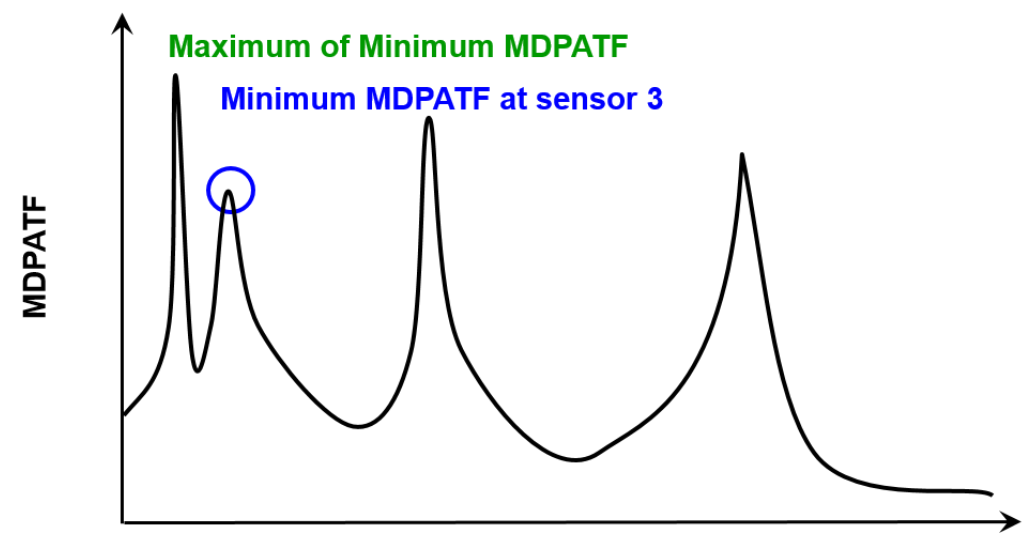

Frequency $(\mathrm{Hz})$

(c) Sensor location 3

Fig. 6. Magnitude of driving point acceleration transfer function at three sensor locations with four modes. 


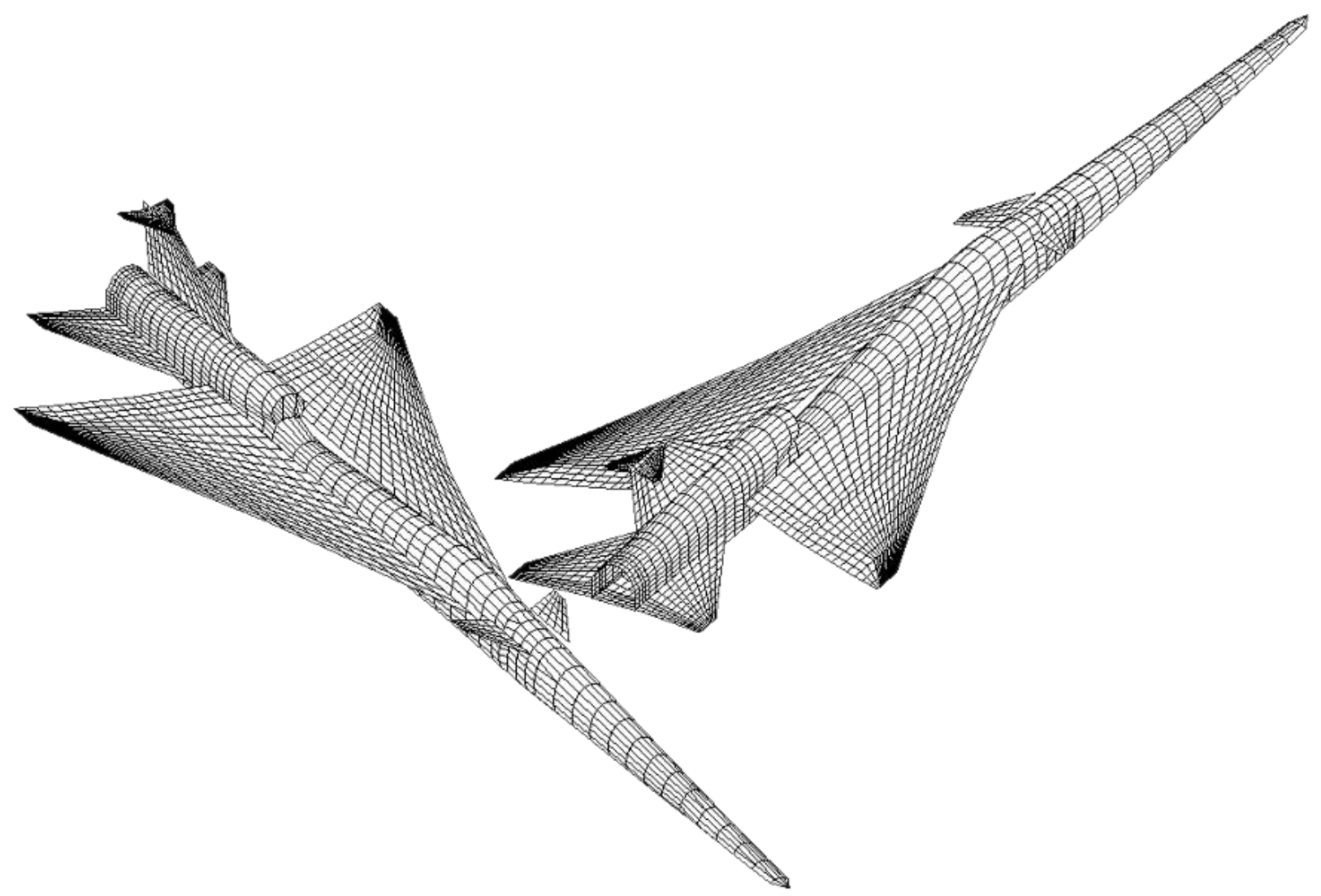

Fig. 7. The aerodynamic model of the $\mathrm{C} 609$ configuration.

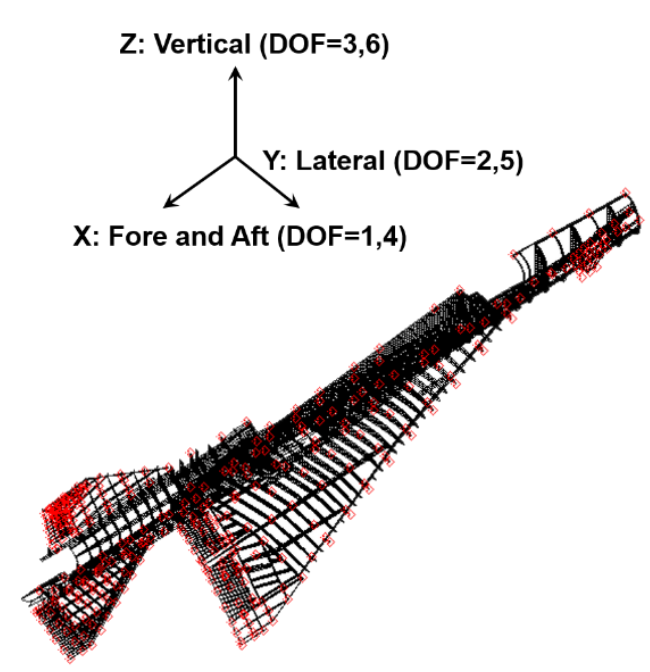

(a) LM's ROM with 1879 DOF

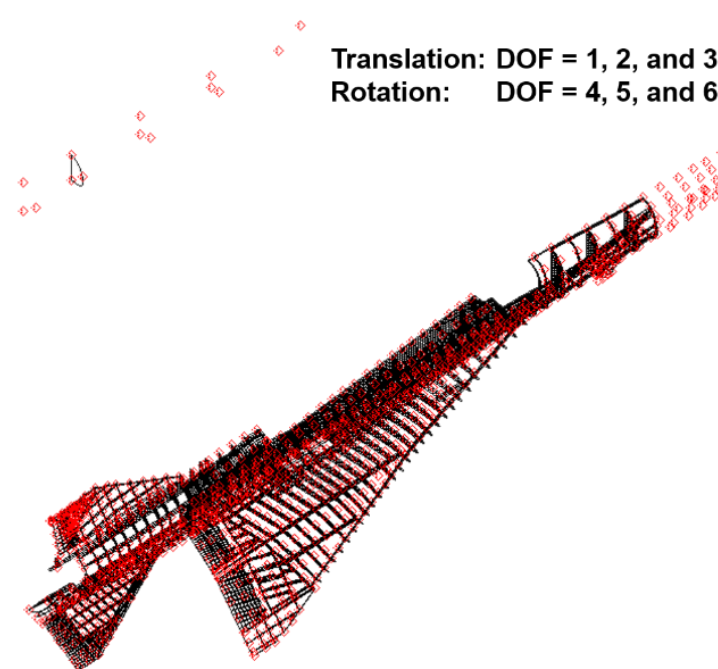

(b) NASA's ROM with 5344 DOF

Fig. 8. Candidate accelerometer and shaker locations. 
Accelerometer number: node number (DOF)

(3) 2 : Forty accelerometers

8: 2281159(3)

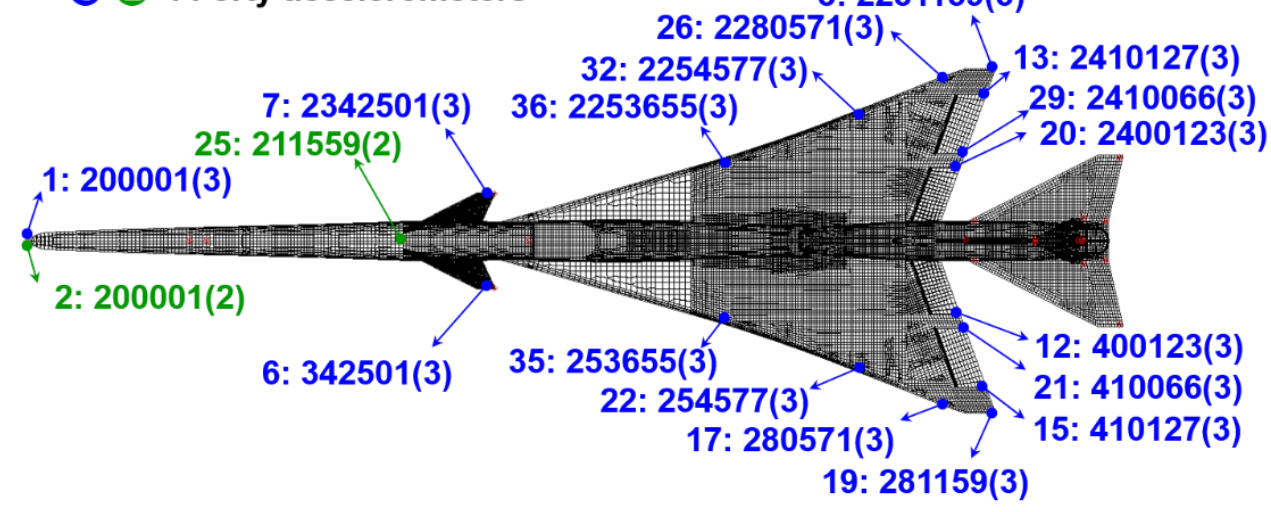

(a) Top view

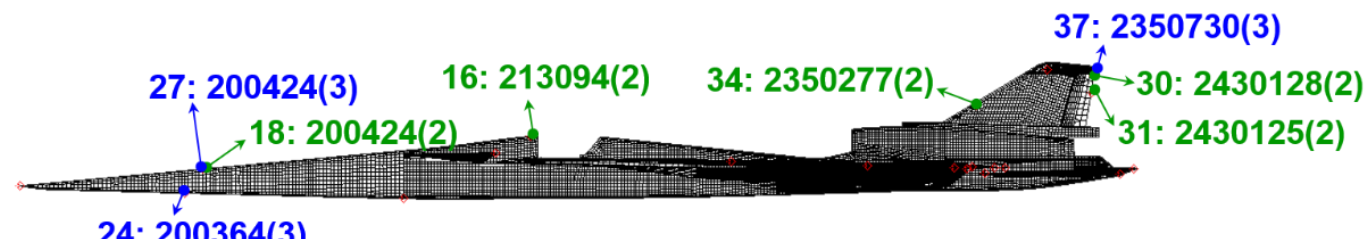

(b) Side view

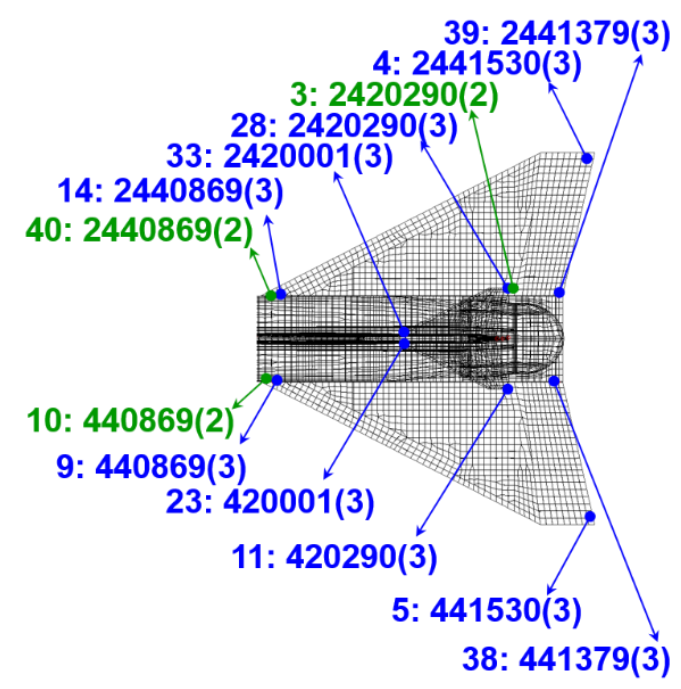

(c) Zoomed empennage

Fig. 9. Forty accelerometer locations for the ground vibration test. 
Accelerometer number: node number (DOF)

(3) 2 : First $\mathbf{4 0}$ accelerometers

32 : Additional 39 accelerometers

55:2410001(3) 78:2280491(3)

76:2259179(3)

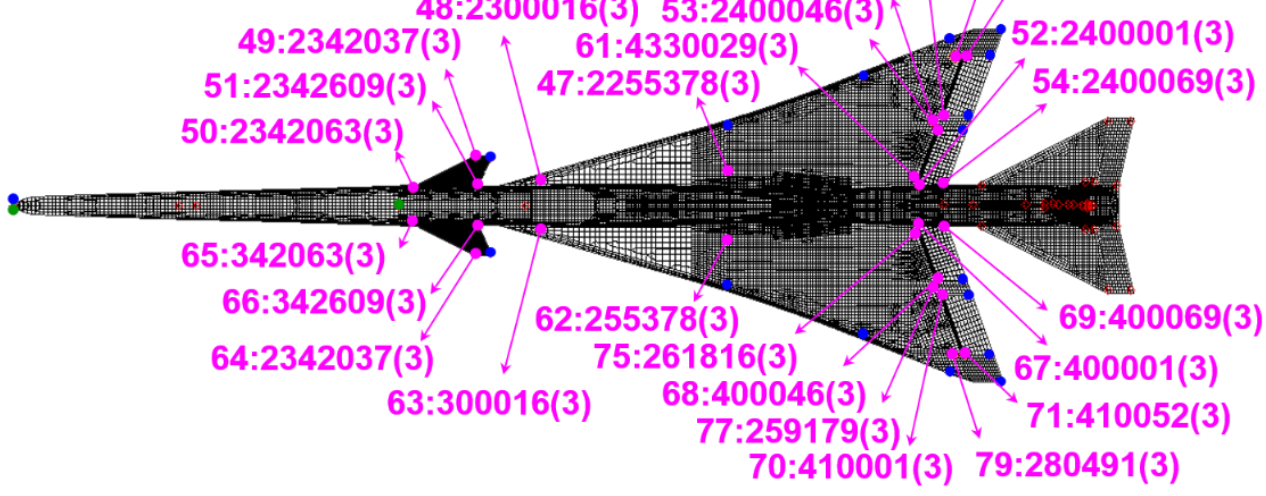

(a) Top view

45:2430076(2)

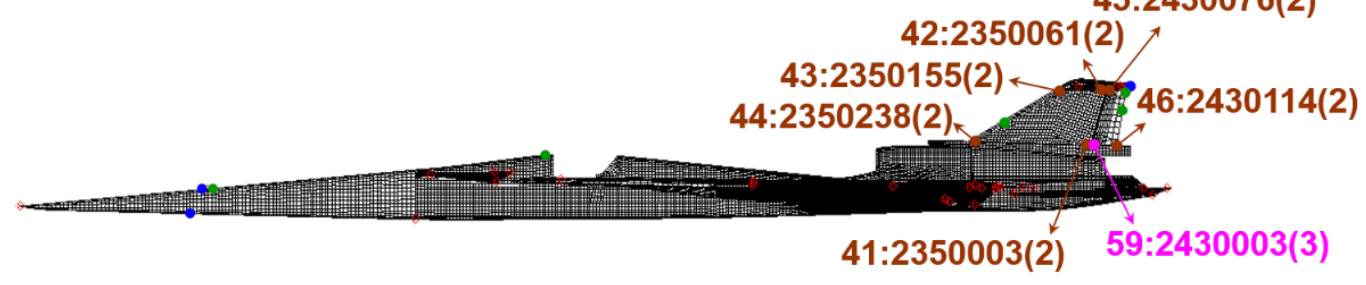

(b) Side view

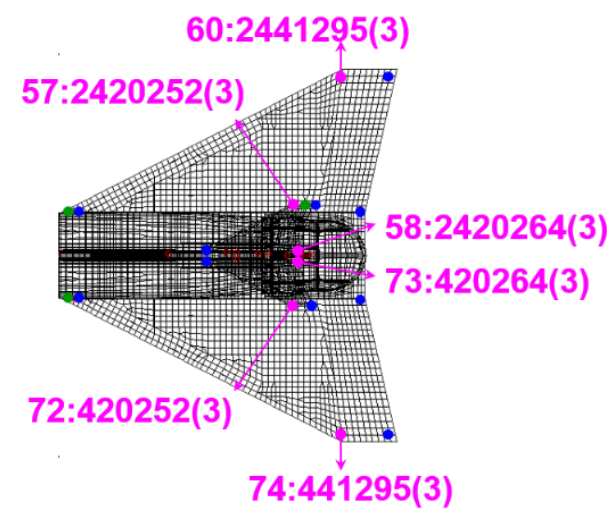

(c) Zoomed empennage

Fig. 10. Additional 39 accelerometer locations for the ground vibration test. 


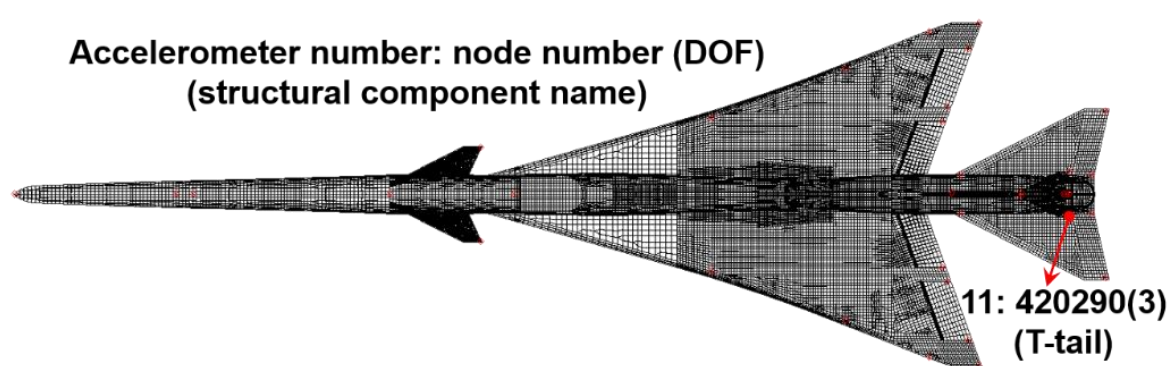

(a) One shaker

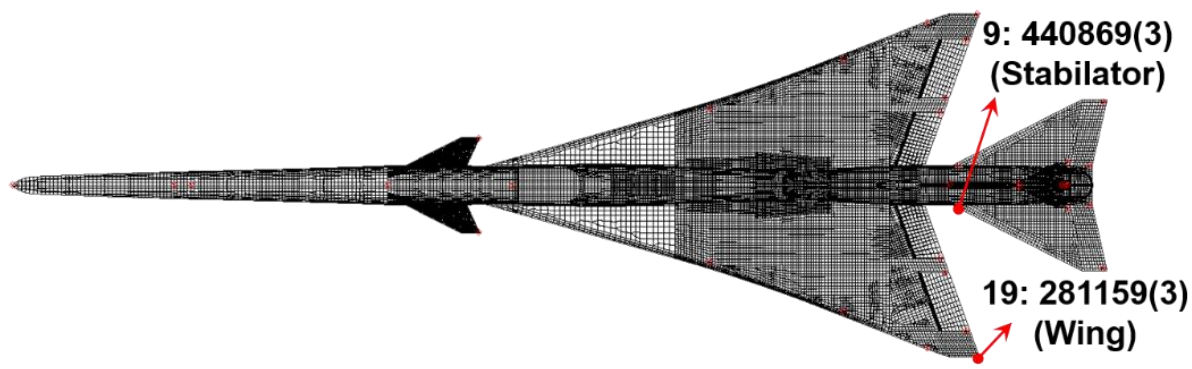

(b) Two shakers

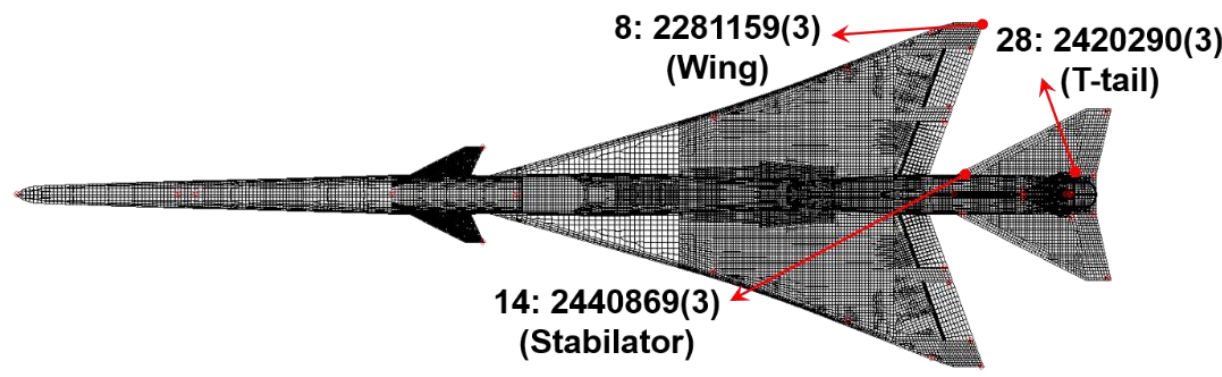

(c) Three shakers

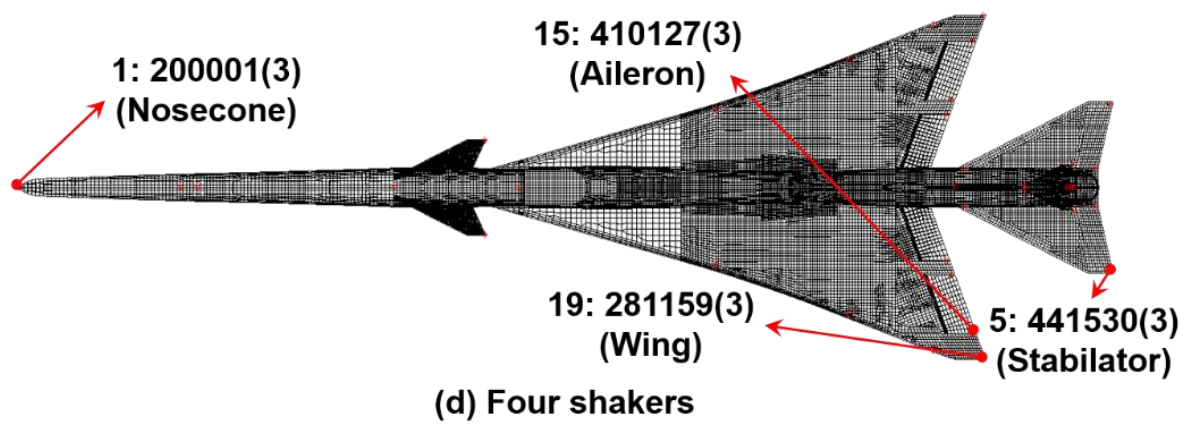

Fig. 11. Optimum shaker locations. 


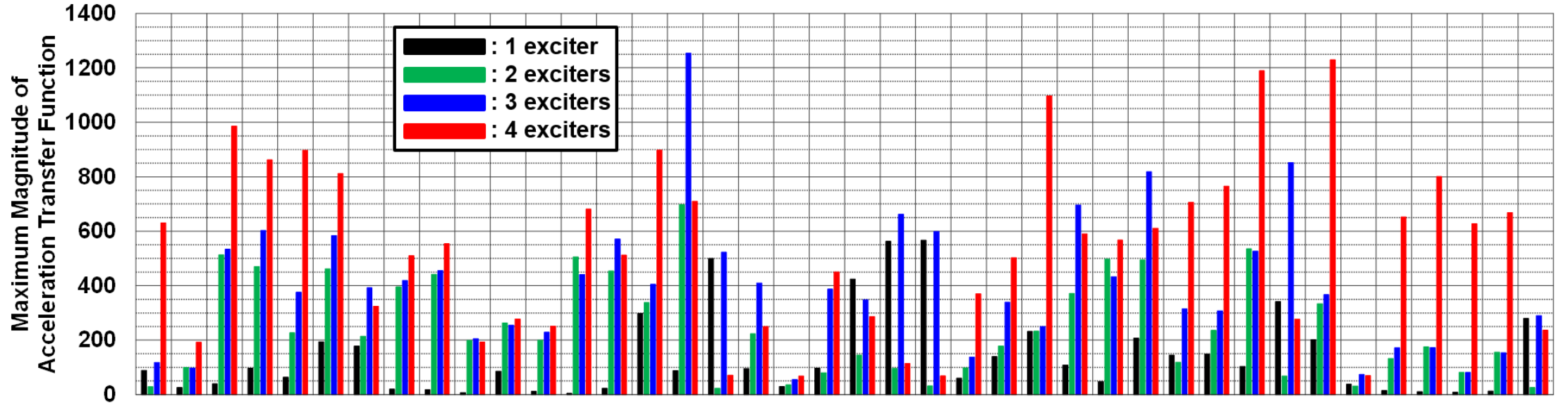

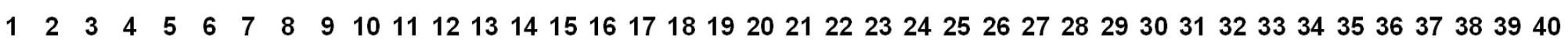
Flexible Mode Number

Fig. 12. Maximum acceleration transfer function with different numbers of shakers. 


\section{Appendix A}

The magnitude of acceleration transfer function (MATF) for Modes 1 through 40 at 79 accelerometer locations using four shakers are given in tables A1 through A4

Table A1. The MATF for Modes 1 through 10 at 79 accelerometer locations using four shakers.

\begin{tabular}{|c|c|c|c|c|c|c|c|c|c|c|}
\hline $\begin{array}{c}\text { Accelerometer } \\
\text { number }\end{array}$ & Mode 1 & Mode 2 & Mode 3 & Mode 4 & Mode 5 & Mode 6 & Mode 7 & Mode 8 & Mode 9 & Mode 10 \\
\hline 1 & 630.96 & 41.07 & 222.15 & 9.55 & 897.10 & 129.21 & 33.32 & 4.89 & 51.80 & 2.85 \\
\hline 2 & 1.45 & 164.52 & 113.61 & 297.11 & 29.17 & 384.86 & 324.16 & 4.75 & 3.40 & 6.63 \\
\hline 3 & 0.48 & 36.68 & 16.27 & 501.15 & 87.35 & 811.72 & 214.37 & 51.32 & 2.34 & 5.00 \\
\hline 4 & 144.68 & 19.97 & 105.01 & 220.71 & 277.16 & 73.31 & 41.01 & 510.13 & 548.36 & 11.80 \\
\hline 5 & 144.91 & 25.44 & 103.05 & 211.78 & 258.41 & 137.00 & 29.11 & 509.87 & 554.06 & 26.75 \\
\hline 6 & 30.41 & 9.35 & 35.09 & 132.94 & 293.29 & 214.19 & 42.88 & 48.58 & 53.02 & 192.92 \\
\hline 7 & 29.84 & 8.78 & 18.66 & 137.48 & 248.10 & 287.71 & 70.67 & 51.70 & 50.46 & 190.93 \\
\hline 8 & 11.64 & 169.24 & 945.19 & 862.07 & 416.16 & 664.83 & 127.59 & 11.34 & 5.06 & 60.70 \\
\hline 9 & 25.24 & 4.65 & 24.29 & 3.88 & 91.01 & 25.45 & 25.93 & 396.39 & 484.31 & 30.85 \\
\hline 10 & 0.71 & 1.92 & 2.76 & 18.99 & 7.45 & 8.67 & 48.97 & 30.84 & 30.65 & 9.53 \\
\hline 11 & 112.76 & 18.99 & 78.49 & 167.22 & 117.28 & 315.33 & 115.52 & 21.36 & 20.46 & 4.25 \\
\hline 12 & 8.85 & 19.58 & 103.95 & 34.92 & 41.61 & 8.35 & 24.13 & 10.07 & 7.85 & 18.00 \\
\hline 13 & 9.95 & 108.85 & 604.91 & 489.55 & 188.08 & 320.16 & 43.51 & 2.31 & 3.88 & 2.12 \\
\hline 14 & 25.19 & 4.31 & 23.83 & 3.89 & 92.49 & 6.23 & 21.63 & 397.51 & 479.52 & 17.95 \\
\hline 15 & 10.94 & 122.85 & 632.21 & 459.45 & 139.91 & 347.73 & 38.24 & 5.72 & 7.71 & 6.22 \\
\hline 16 & 0.28 & 11.67 & 10.43 & 99.35 & 7.74 & 48.18 & 63.27 & 7.54 & 0.68 & 12.84 \\
\hline 17 & 10.27 & 106.63 & 549.48 & 354.18 & 106.60 & 208.27 & 30.55 & 7.05 & 5.03 & 9.07 \\
\hline 18 & 0.83 & 68.00 & 45.93 & 73.33 & 10.56 & 121.47 & 42.67 & 3.06 & 0.73 & 5.23 \\
\hline 19 & 13.65 & 192.42 & 986.17 & 807.76 & 319.95 & 728.40 & 115.11 & 14.43 & 11.23 & 63.75 \\
\hline 20 & 8.95 & 18.29 & 98.25 & 37.03 & 37.03 & 16.38 & 22.16 & 8.95 & 7.12 & 19.07 \\
\hline 21 & 8.61 & 49.73 & 258.41 & 165.59 & 12.80 & 119.75 & 2.35 & 8.51 & 6.82 & 14.53 \\
\hline 22 & 38.59 & 25.03 & 129.06 & 16.07 & 43.10 & 134.51 & 6.42 & 3.56 & 5.49 & 5.21 \\
\hline 23 & 72.11 & 10.31 & 52.60 & 9.81 & 47.08 & 21.95 & 4.24 & 1.09 & 5.33 & 0.77 \\
\hline 24 & 356.48 & 17.10 & 95.46 & 3.15 & 227.34 & 32.05 & 6.79 & 2.22 & 4.10 & 2.23 \\
\hline 25 & 0.18 & 11.66 & 8.90 & 22.49 & 9.96 & 112.54 & 64.43 & 3.76 & 1.27 & 7.86 \\
\hline 26 & 9.15 & 96.20 & 533.17 & 383.32 & 136.89 & 191.68 & 31.47 & 4.26 & 2.65 & 8.37 \\
\hline 27 & 327.33 & 14.79 & 82.78 & 2.65 & 170.70 & 23.73 & 4.57 & 1.53 & 1.83 & 1.66 \\
\hline 28 & 112.68 & 15.78 & 82.93 & 173.23 & 167.60 & 280.47 & 105.67 & 21.28 & 21.40 & 3.97 \\
\hline 29 & 8.39 & 44.22 & 243.85 & 174.08 & 30.86 & 116.05 & 2.41 & 6.28 & 4.79 & 14.37 \\
\hline 30 & 0.40 & 32.25 & 14.93 & 409.45 & 69.47 & 622.16 & 146.98 & 36.39 & 1.99 & 4.15 \\
\hline 31 & 0.34 & 27.00 & 13.08 & 302.36 & 50.04 & 444.83 & 87.47 & 26.24 & 1.55 & 4.64 \\
\hline
\end{tabular}




\begin{tabular}{|c|c|c|c|c|c|c|c|c|c|c|}
\hline 32 & 38.41 & 25.38 & 137.32 & 6.00 & 57.27 & 117.49 & 12.61 & 3.84 & 5.75 & 4.78 \\
\hline 33 & 72.10 & 9.97 & 52.92 & 13.57 & 49.95 & 11.56 & 5.76 & 0.95 & 5.39 & 0.72 \\
\hline 34 & 0.21 & 7.80 & 2.82 & 94.98 & 4.58 & 22.12 & 8.30 & 8.10 & 0.79 & 5.76 \\
\hline 35 & 64.37 & 5.48 & 25.93 & 101.28 & 23.29 & 189.13 & 7.00 & 8.18 & 7.40 & 5.82 \\
\hline 36 & 64.05 & 4.05 & 14.57 & 103.38 & 49.80 & 182.46 & 12.01 & 7.79 & 7.10 & 6.33 \\
\hline 37 & 104.71 & 13.25 & 69.57 & 6.00 & 102.67 & 9.90 & 1.68 & 0.80 & 10.48 & 0.33 \\
\hline 38 & 124.64 & 17.38 & 82.91 & 59.82 & 178.35 & 58.15 & 13.58 & 279.22 & 312.59 & 18.77 \\
\hline 39 & 124.59 & 15.41 & 83.68 & 66.35 & 184.29 & 16.70 & 23.28 & 279.53 & 309.31 & 9.51 \\
\hline 40 & 0.26 & 1.89 & 1.40 & 19.04 & 4.00 & 6.93 & 50.49 & 30.88 & 30.60 & 8.62 \\
\hline 41 & 0.25 & 12.78 & 7.19 & 67.19 & 6.07 & 43.31 & 25.57 & 0.61 & 0.38 & 2.37 \\
\hline 42 & 0.31 & 29.03 & 12.89 & 385.45 & 62.46 & 559.58 & 142.01 & 28.01 & 1.26 & 1.33 \\
\hline 43 & 0.28 & 19.60 & 7.95 & 261.98 & 32.91 & 280.82 & 70.47 & 2.81 & 0.62 & 4.17 \\
\hline 44 & 0.22 & 3.77 & 1.08 & 53.12 & 1.07 & 14.01 & 13.22 & 6.81 & 0.71 & 5.15 \\
\hline 45 & 0.32 & 29.79 & 13.35 & 392.27 & 64.34 & 576.82 & 144.53 & 29.88 & 1.37 & 1.98 \\
\hline 46 & 0.32 & 16.84 & 9.59 & 98.84 & 14.04 & 115.08 & 20.34 & 8.81 & 0.74 & 5.18 \\
\hline 47 & 61.95 & 3.74 & 18.86 & 46.12 & 35.76 & 77.91 & 6.36 & 3.32 & 5.64 & 3.06 \\
\hline 48 & 8.91 & 5.57 & 24.58 & 41.90 & 118.64 & 86.03 & 3.76 & 4.87 & 4.51 & 6.79 \\
\hline 49 & 42.73 & 8.52 & 14.29 & 133.11 & 230.23 & 272.73 & 65.16 & 47.04 & 46.20 & 171.29 \\
\hline 50 & 89.57 & 2.24 & 1.06 & 29.18 & 108.65 & 61.16 & 6.53 & 3.73 & 9.40 & 5.23 \\
\hline 51 & 35.43 & 4.24 & 15.47 & 40.60 & 137.77 & 86.86 & 11.69 & 8.05 & 11.16 & 21.49 \\
\hline 52 & 5.10 & 5.83 & 33.10 & 41.24 & 57.62 & 4.18 & 4.82 & 2.74 & 2.70 & 3.31 \\
\hline 53 & 1.76 & 15.76 & 84.74 & 22.69 & 36.95 & 1.90 & 12.36 & 4.70 & 2.93 & 11.42 \\
\hline 54 & 5.59 & 3.54 & 19.21 & 26.98 & 54.24 & 18.66 & 2.00 & 5.88 & 5.94 & 8.73 \\
\hline 55 & 1.97 & 30.35 & 166.12 & 88.02 & 10.81 & 33.98 & 7.17 & 4.17 & 2.31 & 12.13 \\
\hline 56 & 0.93 & 91.34 & 506.45 & 380.05 & 134.82 & 215.49 & 29.19 & 1.77 & 1.15 & 3.78 \\
\hline 57 & 105.16 & 14.79 & 77.09 & 167.01 & 147.45 & 267.56 & 99.46 & 19.16 & 17.72 & 3.28 \\
\hline 58 & 103.99 & 13.52 & 72.25 & 21.64 & 115.19 & 23.19 & 10.42 & 3.36 & 14.35 & 1.11 \\
\hline 59 & 82.42 & 11.11 & 58.80 & 9.88 & 70.87 & 4.74 & 2.85 & 0.60 & 8.50 & 0.26 \\
\hline 60 & 126.37 & 17.73 & 92.49 & 203.81 & 219.54 & 66.52 & 31.01 & 364.26 & 380.79 & 6.32 \\
\hline 61 & 7.80 & 1.90 & 10.43 & 28.40 & 54.10 & 3.01 & 2.04 & 2.38 & 1.99 & 3.76 \\
\hline 62 & 62.11 & 4.44 & 23.89 & 43.93 & 23.76 & 83.25 & 2.01 & 3.74 & 5.95 & 2.64 \\
\hline 63 & 8.66 & 5.90 & 30.18 & 38.73 & 130.50 & 53.83 & 4.88 & 4.07 & 4.20 & 6.61 \\
\hline 64 & 43.30 & 8.99 & 30.70 & 128.95 & 273.25 & 204.25 & 39.20 & 44.10 & 48.42 & 173.09 \\
\hline 65 & 89.74 & 2.32 & 4.66 & 27.33 & 116.66 & 31.25 & 3.79 & 2.62 & 9.02 & 5.49 \\
\hline 66 & 35.65 & 4.49 & 20.83 & 37.75 & 149.66 & 49.34 & 1.02 & 6.80 & 11.01 & 21.75 \\
\hline 67 & 5.07 & 7.00 & 33.78 & 39.40 & 57.30 & 10.94 & 4.74 & 2.99 & 2.86 & 2.80 \\
\hline 68 & 1.87 & 16.67 & 88.50 & 20.62 & 38.46 & 8.67 & 12.52 & 5.30 & 3.34 & 10.90 \\
\hline 69 & 5.66 & 4.16 & 17.96 & 25.22 & 56.80 & 7.64 & 3.62 & 6.01 & 5.86 & 7.76 \\
\hline
\end{tabular}




\begin{tabular}{|c|c|c|c|c|c|c|c|c|c|c|}
\hline 70 & 2.30 & 33.18 & 173.53 & 82.10 & 17.13 & 29.72 & 7.55 & 5.64 & 3.56 & 12.02 \\
\hline 71 & 2.15 & 101.94 & 525.70 & 354.01 & 101.29 & 233.23 & 26.87 & 4.26 & 3.71 & 4.97 \\
\hline 72 & 105.24 & 17.90 & 72.76 & 161.50 & 99.72 & 297.48 & 107.15 & 19.26 & 16.87 & 3.56 \\
\hline 73 & 104.00 & 13.95 & 71.79 & 16.44 & 109.26 & 49.85 & 17.39 & 3.39 & 14.22 & 1.25 \\
\hline 74 & 126.60 & 22.67 & 90.80 & 196.13 & 202.85 & 117.08 & 20.67 & 364.23 & 384.79 & 16.73 \\
\hline 75 & 7.79 & 2.54 & 10.62 & 27.46 & 53.51 & 13.84 & 2.43 & 2.50 & 1.99 & 3.32 \\
\hline 76 & 4.87 & 20.90 & 113.53 & 43.19 & 27.36 & 5.58 & 9.26 & 3.42 & 1.72 & 9.55 \\
\hline 77 & 5.04 & 22.41 & 117.80 & 39.45 & 29.50 & 2.87 & 8.95 & 4.26 & 2.44 & 9.35 \\
\hline 78 & 4.83 & 85.54 & 473.88 & 342.75 & 116.37 & 179.79 & 25.03 & 2.16 & 1.23 & 3.83 \\
\hline 79 & 5.88 & 95.02 & 490.21 & 317.95 & 87.93 & 194.05 & 23.73 & 4.69 & 3.55 & 5.00 \\
\hline Maximum & 630.96 & 192.42 & 986.17 & 862.07 & 897.10 & 811.72 & 324.16 & 510.13 & 554.06 & 192.92 \\
\hline
\end{tabular}

Table A2. The MATF for Modes 11 through 20 at 79 accelerometer locations using four shakers.

\begin{tabular}{|c|c|c|c|c|c|c|c|c|c|c|}
\hline $\begin{array}{c}\text { Accelerometer } \\
\text { number }\end{array}$ & Mode 11 & Mode 12 & Mode 13 & Mode 14 & Mode 15 & Mode 16 & Mode 17 & Mode 18 & Mode 19 & Mode 20 \\
\hline 1 & 20.46 & 29.51 & 162.96 & 13.14 & 897.43 & 542.27 & 11.98 & 26.26 & 7.66 & 146.31 \\
\hline 2 & 35.04 & 3.09 & 7.69 & 65.62 & 22.65 & 38.17 & 11.31 & 250.04 & 7.95 & 135.64 \\
\hline 3 & 45.39 & 5.95 & 2.37 & 40.48 & 228.89 & 531.48 & 5.48 & 5.26 & 4.33 & 12.61 \\
\hline 4 & 45.70 & 9.75 & 9.84 & 12.18 & 12.99 & 157.68 & 3.41 & 33.76 & 2.64 & 5.14 \\
\hline 5 & 35.08 & 22.91 & 16.89 & 17.31 & 92.15 & 118.26 & 3.85 & 30.61 & 2.77 & 12.63 \\
\hline 6 & 117.81 & 251.83 & 503.28 & 408.22 & 226.72 & 297.10 & 4.32 & 26.54 & 4.12 & 6.85 \\
\hline 7 & 277.73 & 209.20 & 577.31 & 393.01 & 358.40 & 29.03 & 3.65 & 29.12 & 5.37 & 12.32 \\
\hline 8 & 45.18 & 88.20 & 596.68 & 512.38 & 105.98 & 617.94 & 7.01 & 29.77 & 6.70 & 74.71 \\
\hline 9 & 48.03 & 29.56 & 13.68 & 53.70 & 132.15 & 709.98 & 15.75 & 86.55 & 11.53 & 51.75 \\
\hline 10 & 39.69 & 4.55 & 2.45 & 3.72 & 63.81 & 111.93 & 4.07 & 227.59 & 67.56 & 108.61 \\
\hline 11 & 48.04 & 8.02 & 2.72 & 25.54 & 534.85 & 132.67 & 70.81 & 48.95 & 15.09 & 88.66 \\
\hline 12 & 15.85 & 21.73 & 143.63 & 141.78 & 162.98 & 112.18 & 7.06 & 24.25 & 34.23 & 388.98 \\
\hline 13 & 4.94 & 3.07 & 55.74 & 92.63 & 25.64 & 175.15 & 3.54 & 62.70 & 7.83 & 97.26 \\
\hline 14 & 58.22 & 14.08 & 1.33 & 44.19 & 370.20 & 564.03 & 8.04 & 90.65 & 4.30 & 18.50 \\
\hline 15 & 8.36 & 9.61 & 71.17 & 82.41 & 133.42 & 76.05 & 14.74 & 48.16 & 25.64 & 223.33 \\
\hline 16 & 1.94 & 0.53 & 1.83 & 20.58 & 15.74 & 35.77 & 0.39 & 7.17 & 1.07 & 8.07 \\
\hline 17 & 6.66 & 7.50 & 31.02 & 33.11 & 58.00 & 41.12 & 4.71 & 7.92 & 9.07 & 64.60 \\
\hline 18 & 0.45 & 0.32 & 0.67 & 5.19 & 2.82 & 7.89 & 2.76 & 61.94 & 2.04 & 33.58 \\
\hline 19 & 107.91 & 84.71 & 681.69 & 426.64 & 486.64 & 284.79 & 13.66 & 30.56 & 11.06 & 28.04 \\
\hline 20 & 5.51 & 19.46 & 115.61 & 158.31 & 51.95 & 235.92 & 9.22 & 54.31 & 34.81 & 450.57 \\
\hline 21 & 17.57 & 20.99 & 170.26 & 155.28 & 74.49 & 34.84 & 7.49 & 37.01 & 17.61 & 207.71 \\
\hline 22 & 17.24 & 7.97 & 64.55 & 8.54 & 67.54 & 50.71 & 2.94 & 11.04 & 7.23 & 85.38 \\
\hline 23 & 1.71 & 0.93 & 3.12 & 1.10 & 101.79 & 53.08 & 31.40 & 6.38 & 8.06 & 90.40 \\
\hline 24 & 2.65 & 2.70 & 14.57 & 3.49 & 167.39 & 105.41 & 2.61 & 7.79 & 4.72 & 47.78 \\
\hline
\end{tabular}




\begin{tabular}{|c|c|c|c|c|c|c|c|c|c|c|}
\hline 25 & 13.50 & 1.08 & 3.91 & 36.40 & 14.74 & 28.66 & 3.02 & 64.10 & 2.30 & 35.60 \\
\hline 26 & 1.57 & 5.81 & 23.37 & 35.00 & 14.39 & 82.68 & 1.24 & 11.02 & 4.83 & 64.14 \\
\hline 27 & 2.75 & 2.98 & 18.22 & 3.07 & 157.15 & 97.28 & 1.69 & 5.47 & 2.88 & 34.30 \\
\hline 28 & 40.08 & 15.72 & 4.50 & 28.30 & 248.91 & 599.17 & 70.74 & 86.20 & 19.69 & 262.01 \\
\hline 29 & 2.21 & 18.54 & 139.85 & 176.02 & 10.54 & 87.45 & 2.12 & 54.42 & 9.45 & 129.10 \\
\hline 30 & 20.43 & 2.68 & 1.32 & 20.04 & 87.52 & 213.47 & 2.10 & 19.56 & 2.76 & 17.35 \\
\hline 31 & 3.73 & 0.77 & 0.84 & 10.16 & 39.57 & 100.05 & 1.28 & 25.57 & 3.23 & 23.28 \\
\hline 32 & 12.24 & 11.03 & 63.42 & 17.70 & 14.85 & 92.11 & 2.15 & 19.22 & 6.12 & 67.50 \\
\hline 33 & 1.12 & 1.01 & 3.14 & 1.16 & 91.68 & 80.61 & 31.38 & 16.25 & 7.62 & 107.75 \\
\hline 34 & 2.35 & 0.85 & 0.99 & 12.02 & 94.71 & 222.31 & 2.58 & 2.23 & 2.05 & 3.67 \\
\hline 35 & 3.96 & 5.03 & 20.39 & 58.44 & 58.44 & 23.56 & 1.42 & 7.08 & 1.83 & 15.83 \\
\hline 36 & 7.64 & 3.03 & 10.12 & 60.86 & 23.73 & 67.20 & 1.58 & 9.24 & 2.49 & 14.40 \\
\hline 37 & 1.38 & 4.26 & 0.53 & 0.95 & 65.62 & 40.37 & 1.29 & 1.20 & 1.79 & 16.97 \\
\hline 38 & 26.86 & 14.80 & 10.20 & 24.92 & 57.69 & 247.30 & 6.64 & 33.68 & 4.76 & 17.17 \\
\hline 39 & 32.80 & 5.36 & 3.57 & 20.28 & 124.18 & 211.32 & 2.97 & 32.57 & 1.89 & 2.34 \\
\hline 40 & 38.04 & 6.19 & 1.27 & 3.12 & 80.14 & 107.97 & 5.53 & 234.58 & 67.82 & 171.30 \\
\hline 41 & 18.43 & 2.32 & 0.51 & 8.53 & 50.02 & 115.17 & 1.23 & 14.05 & 2.13 & 12.55 \\
\hline 42 & 25.03 & 3.23 & 1.21 & 17.19 & 68.34 & 161.15 & 1.51 & 1.50 & 0.96 & 0.87 \\
\hline 43 & 8.92 & 1.39 & 0.89 & 6.17 & 78.39 & 192.91 & 2.38 & 4.74 & 2.05 & 3.99 \\
\hline 44 & 4.14 & 0.88 & 0.76 & 8.59 & 72.56 & 167.83 & 1.91 & 1.68 & 1.41 & 1.27 \\
\hline 45 & 24.47 & 3.15 & 1.25 & 18.30 & 75.94 & 180.31 & 1.70 & 4.56 & 0.94 & 3.43 \\
\hline 46 & 23.54 & 2.99 & 0.61 & 6.24 & 34.50 & 72.23 & 1.46 & 31.85 & 3.46 & 28.15 \\
\hline 47 & 4.09 & 3.10 & 12.79 & 27.24 & 28.43 & 37.99 & 0.84 & 3.39 & 1.16 & 6.13 \\
\hline 48 & 2.00 & 3.14 & 18.64 & 22.56 & 3.35 & 31.39 & 0.99 & 3.82 & 1.24 & 7.89 \\
\hline 49 & 247.16 & 185.65 & 504.23 & 342.93 & 284.44 & 21.01 & 2.92 & 24.79 & 4.42 & 6.60 \\
\hline 50 & 4.69 & 2.62 & 37.02 & 13.20 & 139.45 & 61.84 & 1.64 & 1.58 & 1.38 & 13.48 \\
\hline 51 & 26.91 & 17.81 & 23.53 & 20.39 & 30.08 & 13.05 & 1.05 & 3.83 & 0.92 & 1.77 \\
\hline 52 & 3.69 & 0.92 & 15.27 & 3.19 & 30.72 & 117.37 & 1.61 & 6.36 & 2.85 & 27.09 \\
\hline 53 & 1.80 & 11.85 & 70.24 & 87.84 & 16.74 & 76.79 & 2.37 & 17.28 & 9.64 & 124.83 \\
\hline 54 & 7.07 & 5.91 & 15.82 & 51.45 & 54.56 & 226.04 & 6.01 & 30.80 & 19.01 & 235.30 \\
\hline 55 & 3.53 & 15.37 & 105.14 & 118.47 & 4.63 & 41.17 & 0.92 & 20.19 & 3.93 & 55.16 \\
\hline 56 & 1.90 & 1.36 & 13.82 & 22.08 & 14.75 & 93.08 & 1.40 & 12.50 & 1.42 & 5.75 \\
\hline 57 & 35.66 & 12.79 & 3.31 & 24.14 & 166.91 & 471.40 & 48.86 & 65.59 & 14.10 & 184.47 \\
\hline 58 & 4.54 & 7.39 & 1.61 & 5.64 & 173.26 & 184.49 & 30.69 & 21.71 & 5.66 & 83.85 \\
\hline 59 & 0.86 & 2.87 & 1.51 & 0.77 & 37.02 & 22.07 & 0.68 & 0.92 & 1.11 & 10.92 \\
\hline 60 & 28.40 & 5.78 & 8.12 & 1.74 & 79.26 & 254.28 & 4.36 & 43.92 & 2.54 & 8.09 \\
\hline 61 & 2.27 & 2.13 & 2.49 & 11.27 & 24.08 & 84.43 & 1.15 & 4.50 & 1.81 & 17.04 \\
\hline 62 & 1.22 & 4.06 & 17.43 & 24.65 & 42.87 & 3.75 & 0.97 & 2.60 & 1.16 & 5.93 \\
\hline
\end{tabular}




\begin{tabular}{|c|c|c|c|c|c|c|c|c|c|c|}
\hline 63 & 2.61 & 3.08 & 15.18 & 22.35 & 20.08 & 12.82 & 0.71 & 0.91 & 1.57 & 16.41 \\
\hline 64 & 104.65 & 223.49 & 439.43 & 356.00 & 174.01 & 238.37 & 3.55 & 23.68 & 3.38 & 7.25 \\
\hline 65 & 1.27 & 2.67 & 34.96 & 15.15 & 125.32 & 92.94 & 1.83 & 4.25 & 1.37 & 6.26 \\
\hline 66 & 10.94 & 21.66 & 19.19 & 20.80 & 27.56 & 19.27 & 0.73 & 3.40 & 1.03 & 6.48 \\
\hline 67 & 1.62 & 1.51 & 14.92 & 4.30 & 96.26 & 45.96 & 1.40 & 4.14 & 2.52 & 23.90 \\
\hline 68 & 10.80 & 12.51 & 85.80 & 78.01 & 51.84 & 37.23 & 2.26 & 8.35 & 9.81 & 109.65 \\
\hline 69 & 2.34 & 7.60 & 24.73 & 48.15 & 172.70 & 97.42 & 4.34 & 14.88 & 18.19 & 203.58 \\
\hline 70 & 15.39 & 15.73 & 125.77 & 103.39 & 37.17 & 17.68 & 2.42 & 13.24 & 6.13 & 77.09 \\
\hline 71 & 4.46 & 3.63 & 17.04 & 18.89 & 69.15 & 42.05 & 3.95 & 10.99 & 5.52 & 35.07 \\
\hline 72 & 42.18 & 6.11 & 2.34 & 21.94 & 404.65 & 133.18 & 48.88 & 40.38 & 11.03 & 51.99 \\
\hline 73 & 9.49 & 6.16 & 1.42 & 4.45 & 224.25 & 57.65 & 30.69 & 6.23 & 5.08 & 46.25 \\
\hline 74 & 21.55 & 14.42 & 11.99 & 4.27 & 107.23 & 246.10 & 4.55 & 40.89 & 3.23 & 18.86 \\
\hline 75 & 0.87 & 2.60 & 0.58 & 10.95 & 70.08 & 31.13 & 0.64 & 2.95 & 1.68 & 15.19 \\
\hline 76 & 2.56 & 11.02 & 68.53 & 76.97 & 3.45 & 7.58 & 0.69 & 8.43 & 2.79 & 36.16 \\
\hline 77 & 11.01 & 11.15 & 82.06 & 67.37 & 3.30 & 5.16 & 1.96 & 5.23 & 3.29 & 37.41 \\
\hline 78 & 0.88 & 1.30 & 7.88 & 7.49 & 12.83 & 78.47 & 1.00 & 2.01 & 2.24 & 24.85 \\
\hline 79 & 3.75 & 3.63 & 8.94 & 5.87 & 57.63 & 36.97 & 2.90 & 4.28 & 4.00 & 12.53 \\
\hline Maximum & 277.73 & 251.83 & 681.69 & 512.38 & 897.43 & 709.98 & 70.81 & 250.04 & 67.82 & 450.57 \\
\hline
\end{tabular}

Table A3. The MATF for Modes 21 through 30 at 79 accelerometer locations using four shakers.

\begin{tabular}{|c|c|c|c|c|c|c|c|c|c|c|}
\hline $\begin{array}{c}\text { Accelerometer } \\
\text { number }\end{array}$ & Mode 21 & Mode 22 & Mode 23 & Mode 24 & Mode 25 & Mode 26 & Mode 27 & Mode 28 & Mode 29 & Mode 30 \\
\hline 1 & 67.74 & 9.59 & 9.34 & 18.86 & 25.78 & 1070.24 & 133.44 & 60.04 & 23.55 & 79.07 \\
\hline 2 & 159.69 & 11.22 & 11.32 & 45.56 & 121.07 & 23.23 & 38.35 & 6.39 & 36.40 & 114.57 \\
\hline 3 & 14.15 & 15.31 & 7.84 & 5.47 & 11.23 & 119.40 & 220.88 & 37.00 & 367.12 & 513.40 \\
\hline 4 & 7.55 & 9.92 & 4.47 & 26.08 & 72.04 & 298.08 & 542.83 & 446.19 & 173.24 & 319.43 \\
\hline 5 & 6.41 & 10.11 & 5.45 & 28.53 & 69.43 & 303.44 & 387.24 & 567.43 & 97.90 & 153.54 \\
\hline 6 & 4.90 & 12.13 & 8.76 & 43.46 & 135.79 & 94.85 & 21.24 & 7.21 & 226.09 & 277.86 \\
\hline 7 & 5.46 & 12.95 & 9.96 & 49.00 & 139.27 & 85.33 & 9.14 & 12.88 & 226.40 & 302.50 \\
\hline 8 & 51.68 & 13.72 & 6.49 & 47.28 & 125.92 & 96.71 & 56.48 & 5.92 & 610.75 & 60.46 \\
\hline 9 & 12.93 & 20.08 & 13.80 & 43.97 & 97.74 & 388.81 & 415.49 & 549.15 & 73.50 & 117.09 \\
\hline 10 & 221.30 & 7.37 & 8.34 & 16.66 & 39.90 & 278.10 & 164.49 & 68.59 & 19.79 & 131.74 \\
\hline 11 & 219.79 & 112.92 & 67.45 & 51.75 & 143.01 & 508.99 & 130.41 & 59.41 & 255.41 & 208.00 \\
\hline 12 & 286.49 & 106.53 & 58.86 & 370.28 & 363.64 & 910.10 & 101.94 & 64.70 & 404.11 & 131.00 \\
\hline 13 & 140.12 & 18.15 & 13.40 & 152.35 & 453.40 & 1097.39 & 36.96 & 46.38 & 42.52 & 652.44 \\
\hline 14 & 33.34 & 14.15 & 6.18 & 36.33 & 95.46 & 308.71 & 590.53 & 427.03 & 125.94 & 223.49 \\
\hline 15 & 31.85 & 31.86 & 32.44 & 237.93 & 374.82 & 912.34 & 169.69 & 33.26 & 163.60 & 706.03 \\
\hline 16 & 6.88 & 5.29 & 3.45 & 22.10 & 68.25 & 5.93 & 4.43 & 4.01 & 168.18 & 227.71 \\
\hline 17 & 36.03 & 10.64 & 5.85 & 21.26 & 41.49 & 128.37 & 53.08 & 16.13 & 382.09 & 82.99 \\
\hline
\end{tabular}




\begin{tabular}{|c|c|c|c|c|c|c|c|c|c|c|}
\hline 18 & 41.08 & 4.68 & 4.17 & 24.43 & 69.91 & 6.92 & 16.37 & 3.06 & 64.80 & 52.59 \\
\hline 19 & 72.71 & 16.80 & 14.20 & 71.98 & 105.12 & 126.36 & 25.87 & 18.77 & 535.33 & 48.11 \\
\hline 20 & 155.34 & 109.82 & 52.01 & 294.95 & 502.51 & 528.55 & 292.46 & 36.07 & 480.78 & 178.72 \\
\hline 21 & 51.95 & 21.84 & 15.70 & 145.08 & 241.93 & 568.35 & 134.20 & 19.37 & 502.54 & 292.12 \\
\hline 22 & 32.76 & 8.78 & 6.54 & 46.92 & 79.42 & 164.80 & 34.68 & 4.32 & 47.85 & 6.37 \\
\hline 23 & 58.95 & 14.09 & 8.60 & 19.43 & 28.22 & 387.99 & 18.78 & 104.98 & 65.59 & 72.84 \\
\hline 24 & 21.39 & 5.23 & 5.39 & 11.16 & 13.89 & 473.94 & 60.80 & 26.15 & 13.27 & 49.63 \\
\hline 25 & 39.82 & 2.86 & 1.95 & 4.46 & 17.65 & 4.47 & 1.96 & 1.88 & 88.34 & 105.89 \\
\hline 26 & 28.58 & 10.14 & 4.30 & 14.24 & 48.24 & 186.58 & 35.04 & 9.38 & 423.78 & 85.04 \\
\hline 27 & 15.27 & 2.58 & 2.69 & 6.06 & 7.72 & 264.44 & 31.84 & 13.28 & 4.32 & 15.19 \\
\hline 28 & 123.27 & 114.97 & 69.21 & 54.05 & 129.46 & 144.02 & 175.09 & 63.46 & 268.07 & 196.43 \\
\hline 29 & 117.56 & 21.33 & 12.39 & 95.55 & 290.53 & 722.28 & 44.13 & 28.62 & 519.87 & 277.47 \\
\hline 30 & 23.48 & 16.79 & 9.40 & 2.46 & 6.33 & 56.61 & 100.70 & 12.48 & 61.14 & 241.22 \\
\hline 31 & 31.44 & 14.69 & 7.94 & 4.44 & 11.40 & 92.89 & 160.14 & 19.33 & 73.08 & 273.83 \\
\hline 32 & 42.66 & 8.25 & 4.62 & 30.47 & 93.02 & 206.01 & 11.83 & 5.56 & 43.77 & 3.64 \\
\hline 33 & 31.36 & 15.41 & 9.89 & 18.53 & 17.35 & 322.42 & 57.55 & 106.48 & 92.29 & 49.59 \\
\hline 34 & 3.62 & 2.32 & 1.72 & 4.03 & 10.31 & 46.22 & 70.02 & 8.28 & 43.58 & 5.92 \\
\hline 35 & 6.53 & 3.93 & 2.85 & 10.83 & 27.96 & 123.49 & 14.17 & 7.22 & 55.18 & 63.95 \\
\hline 36 & 7.82 & 2.81 & 1.78 & 9.86 & 26.05 & 113.57 & 19.40 & 7.73 & 45.36 & 74.50 \\
\hline 37 & 9.08 & 1.70 & 1.51 & 6.25 & 4.71 & 131.34 & 12.17 & 37.79 & 7.80 & 5.00 \\
\hline 38 & 9.44 & 7.91 & 6.06 & 16.52 & 34.37 & 149.96 & 138.95 & 205.07 & 22.96 & 33.76 \\
\hline 39 & 11.97 & 4.67 & 2.39 & 11.52 & 31.51 & 76.19 & 198.22 & 162.69 & 55.41 & 108.21 \\
\hline 40 & 196.96 & 6.60 & 7.70 & 16.25 & 38.27 & 189.75 & 196.81 & 54.97 & 21.34 & 117.87 \\
\hline 41 & 16.52 & 1.34 & 0.91 & 2.83 & 6.50 & 56.89 & 82.97 & 8.33 & 16.00 & 22.87 \\
\hline 42 & 0.86 & 5.99 & 3.43 & 1.71 & 4.92 & 15.65 & 23.21 & 2.53 & 25.21 & 17.00 \\
\hline 43 & 5.18 & 5.05 & 2.26 & 4.98 & 14.88 & 45.21 & 107.25 & 20.61 & 219.85 & 254.71 \\
\hline 44 & 1.60 & 1.54 & 1.42 & 3.31 & 8.32 & 39.94 & 51.43 & 5.00 & 16.07 & 47.80 \\
\hline 45 & 5.22 & 9.28 & 5.30 & 1.94 & 4.73 & 11.62 & 15.60 & 1.94 & 3.34 & 32.88 \\
\hline 46 & 37.08 & 8.81 & 4.19 & 7.72 & 19.69 & 135.05 & 215.41 & 23.69 & 84.23 & 240.11 \\
\hline 47 & 2.70 & 1.73 & 1.23 & 4.66 & 14.85 & 109.31 & 15.22 & 6.15 & 13.49 & 28.60 \\
\hline 48 & 8.79 & 4.04 & 2.97 & 15.68 & 42.81 & 116.57 & 11.55 & 7.85 & 73.69 & 95.60 \\
\hline 49 & 4.46 & 10.18 & 7.91 & 37.73 & 106.07 & 82.38 & 8.84 & 9.94 & 151.74 & 203.03 \\
\hline 50 & 3.23 & 3.15 & 2.36 & 11.22 & 32.10 & 14.28 & 2.77 & 4.84 & 71.40 & 97.32 \\
\hline 51 & 4.21 & 2.34 & 1.78 & 8.18 & 21.40 & 82.92 & 9.67 & 6.02 & 47.33 & 67.05 \\
\hline 52 & 9.77 & 3.53 & 1.40 & 4.64 & 15.15 & 54.96 & 26.37 & 3.41 & 6.24 & 16.79 \\
\hline 53 & 43.69 & 27.01 & 12.23 & 64.82 & 110.83 & 103.55 & 43.32 & 5.39 & 46.84 & 18.02 \\
\hline 54 & 81.82 & 54.63 & 25.32 & 144.83 & 255.07 & 202.11 & 123.10 & 15.11 & 332.77 & 138.90 \\
\hline 55 & 40.63 & 8.40 & 4.36 & 21.95 & 68.05 & 157.16 & 23.48 & 4.91 & 269.67 & 44.87 \\
\hline
\end{tabular}




\begin{tabular}{|c|c|c|c|c|c|c|c|c|c|c|}
\hline 56 & 26.42 & 2.74 & 1.70 & 31.79 & 91.16 & 166.82 & 20.91 & 6.82 & 221.03 & 92.60 \\
\hline 57 & 98.23 & 85.80 & 51.51 & 39.00 & 95.30 & 63.55 & 117.99 & 33.02 & 164.09 & 119.80 \\
\hline 58 & 22.06 & 26.74 & 16.34 & 14.03 & 30.51 & 46.65 & 46.72 & 15.64 & 84.34 & 64.61 \\
\hline 59 & 5.24 & 0.99 & 1.01 & 3.35 & 2.31 & 73.17 & 7.28 & 26.70 & 5.24 & 2.24 \\
\hline 60 & 11.09 & 10.63 & 4.62 & 27.31 & 74.63 & 282.93 & 523.67 & 416.41 & 149.84 & 274.35 \\
\hline 61 & 6.14 & 1.66 & 0.84 & 3.21 & 4.86 & 50.89 & 26.48 & 3.55 & 36.15 & 4.71 \\
\hline 62 & 2.80 & 2.45 & 1.98 & 6.76 & 15.01 & 112.21 & 13.79 & 6.11 & 21.78 & 19.63 \\
\hline 63 & 2.50 & 3.05 & 2.26 & 11.64 & 37.34 & 117.70 & 17.81 & 4.97 & 72.51 & 77.51 \\
\hline 64 & 2.51 & 9.32 & 6.73 & 32.87 & 102.60 & 89.65 & 17.15 & 5.43 & 151.59 & 185.77 \\
\hline 65 & 7.01 & 3.26 & 2.48 & 10.62 & 32.01 & 16.18 & 7.25 & 3.25 & 71.28 & 78.12 \\
\hline 66 & 1.85 & 1.85 & 1.53 & 5.94 & 18.30 & 83.80 & 13.32 & 4.27 & 47.38 & 46.50 \\
\hline 67 & 15.58 & 3.15 & 1.84 & 7.55 & 14.25 & 74.65 & 8.21 & 7.92 & 8.32 & 26.13 \\
\hline 68 & 79.09 & 26.48 & 14.37 & 82.21 & 79.71 & 170.22 & 14.11 & 9.21 & 41.48 & 18.78 \\
\hline 69 & 147.50 & 53.00 & 29.27 & 183.46 & 187.66 & 373.41 & 47.35 & 31.65 & 283.19 & 117.16 \\
\hline 70 & 27.01 & 7.67 & 4.91 & 31.52 & 57.10 & 111.91 & 37.02 & 14.67 & 236.57 & 31.03 \\
\hline 71 & 17.20 & 7.05 & 6.93 & 49.70 & 75.00 & 152.20 & 16.74 & 13.01 & 183.55 & 80.11 \\
\hline 72 & 161.48 & 84.47 & 50.43 & 36.89 & 103.48 & 320.60 & 91.36 & 30.29 & 158.17 & 125.29 \\
\hline 73 & 59.01 & 26.00 & 15.93 & 12.65 & 34.59 & 139.54 & 35.07 & 14.46 & 81.97 & 66.57 \\
\hline 74 & 7.73 & 11.53 & 6.50 & 30.38 & 72.97 & 312.99 & 372.52 & 530.14 & 84.04 & 129.92 \\
\hline 75 & 9.76 & 1.55 & 1.04 & 3.48 & 6.20 & 72.63 & 7.69 & 6.87 & 29.44 & 6.08 \\
\hline 76 & 16.22 & 5.18 & 2.11 & 2.39 & 2.20 & 11.28 & 17.40 & 2.64 & 166.59 & 63.27 \\
\hline 77 & 21.70 & 5.68 & 3.68 & 3.50 & 3.52 & 5.93 & 11.76 & 10.25 & 142.06 & 52.40 \\
\hline 78 & 5.83 & 4.05 & 1.10 & 6.72 & 14.62 & 22.38 & 20.32 & 2.98 & 241.46 & 36.54 \\
\hline 79 & 18.24 & 4.96 & 2.75 & 10.62 & 12.43 & 6.06 & 19.55 & 8.94 & 215.57 & 34.76 \\
\hline Maximum & 286.49 & 114.97 & 69.21 & 370.28 & 502.51 & 1097.39 & 590.53 & 567.43 & 610.75 & 706.03 \\
\hline
\end{tabular}

Table A4. The MATF for Modes 31 through 40 at 79 accelerometer locations using four shakers.

\begin{tabular}{|c|c|c|c|c|c|c|c|c|c|c|c|}
\hline $\begin{array}{l}\text { Accelerometer } \\
\text { number }\end{array}$ & Mode 31 & Mode 32 & Mode 33 & Mode 34 & Mode 35 & Mode 36 & Mode 37 & Mode 38 & Mode 39 & Mode 40 & Minimum \\
\hline 1 & 28.05 & 215.29 & 88.63 & 856.02 & 24.24 & 20.44 & 170.99 & 244.29 & 21.07 & 24.77 & 2.85 \\
\hline 2 & 296.74 & 42.32 & 59.38 & 50.95 & 40.45 & 410.08 & 17.94 & 3.44 & 6.66 & 2.48 & 1.45 \\
\hline 3 & 367.99 & 299.40 & 209.30 & 378.93 & 11.21 & 11.40 & 4.75 & 7.21 & 14.53 & 10.71 & 0.48 \\
\hline 4 & 90.05 & 374.88 & 106.26 & 682.96 & 28.71 & 131.75 & 186.29 & 137.90 & 49.58 & 40.98 & 2.64 \\
\hline 5 & 66.44 & 277.07 & 54.15 & 733.90 & 17.42 & 83.53 & 147.66 & 97.50 & 35.11 & 69.62 & 2.77 \\
\hline 6 & 239.62 & 37.68 & 31.31 & 224.22 & 9.94 & 68.68 & 43.50 & 66.98 & 108.74 & 3.33 & 3.33 \\
\hline 7 & 244.99 & 81.51 & 17.11 & 78.74 & 11.23 & 66.76 & 38.15 & 81.78 & 99.25 & 2.26 & 2.26 \\
\hline 8 & 208.52 & 806.31 & 229.67 & 42.40 & 18.29 & 142.15 & 221.37 & 70.56 & 182.83 & 7.83 & 5.06 \\
\hline 9 & 45.94 & 152.87 & 25.68 & 322.11 & 9.69 & 55.21 & 31.18 & 9.89 & 16.54 & 8.59 & 3.88 \\
\hline 10 & 26.96 & 55.17 & 38.29 & 11.27 & 5.74 & 48.14 & 8.27 & 3.07 & 12.18 & 1.60 & 0.71 \\
\hline
\end{tabular}




\begin{tabular}{|c|c|c|c|c|c|c|c|c|c|c|c|}
\hline 11 & 228.41 & 247.27 & 190.42 & 493.88 & 12.60 & 18.01 & 12.44 & 6.07 & 19.82 & 132.60 & 2.72 \\
\hline 12 & 331.70 & 711.77 & 62.08 & 191.76 & 9.28 & 93.55 & 85.08 & 26.41 & 9.20 & 8.87 & 7.06 \\
\hline 13 & 607.22 & 1076.83 & 276.98 & 580.84 & 65.36 & 610.43 & 801.17 & 239.81 & 668.16 & 34.23 & 2.12 \\
\hline 14 & 61.73 & 222.25 & 56.17 & 321.17 & 14.59 & 73.14 & 53.86 & 28.37 & 17.83 & 3.09 & 1.33 \\
\hline 15 & 765.64 & 1189.52 & 115.13 & 937.28 & 33.64 & 652.60 & 719.39 & 356.31 & 660.88 & 46.15 & 5.72 \\
\hline 16 & 209.12 & 42.43 & 18.03 & 54.87 & 9.43 & 84.86 & 2.97 & 7.76 & 76.04 & 1.49 & 0.28 \\
\hline 17 & 153.19 & 662.53 & 54.32 & 288.55 & 10.78 & 57.35 & 187.36 & 57.39 & 109.33 & 4.32 & 4.32 \\
\hline 18 & 49.94 & 22.36 & 24.36 & 53.03 & 18.42 & 190.62 & 11.46 & 4.75 & 61.04 & 1.82 & 0.32 \\
\hline 19 & 319.71 & 1106.53 & 98.81 & 503.85 & 24.71 & 128.95 & 253.11 & 99.38 & 196.41 & 16.84 & 11.06 \\
\hline 20 & 249.27 & 578.04 & 109.91 & 88.94 & 11.32 & 75.71 & 85.20 & 20.25 & 3.85 & 8.20 & 3.85 \\
\hline 21 & 69.08 & 545.88 & 46.66 & 180.69 & 9.29 & 14.78 & 303.21 & 80.80 & 138.79 & 10.32 & 2.35 \\
\hline 22 & 11.08 & 25.54 & 4.32 & 20.88 & 4.39 & 14.23 & 117.70 & 65.57 & 126.89 & 5.19 & 2.94 \\
\hline 23 & 79.01 & 131.53 & 68.86 & 70.09 & 4.95 & 17.12 & 2.37 & 4.90 & 3.30 & 231.92 & 0.77 \\
\hline 24 & 22.92 & 146.59 & 62.72 & 638.66 & 13.82 & 10.88 & 190.92 & 627.69 & 80.53 & 30.22 & 2.22 \\
\hline 25 & 69.01 & 21.52 & 8.55 & 37.98 & 6.01 & 67.48 & 6.67 & 4.67 & 54.28 & 1.46 & 0.18 \\
\hline 26 & 88.75 & 464.65 & 139.79 & 69.24 & 10.18 & 71.80 & 169.47 & 42.90 & 102.10 & 2.98 & 1.24 \\
\hline 27 & 5.20 & 37.49 & 14.23 & 114.91 & 2.37 & 2.15 & 18.02 & 229.89 & 37.57 & 24.28 & 1.53 \\
\hline 28 & 225.86 & 214.48 & 197.36 & 530.77 & 10.08 & 13.22 & 3.94 & 6.09 & 8.51 & 131.08 & 3.94 \\
\hline 29 & 79.48 & 324.49 & 116.60 & 203.50 & 11.07 & 20.76 & 281.66 & 61.00 & 125.31 & 3.49 & 2.12 \\
\hline 30 & 37.19 & 92.40 & 187.44 & 1095.20 & 65.20 & 36.26 & 23.43 & 23.95 & 81.86 & 14.13 & 0.40 \\
\hline 31 & 38.35 & 117.38 & 221.33 & 1229.22 & 69.36 & 40.00 & 23.23 & 22.84 & 73.89 & 12.62 & 0.34 \\
\hline 32 & 5.65 & 10.74 & 3.12 & 36.81 & 1.14 & 8.22 & 119.27 & 47.95 & 123.05 & 4.21 & 1.14 \\
\hline 33 & 77.16 & 34.92 & 81.01 & 368.42 & 6.35 & 5.24 & 7.07 & 4.65 & 34.81 & 236.62 & 0.72 \\
\hline 34 & 6.15 & 13.23 & 12.87 & 34.11 & 1.54 & 2.29 & 2.95 & 0.59 & 8.68 & 0.83 & 0.21 \\
\hline 35 & 57.18 & 14.53 & 7.47 & 101.24 & 6.06 & 54.50 & 35.02 & 27.39 & 95.88 & 2.33 & 1.42 \\
\hline 36 & 56.19 & 46.39 & 13.25 & 51.32 & 3.05 & 42.47 & 38.22 & 12.22 & 91.46 & 2.20 & 1.58 \\
\hline 37 & 3.30 & 20.00 & 5.80 & 57.15 & 0.78 & 4.15 & 2.73 & 2.28 & 3.62 & 14.70 & 0.33 \\
\hline 38 & 23.43 & 143.16 & 30.30 & 359.38 & 6.77 & 19.64 & 82.80 & 58.52 & 5.65 & 34.89 & 4.76 \\
\hline 39 & 34.21 & 173.70 & 45.40 & 350.43 & 12.22 & 45.30 & 94.30 & 69.95 & 16.01 & 27.88 & 1.89 \\
\hline 40 & 26.15 & 12.63 & 26.36 & 146.67 & 4.08 & 46.46 & 9.31 & 2.16 & 12.73 & 0.77 & 0.26 \\
\hline 41 & 19.26 & 35.63 & 37.48 & 104.32 & 1.79 & 1.38 & 0.85 & 4.82 & 17.35 & 3.21 & 0.25 \\
\hline 42 & 26.94 & 28.77 & 27.44 & 85.03 & 2.25 & 3.78 & 2.29 & 1.28 & 0.92 & 0.90 & 0.31 \\
\hline 43 & 195.95 & 168.31 & 121.82 & 267.37 & 5.90 & 8.95 & 4.20 & 1.75 & 1.71 & 1.23 & 0.28 \\
\hline 44 & 33.07 & 36.19 & 27.56 & 61.01 & 1.59 & 4.77 & 2.39 & 0.98 & 7.28 & 0.50 & 0.22 \\
\hline 45 & 15.07 & 2.84 & 10.87 & 103.30 & 8.49 & 2.99 & 5.12 & 2.90 & 13.35 & 1.70 & 0.32 \\
\hline 46 & 38.63 & 132.24 & 217.22 & 1096.74 & 55.63 & 33.35 & 15.83 & 14.12 & 39.80 & 7.63 & 0.32 \\
\hline 47 & 21.05 & 29.17 & 8.67 & 63.84 & 1.31 & 12.30 & 3.82 & 19.32 & 41.04 & 1.00 & 0.84 \\
\hline 48 & 56.31 & 35.41 & 11.62 & 40.07 & 2.40 & 29.15 & 2.02 & 22.67 & 28.65 & 1.21 & 0.99 \\
\hline
\end{tabular}




\begin{tabular}{|c|c|c|c|c|c|c|c|c|c|c|c|}
\hline 49 & 166.91 & 53.55 & 9.99 & 50.32 & 8.66 & 56.55 & 18.81 & 27.57 & 46.68 & 1.26 & 1.26 \\
\hline 50 & 65.72 & 44.05 & 14.19 & 107.76 & 2.51 & 13.28 & 34.43 & 74.99 & 34.02 & 1.09 & 1.06 \\
\hline 51 & 38.95 & 38.20 & 13.45 & 93.49 & 1.97 & 21.70 & 16.35 & 12.83 & 24.96 & 1.88 & 0.92 \\
\hline 52 & 6.06 & 49.88 & 31.38 & 31.84 & 2.19 & 7.13 & 23.05 & 19.42 & 11.87 & 3.71 & 0.92 \\
\hline 53 & 37.50 & 131.82 & 44.17 & 19.28 & 5.66 & 53.50 & 11.00 & 7.68 & 7.49 & 1.07 & 1.07 \\
\hline 54 & 176.88 & 498.99 & 133.07 & 97.79 & 12.19 & 88.92 & 23.78 & 18.49 & 17.63 & 2.72 & 2.00 \\
\hline 55 & 124.35 & 423.16 & 122.89 & 42.66 & 16.42 & 151.83 & 65.97 & 30.53 & 101.79 & 6.82 & 0.92 \\
\hline 56 & 146.27 & 432.45 & 120.23 & 46.72 & 15.29 & 139.85 & 6.85 & 7.51 & 10.79 & 2.17 & 0.93 \\
\hline 57 & 133.61 & 128.70 & 112.63 & 281.31 & 5.41 & 7.62 & 2.60 & 4.03 & 3.76 & 95.89 & 2.60 \\
\hline 58 & 75.88 & 76.42 & 69.01 & 193.74 & 3.84 & 5.52 & 3.32 & 1.49 & 10.25 & 41.10 & 1.11 \\
\hline 59 & 2.20 & 7.38 & 3.30 & 33.44 & 0.54 & 1.89 & 0.72 & 0.62 & 1.41 & 7.04 & 0.26 \\
\hline 60 & 76.86 & 321.39 & 88.90 & 572.29 & 23.20 & 102.39 & 142.50 & 98.94 & 32.95 & 28.83 & 1.74 \\
\hline 61 & 23.29 & 34.83 & 4.03 & 13.98 & 1.12 & 12.31 & 20.23 & 11.44 & 5.50 & 2.29 & 0.84 \\
\hline 62 & 20.80 & 16.78 & 7.19 & 79.11 & 2.99 & 19.83 & 4.34 & 25.96 & 42.88 & 1.25 & 0.97 \\
\hline 63 & 51.64 & 11.26 & 7.59 & 95.91 & 3.83 & 27.67 & 5.48 & 25.43 & 20.84 & 1.80 & 0.71 \\
\hline 64 & 163.15 & 25.11 & 21.85 & 138.24 & 6.96 & 57.66 & 20.25 & 20.11 & 48.35 & 1.58 & 1.58 \\
\hline 65 & 61.26 & 20.63 & 14.56 & 163.91 & 3.58 & 12.55 & 39.40 & 70.15 & 43.67 & 2.33 & 1.27 \\
\hline 66 & 34.15 & 20.47 & 11.29 & 133.75 & 4.17 & 20.76 & 20.70 & 9.90 & 22.62 & 2.63 & 0.73 \\
\hline 67 & 12.99 & 82.61 & 6.32 & 114.59 & 3.95 & 4.83 & 28.79 & 24.47 & 16.78 & 2.14 & 1.40 \\
\hline 68 & 57.11 & 177.58 & 13.79 & 125.54 & 3.54 & 50.60 & 3.84 & 11.24 & 8.62 & 1.79 & 1.79 \\
\hline 69 & 252.19 & 649.91 & 53.66 & 332.18 & 10.30 & 86.29 & 14.70 & 25.72 & 21.83 & 6.09 & 2.34 \\
\hline 70 & 185.43 & 562.09 & 42.86 & 313.65 & 11.51 & 150.90 & 38.74 & 49.46 & 94.89 & 8.12 & 2.30 \\
\hline 71 & 208.91 & 559.66 & 46.31 & 304.94 & 5.83 & 137.24 & 33.10 & 9.51 & 19.53 & 5.10 & 2.15 \\
\hline 72 & 135.14 & 141.19 & 109.13 & 284.85 & 6.95 & 8.90 & 7.10 & 4.08 & 10.00 & 95.99 & 2.34 \\
\hline 73 & 76.95 & 81.67 & 67.93 & 185.68 & 5.22 & 7.32 & 3.48 & 1.83 & 7.38 & 39.42 & 1.25 \\
\hline 74 & 56.50 & 239.74 & 46.56 & 610.72 & 14.70 & 64.65 & 114.60 & 72.22 & 23.83 & 46.51 & 3.23 \\
\hline 75 & 25.91 & 32.62 & 4.00 & 35.25 & 2.03 & 18.91 & 21.60 & 13.89 & 8.43 & 1.29 & 0.58 \\
\hline 76 & 102.72 & 295.69 & 80.46 & 47.92 & 9.74 & 86.90 & 41.78 & 9.74 & 27.11 & 0.57 & 0.57 \\
\hline 77 & 145.90 & 382.30 & 30.43 & 204.49 & 5.78 & 87.67 & 29.89 & 16.45 & 26.25 & 3.58 & 1.96 \\
\hline 78 & 60.46 & 284.92 & 83.60 & 41.75 & 6.00 & 44.12 & 123.05 & 39.21 & 100.41 & 3.47 & 0.88 \\
\hline 79 & 100.25 & 401.53 & 33.71 & 171.43 & 7.09 & 35.25 & 133.72 & 53.44 & 105.73 & 3.74 & 2.75 \\
\hline Maximum & 765.64 & 1189.52 & 276.98 & 1229.22 & 69.36 & 652.60 & 801.17 & 627.69 & 668.16 & 236.62 & \\
\hline
\end{tabular}

